\title{
Evaluating Steam Conditioning Manipulations and Grain Expressed Enzymes Effects on Feed Manufacturing Metrics, Feed Hygiene, Broiler Performance, and Bone Mineralization
}

John William Boney

Follow this and additional works at: https://researchrepository.wvu.edu/etd

\section{Recommended Citation}

Boney, John William, "Evaluating Steam Conditioning Manipulations and Grain Expressed Enzymes Effects on Feed Manufacturing Metrics, Feed Hygiene, Broiler Performance, and Bone Mineralization" (2017). Graduate Theses, Dissertations, and Problem Reports. 5234.

https://researchrepository.wvu.edu/etd/5234

This Dissertation is protected by copyright and/or related rights. It has been brought to you by the The Research Repository @ WVU with permission from the rights-holder(s). You are free to use this Dissertation in any way that is permitted by the copyright and related rights legislation that applies to your use. For other uses you must obtain permission from the rights-holder(s) directly, unless additional rights are indicated by a Creative Commons license in the record and/ or on the work itself. This Dissertation has been accepted for inclusion in WVU Graduate Theses, Dissertations, and Problem Reports collection by an authorized administrator of The Research Repository @ WVU.

For more information, please contact researchrepository@mail.wvu.edu. 
Evaluating Steam Conditioning Manipulations and Grain Expressed Enzymes Effects on Feed Manufacturing Metrics, Feed Hygiene, Broiler Performance, and Bone Mineralization

John William Boney

Dissertation submitted to the Davis College of Agriculture, Natural Resources, and Design at West Virginia University in partial fulfillment of the requirements

for the degree of

Doctor of Philosophy

In

Nutrition and Food Science

Joseph Moritz, Ph.D., Chair

Robert L. Taylor Jr., Ph.D.

Jacek Jaczynski, Ph.D.

Jennifer Weidhaas, Ph.D.

Michael Lilburn, Ph.D.

Omar Gutierrez, Ph.D.

Division of Animal and Nutritional Sciences

Morgantown, West Virginia

2017

Keywords: Steam conditioning, surrogate, broiler, phytase, performance, mineralization Copyright 2017 John Boney 


\begin{abstract}
Evaluating Steam Conditioning Manipulations and Grain Expressed Enzymes Effects on Feed Manufacturing Metrics, Feed Hygiene, Broiler Performance, and Bone Mineralization

John William Boney

Animal well-being, evolving feed manufacturing regulatory programs, and consumer perception drive the continued need to provide safe feed to animals. Considering the performance benefits associated with feeding pelleted feed, the concepts of hygienic feed production and production of highly durable pellets may interact to benefit the broiler chicken. In addition to hygienic and physical attributes, poultry nutrition may be enhanced by cereal grains expressing enzymatic activity. These additives may provide additional opportunities to support dietary phosphorus $(\mathrm{P})$ requirements in growing broilers, further contributing to improved animal welfare conditions in an economically favorable manner. In order to study the effects of these unique aspects of feed and poultry production, multiple experiments were designed.
\end{abstract}

Initially, two experiments were conducted, using both short-term (ST) and long-term (LT) steam conditioning, to determine the effects of antimicrobial inclusion and conditioning temperature variations on feed manufacturing metrics (EXP1) and the mitigation of a Salmonella surrogate (EXP2). A split-plot design was utilized where ST (10s) or LT (60s) steam conditioning served as whole plot units. Each whole plot unit contained both a $2 \times 3$ (EXP1) and a 2 x 4 (EXP2) factorial arrangement of treatments varying in antimicrobial inclusion (With or Without) and degree of thermal processing ((Unprocessed Mash), 71, 82, 88 ${ }^{\circ} \mathrm{C}$ ). In EXP1, conditioning time and antimicrobial inclusion interacted $(\mathrm{P}=0.03)$ by decreasing pellet durability when antimicrobial was included to diets subjected to ST conditioning. Durability detriments were not apparent when LT conditioning was utilized. In EXP2, conditioning time, antimicrobial inclusion, and degree of thermal processing interacted $(\mathrm{P}<0.0001)$, decreasing mitigation when ST conditioning was applied to surrogate inoculated feed at $71^{\circ} \mathrm{C}$, relative to higher conditioning temperatures and when ST and LT conditioning was applied to antimicrobial treated feed.

Then, two additional experiments were conducted to study variables common to phytase enzyme optimization when supplied to $\mathrm{P}$ deficient diets. The objectives of the third experiment were to describe the effects of Corn-Expressed Phytase (CEP) varying in particle size (1.5, 2.0, or $2.5 \mathrm{~mm}$ ), concentration (500 or 3,000 FTU/kg), and coating (with or without) on $38 \mathrm{~d}$ broiler performance and tibia mineralization. Treatments were arranged in a $3 \times 2 \times 2$ factorial in a randomized complete block design (RCBD). Commercial phytase, supplemented at 500 or 3,000 FTU/kg, as well as positive control (PC) and negative control (NC) diets were also fed. Broilers fed CEP at 3,000 FTU/kg demonstrated improved live weight gain (LWG), feed conversion ratio (FCR), and bone mineralization compared to broilers fed CEP at $500 \mathrm{FTU} / \mathrm{kg}(\mathrm{P}<0.05)$. Broilers fed CEP of 2.0mm had improved FCR compared to broilers fed CEP of $2.5 \mathrm{~mm}(\mathrm{P}<0.05)$. Coating did not affect broiler performance or tibia mineralization. The efficacy of CEP was 
comparable to the positive control diet and commercial phytase product when particle size and concentration was optimized.

Finally, the objective of the fourth experiment were to describe the effects of various CEP product coatings and concentrations on $38 \mathrm{~d}$ broiler performance and bone mineralization. Treatments were arranged in a $5 \times 2$ factorial in a RCBD that varied in proprietary CEP coating technique (Product 1- Product 5) and concentration (500 or 1,500 FTU/kg). PC and NC diets, varying in non-phytate $\mathrm{P}(0.46 \%$ vs $0.25 \%$ respectively), were also fed. Product coating affected FI and LWG, decreasing consumption and gains when broilers were provided either Product 1 or Product $4(\mathrm{P}<0.05)$. Broilers fed CEP at 1,500 FTU/kg increased FI by $259 \mathrm{~g}$ per bird $(\mathrm{P}<0.0001)$, LWG by 240 g per bird $(\mathrm{P}<0.0001)$, and all bone mineralization metrics $(\mathrm{P}<0.05)$, relative to those fed CEP at $500 \mathrm{FTU} / \mathrm{kg}$. Multiple comparison analyses show PC fed birds improved performance above $\mathrm{NC}$ fed birds $(\mathrm{P}<0.05)$. Within the parameters of these four experiments, optimizing CEP particle size, dietary concentrations, and proprietary coating techniques may liberate bound $\mathrm{P}$ in the diet, improving broiler performance and bone mineralization. Furthermore, both ST and LT steam conditioning display the potential to mitigate bacteria in feed. However, degree of bacteria mitigation and pellet quality are dependent on specific manufacturing and additive strategies. 


\section{DEDICATION}

I would like to dedicate this dissertation to my parents, Lon and Ginny, and late grandparents who instilled the principles of hard work and dedication. I was taught at an early age that "anything worth doing is worth doing right". 


\section{AKNOWLEDGEMENTS}

I would like to thank my advisor and friend, Dr. Joe Moritz for believing in my abilities and challenging me to continue my education in such a thriving sector of animal agriculture. I cannot fully express my gratitude in these few lines but I will forever be grateful for the opportunities that he has provided me. I would like to thank the other members of my committee: Drs. Taylor, Jaczynski, Weidhaas, Lilburn, and Gutierrez. Your support and guidance throughout this experience has helped to develop me into the scientist and person that I am today. I would also like to thank the technical support staff at the WVU Animal Science Farm, especially Rick Wood and Fred Roe, for all of the assistance and friendship throughout my research career. Additionally, I would like to thank all other Davis College faculty, graduate students, undergraduate students, and staff members as they have greatly contributed to my success at WVU. With respect to the time commitment put forward by all involved I would like to personally thank all of the past and current students associated with the Moritz research lab: Kelley Wamsley, Kevin Shipe, Ashley Evans, Angela Lamp, Alina Corey, Mark Lemons, Brian Glover, Kolby Foltz, Dani Reese, Tori Homan, Tyler Rigby, Grace Ogden, Ariel Bergeron, Heather Baldwin, Lydia Crites, and Talman Hylton. These folks have spent countless hours assisting with my research demands which include evenings, weekends, holidays, snow storms, and spring breaks. My success directly reflects their individual efforts. Lastly, I would like to thank my family: Lon, Ginny, Jessie, Tyler, and Julie. They have supported my career decisions even though those decisions kept me away from them. Their love and support were monumentally important to my success. 


\section{TABLE OF CONTENTS}

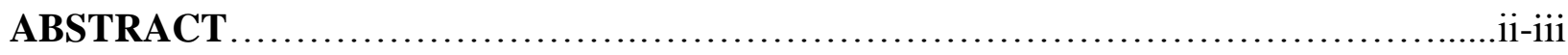

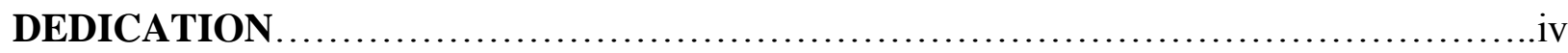

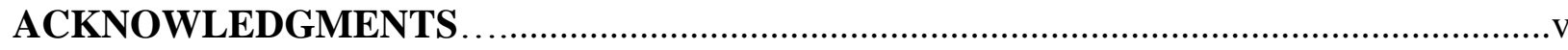

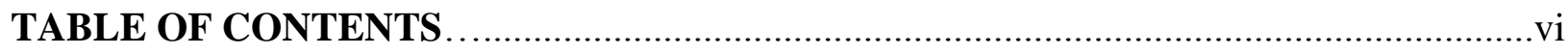

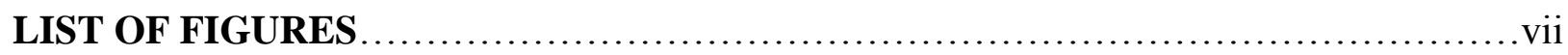

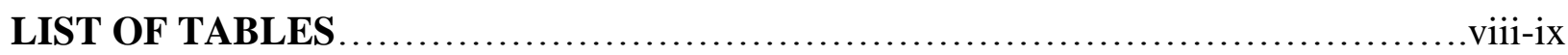

LIST OF SYMBOLS/NOMENCLATURE......................................

CHAPTER 1: LITERATURE REVIEW ....................................... 1-26

CHAPTER 2: The Effects of Steam Conditioning Manipulations and Antimicrobial Inclusion on Feed Manufacturing and Salmonella Surrogate Mitigation...........................................27-48

CHAPTER 3: The Effects of Corn-Expressed Phytase Varying in Particle Size, Concentration, and Coating on D1-38 Broiler Performance and Tibia Ash Analysis......................49-72

CHAPTER 4: Corn-Expressed Phytase Product Coating and Concentration Effects on D1-38 Broiler Performance, Toe Ash, and Tibia Ash.....................................73-95

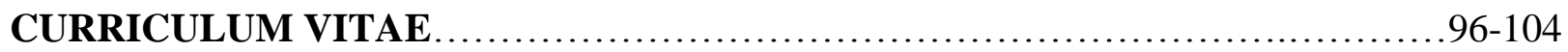




\section{LIST OF FIGURES}

\section{Chapter 2}

Figure 1. Interactive effects of conditioning time and antimicrobial inclusion on pellet

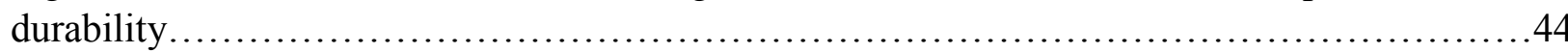

Figure 2. Interactive effects of conditioning time, antimicrobial inclusion, and degree of thermal processing on Enterococcus faecium 8459 mitigation.....................................45 


\section{LIST OF TABLES}

\section{Chapter 2}

Table 1. Dietary composition and calculated nutrients of the basal diet used during inoculation.

Table 2. Conditioning Time, Antimicrobial Inclusion, and Steam Conditioning Temperature Effects on Feed Manufacturing Metrics.

Table 3. Conditioning Time, Antimicrobial Inclusion, and Degree of Thermal Processing Effects on E. faecium 8459 mitigation

\section{Chapter 3}

Table 1. Diet composition of positive and negative control ${ }^{1}$ diets for starter, grower, and finisher periods

Table 2. Descriptive Feed Manufacturing Data for Starter, Grower, and Finisher Growth Periods .66

Table 3. Phytase Activity ${ }^{1}$ and Mineral Analysis for the Finisher (d23-38) Growth Period.

Table 4. Overall (d1-38) effects of feeding diets supplemented with corn-expressed phytase varying in particle size, concentration, and coating on Hubbard x Cobb 500 broiler performance

Table 5. Overall (d1-38) effects of feeding diets supplemented with corn-expressed phytase varying in particle size, concentration, and coating on Hubbard x Cobb 500 tibia mineralization.

Table 6. The effects of feeding starter (d1-10) diets supplemented with corn-expressed phytase varying in particle size, concentration, and coating on Hubbard x Cobb 500 broiler performance.

Table 7. The effects of feeding grower (d11-22) diets supplemented with corn-expressed phytase varying in particle size, concentration, and coating on Hubbard x Cobb 500 broiler performance

Table 8. The effects of feeding finisher (d23-38) diets supplemented with corn-expressed phytase varying in particle size, concentration, and coating on Hubbard x Cobb 500 broiler performance.

\section{Chapter 4}

Table 1. Diet composition of positive and negative control diets ${ }^{1}$ for starter, grower, and finisher periods.

Table 2. Descriptive Feed Manufacturing Data for Starter, Grower, and Finisher Periods.......90

Table 3. Phytase Activity ${ }^{1}$ for Starter, Grower, and Finisher Periods........................91 


\section{LIST OF TABLES (CONTINUED)}

Table 4. Mineral Analysis and nPP Calculations for Starter, Grower, and Finisher Periods.....992

Table 5. Effects of CEP Product and Concentration on Overall Period (d1-38) Broiler

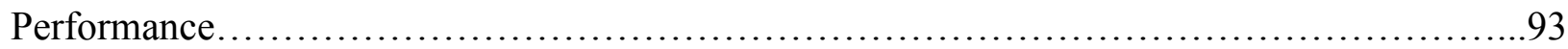

Table 6. Effect of CEP Product and Concentration on D21 and D38 Toe and Tibia Ash........94

Table 7. Effect of CEP Product and Concentration on Starter, Grower, and Finisher Period

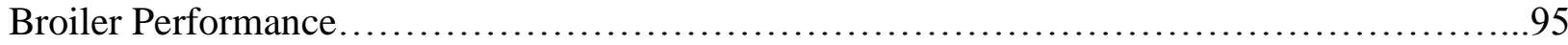




\section{LIST OF SYMBOLS/NOMENCLATURE}

\section{Chapter 1}

1. Highly Pathogenic Avian Influenza- HPAI

2. Mixer-Added Fat- MAF

3. True Amino Acid Digestibility- TAAD

4. Pellet Durability Index- PDI

5. Feed Conversion Ratio- FCR

6. Phosphorus- $\mathrm{P}$

7. Available Phosphorus- aP

8. Non-Phytate Phosphorus- nPP

9. Fytase Units or Phytase Units- FTU

10. Food Safety Modernization Act- FSMA

11. Food and Drug Administration- FDA

12. American Feed Industry Association- AFIA

13. Food Safety and Inspection Service- FSIS

14. Electron beam- E-beam

\section{Chapter 2}

1. Short-Term-ST

2. Long-Term- LT

3. Experiment 1: Feed Manufacturing- EXP1

4. Experiment 2: Enterococcus faecium ATCC 8459 Mitigation- EXP2

5. Completely Randomized Design- CRD

6. American Type Culture Collection- ATCC

7. Brain Heart Infusion- BHI

8. Tryptic Soy Broth- TSB

9. New Holmen Pellet Tester- NHPT

10. Phosphate Buffered Saline- 1xPBS

\section{Chapter 3}

1. Corn-Expressed Phytase- CEP

2. Day- d

3. Live Weight Gain- LWG

4. Feed Conversion Ratio- FCR

5. Phosphorus- $\mathrm{P}$

6. Transgenic Phytase Corn- TPC

7. Non-Phytate Phosphorus- nPP

8. Positive Control- PC

9. Negative Control- NC 


\section{LIST OF SYMBOLS/NOMENCLATURE (CONTNUED)}

10. Hot Pellet Temperature- HPT

11. American Society for Testing Materials- ASTM

12. Feed Intake- FI

\section{Chapter 4}

1. Phosphorus- $\mathrm{P}$

2. Association of Official Analytical Chemists- AOAC

3. Corn-Expressed Phytase- CEP

4. Negative Control- NC

5. Positive Control- PC

6. Hot Pellet Temperature- HPT

7. Feed Intake- FI

8. Non-Phytate Phosphorus- nPP

9. Live Weight Gain- LWG

10. Feed Conversion Ratio- FCR 


\section{CHAPTER 1: LITERATURE REVIEW}

\section{Poultry Consumption- Protein and Products}

\section{A. US Poultry Consumption}

Economic data from 2015, provided by the National Chicken Council, shows that the average United States citizen consumed 106.0 lbs. of poultry [1] while the U.S. Poultry and Egg Association reported consumption of 252.9 eggs per capita [2]. Continued growth in poultry consumption resulted in consumption of $107.6 \mathrm{lbs}$. of poultry per capita in the United States in 2016 [1]. Further breakdown of per capita poultry consumption indicates that of the $107.6 \mathrm{lbs}$. of poultry consumed, $91.0 \mathrm{lbs}$. was chicken and $16.6 \mathrm{lbs}$. was turkey. Additionally, combined per capita consumption of both beef and pork averaged 106.9 lbs. in 2016 [1]. These statistics showcase the magnitude of the United States poultry industry, although the poultry industry is global in nature.

\section{B. US Exports}

The U.S. poultry industry is the world's largest producer and second largest exporter of poultry meat [3]. The U.S. Poultry and Egg Association reported exports of 6.32 billion pounds of broiler meat in 2015 [2]. These export values total nearly 18\% of U.S. poultry production [3]. Although the United States dealt with highly pathogenic avian influenza (HPAI) outbreaks, exports are forecasted to grow through 2017 due to high global demands [4].

\section{Global Markets}

Highly pathogenic avian influenza outbreaks across the globe have constrained global expansion. Brazil's poultry export demands continually increase due to its current HPAI-free status [4]. China's imports are forecasted to increase $40 \%$ due to multiple strains of HPAI [4]. 
China's import needs are fueling the growth to Brazil's exports and is helping to sustain the United States exports, even as they battle influenza outbreaks.

\section{Diet Formulation and Feed Manufacturing}

\section{A. Diet Formulation}

Advances in knowledge of nutritional requirements has aided in the development of leastcost diet formulation programs. The concept of the Ideal Protein Ratio was developed by researchers at the University of Illinois. This concept was designed to meet an animal's requirement for protein accretion and maintenance, having no deficiencies or excesses [5]. This concept was based on lysine concentrations and the requirements of other essential amino acids as a percentage of lysine [5]. Lysine serves as the reference amino acid due to the ease of analysis in feedstuffs, economic feasibility, availability of lysine requirement data, and the fact that lysine is used only for protein accretion and maintenance [5]. Considering its commercial application, this concept is based on digestible amino acid concentrations, which has been shown to promote higher profitability in broiler production systems [6]. Several aspects of the Ideal Protein Ratio are utilized in today's diet formulation programs. Currently, nutritionists use leastcost diet formulations to minimize feeds costs by utilizing a variety of ingredients to meet the nutritional needs of the animal [7]. Kidd et al. reported that commercial adoption of most commercial poultry's first limiting amino acid, methionine, began in the 1960's. Typical second and third limiting amino acids, lysine and threonine, were commercially adopted in the 1970's and 1990's respectively [8]. During these times of scientific advances, technology was advancing in a manner that could incorporate these findings into linear programming models, to create a least-cost formulation program. Kidd and coauthors concluded that as the knowledge of limiting amino acids improves and subsequent amino acids are adopted and included in least-cost 
diet formulation programs, formulations will be closer to meeting the bird's requirements, reducing amino acid overages [8].

\section{B. Feed and feed manufacturing}

The greatest costs in broiler production are associated with feed and feed manufacturing, making up $60-70 \%$ of the costs of the operation [9-11]. Providing feed to broiler chickens in pelleted form is common practice in today's broiler and turkey industries. It is generally accepted that providing pelleted feed improves overall production economics, offsetting feed processing costs with performance improvements. Literature from 1937 describes improvements in growth and feed efficiency when poultry were fed pelleted feed compared to dry mash [12]. Leo Jensen and cohorts studied the eating patterns of broiler chicks and turkey poults in 1962 and discovered a substantial decrease in time spent apprehending feed when fed pellets compared to mash [13]. For example, Jensen et al. reported that poults fed mash diets spent $18.8 \%$ of a 12 hour feeding period consuming meals while poults provided pellets spent only $2.2 \%$ of the same 12 hour feeding period consuming feed. Results for broiler chicks under the same experimentation show that broilers fed mash diets spent $14.3 \%$ of a 12 hour feeding period consuming feed as compared to those fed pellets spending only $4.7 \%$ of the same feeding period eating [13]. Here, the notion of decreased prehension energy expenditure was born and was used to explain broiler performance improvements when fed pelleted feed.

In 1991, Scheideler presented data suggesting that pelleted feed reduced ingredient segregation, ultimately improving feed efficiency and broiler uniformity. Additionally, decreased energy expenditure while apprehending feed provided more net energy for broiler growth [14]. Then, in 1994, Behnke reported several pelleting attributes that improve performance such as: decreased feed wastage, reduced selective feeding, decreased ingredient 
segregation, less time and energy expended for prehension, destruction of pathogenic organisms, thermal modification of starch and protein, and improved palatability [15]. These data suggest broad, pellet-derived performance benefits; however, the authors make no indication to pellet quality or nutritional consequences of pelleting.

\section{Pellet Quality}

In regard to pellet quality, high feed volume demands often contribute to decreased feed quality. Unfortunately, least-cost diet formulations are not capable of incorporating pellet quality factors into formulations. A nutritionist with feed quality knowledge may consider these factors as poultry performance metrics are enhanced when birds are provided pellets. A magnitude of research has been conducted on improving pellet quality. In a review on pelleting broiler diets, Abdollahi and coauthors claim that good pellet quality is usually obtained at the expense of nutritional quality [10]. Thomas and van der Poel claim that knowledge of fundamentals for aggregating particles of different sizes, hardness, and shape is needed to optimize product quality [16]. On a less technical note, Briggs et al. concluded that producing high quality pellets is largely thought of as an art rather than a science [17]. These three articles demonstrate the complexity of high quality feed manufacturing and the confusion surrounding the importance of high pellet quality production in commercial feed production and integrated agriculture.

Improving the physical quality of a pellet may be achieved in a number of ways. Loar et al. increased steam conditioning temperatures from $74^{\circ} \mathrm{C}$ to $85^{\circ} \mathrm{C}$ and from $74^{\circ} \mathrm{C}$ to $96^{\circ} \mathrm{C}$, increasing pellet quality with each incremental increase in conditioning temperature [18]. These authors also reported that decreasing mixer-added fat (MAF) from 2.18\% to $1 \%$ increased pellet durability by 13 percentage points [18]. However, increasing conditioning temperatures above 
$74^{\circ} \mathrm{C}$ decreased methionine digestibility by $2.5 \%$ [18]. Corey et al. contradicted when they reported improvements to pellet quality through decreased MAF without decreasing true amino acid digestibility (TAAD) [9]. These digestibility values are not static and may be affected by numerous dietary factors.

Steam conditioning manipulations can affect feed manufacturing and nutritional quality metrics. In 1986, Cox and cohorts studied varying steam pressures on commercial type diets and reported increased pellet durability with increasing steam pressure [19]. Later, in 1997, van der Poel et al. studied expander conditioning and routine steam pelleting and concluded that expander conditioning did not improve nutrient digestibility in pigs when compared to steam conditioning and pelleting [20]. Lundblad et al. studied various steam conditioning practices which included unconditioned mash, low temperature steam conditioning, high temperature steam conditioning, expander conditioning, and extruder processing. These authors reported that all methods of hydro-thermal processing improved broiler chick starch digestibility. However, steam conditioning improved feed efficiency compared to expander conditioning and extruder processing, which resulted in decreased feed intake and broiler growth [21]. Cutlip et al. increased both steam conditioning temperature and steam pressure, reporting increased pellet durability when feed was conditioned at a higher temperature [22]. Increasing steam pressure trended towards an increased pellet quality; however, these variables did not interact to affect pellet quality [22]. In 2015, dairy scientists studied the effects of conditioning time and reported improved pellet durability index (PDI) when dairy feed was conditioned for 75 seconds (91.3\% PDI) compared to feed conditioned for 50 seconds (73.4\% PDI) [23].

Literature presents manufacturing and additive strategies to maintain nutritional value while producing high quality pellets. Wamsley and Moritz studied commercial and inherent pellet 
binders and concluded that binder inclusion improved pellet quality [24]. Gehring et al. provided insight that explained the lack of commercially available pellet binders that provide available nutrients [25]. In an effort to explore nutritive pellet binding capabilities, Boney and Moritz utilized a pilot scale feed mill and a cecectomized rooster model and reported that the use of moderate inclusions of Spirulina algae and low temperature steam conditioning may improve pellet quality and allow for ease of pellet manufacturing during challenging conditions while maintaining nutrient digestibility [26]. The aforementioned Cutlip experiment reported no detriment to amino acid or energy availability by variations in steam conditioning [22]. Corey et al. reported a three way interaction demonstrating the greatest TAAD when pelleted diets contained $0.5 \%$ calcium lignosulfonate and $3 \%$ mixer-added fat [9]. These authors also support pellet quality improvements from pellet binder inclusions [9].

Performance enhancements stemming from pellet quality improvements are noted in past research. Proudfoot and Hulan reported that higher levels of fines can have a detrimental effect on feed conversion and body weight in turkeys [27]. This was later supported by Behnke who speculated that turkeys appear to be more sensitive to pellet quality and the amount of fines present in the feed [11]. In regard to broilers, Corzo et al. fed broilers 0\% pellets (100\% mash), $32 \%$ pellets (68\% mash), and $64 \%$ pellets (36\% mash). These authors reported superior performance and yield metrics when broilers were provided diets with $64 \%$ pellets compared to $0 \%$ or $32 \%$ pellet diets [28]. When studying modest improvements to pellet quality, Lilly et al. reported a 0.4 point FCR improvement, $10 \mathrm{~g}$ carcass weight increase, and a $4 \mathrm{~g}$ breast weight increase for each 10 percentage-point increase in intact pellets [29]. Lemons and Moritz reported a 1.7 point finisher period FCR improvement when pellet quality improved from 40:60 (\% pellets:\% fines) to 70:30 (\% pellets:\% fines) [30]. When considering the overall (D1-38) 
FCR effects from pellet quality improvements, Lemons and Moritz reported 2.6 point FCR improvement when broilers were provided the 70\% pellet treatment [30]. Glover and Moritz increased pellet quality from $50 \%$ pellets to $70 \%$ pellets and reported a 3 point FCR improvement for the overall (D1-38) period [31].

\section{Dietary Constituents and Feed Additives}

\section{A. Phosphorous}

Although the major role of phosphorus $(\mathrm{P})$ is as a component of bone, $\mathrm{P}$ is also an essential component of organic compounds involved in almost every aspect of metabolism [32]. Phosphorus is a critical and expensive nutrient provided to poultry that supports growth and development of a strong skeleton to withstand the rigors of growth, transport, and processing and must be supplied in adequate, but not excessive, amounts [33]. Angel and cohorts describe available phosphorus (aP) as the $\mathrm{P}$ that is absorbed from the diet into the animal. She further explains that the term non-phytate $\mathrm{P}(\mathrm{nPP})$ is often used interchangeably but is not synonymous to available $\mathrm{P}$ [34]. By definition, $\mathrm{nPP}$ is the total $\mathrm{P}$ in the diet minus the $\mathrm{P}$ that is bound to the phytin molecule. This nPP value is commonly used by today's poultry nutritionists. As scientists consider more closely meeting animal requirements, the notion of digestible $\mathrm{P}$ values arose. A symposium addressing opportunities and challenges of $\mathrm{P}$ utilization evaluation in feed ingredients for poultry was held at the most recent Poultry Science Association meeting in Orlando, FL (2017). Here, Adeola discussed the contribution of urine P to the excreta in total tract $\mathrm{P}$ digestibility and suggested that ileal digestible $\mathrm{P}$ is a more appropriate response criterion than total tract $\mathrm{P}$ digestibility [35]. This distinction is important because total tract $\mathrm{P}$ digestibility is often utilized in monogastric nutrition, specifically swine nutrition. Bedford defined digestible $\mathrm{P}$ as a form of $\mathrm{P}$ that can be absorbed and subsequently used for growth and metabolic purposes 
[36]. Previously, Mutucumarana et al. concluded that $\mathrm{P}$ evaluation based on digestible $\mathrm{P}$

provides more accurate assessment of $\mathrm{P}$ availability than that based on non-phytate $\mathrm{P}$ [37]. As a result, inorganic phosphate addition may be decreased, offering a degree of dietary cost savings. Previously, Summers explained that formulating a diet to meet minimum P requirements would be difficult due to a number of interacting factors, which would ultimately affect the birds $\mathrm{P}$ requirements [38]. Due to these challenges, overfeeding of $\mathrm{P}$ is a common industry practice. As new data and methods emerge, dietary overages may be further reduced.

As a consequence of overfeeding minerals, excess $\mathrm{P}$ in poultry manure, applied to the land as fertilizer, can cause environmental problems such as surface water eutrophication [39]. Crop and livestock farming has created P imbalances stemming from soil P exceeding crop needs, ultimately enriching surface runoff with P [40]. Sims et al. explains that eutrophication concerns in the Mid-Atlantic region of the United States represents a national situation. In this region, nutrient management laws in four states (Delaware [41], Maryland [42], Pennsylvania [43], and Virginia [44]) restrict agricultural land application of nutrients to some extent [45]. These state and region-wide nutrient management restrictions essentially mandated dietary phytase enzyme inclusions. Other efforts to minimize eutrophication is the gasification of poultry litter. Resultant syngas production can be utilized in poultry facility heating. Additionally, Evans et al. provided poultry litter biochar, a by-product of litter gasification, with the addition of phytase, which provided available minerals and amino acids to broilers [46]. Continued efforts to stabilize soil mineral levels as animal protein production continues to increase may provide numerous research opportunities. 


\section{B. Phytate}

Phytates are complex classes of naturally occurring compounds that can influence the functional and nutritional properties of foods [47]. Phytate is found almost exclusively in plants and primarily in seeds, explaining why cereal grains and oil seeds are rich phytate sources [48]. In 1966, a published review on phytate $\mathrm{P}$ utilization by poultry demonstrated a long standing knowledge that plant based ingredients present nutritional challenges when fed to poultry [49]. A proportion of plant $\mathrm{P}$ will be present as phytic acid, which is poorly digested by the bird [32]. Poultry have an inability to utilize this phytic acid is due to the lack of effective endogenous phytase [50]. Phytic acid, or IP6, is a highly reactive acidic compound that readily binds mineral cations, and in this form, is called phytin [34]. Binding of minerals may occur across two phosphate groups, creating a strong association; however, binding can occur within phosphate groups, having a weaker association [32]. Regardless, these minerals remain unavailable to the bird.

\section{Phytase}

In 1966, Cosgrove demonstrated that phytic acid could be dephosphorylated by phosphatase enzymes, commonly called phytase [51]. It was not until 1991 that phytase was commercially introduced into the poultry industry. However, early work by Warden and Schaible in 1962 and Nelson et al. in 1971 confirms phytate P utilization and improvements in bone ash when chicks were provided diets containing phytase, decades before commercial introduction [52-53]. Phytase is described in terms of units per kilogram of feed. Therefore, phytase activity may be defined as fytase units (FTU), where one FTU is the amount of enzyme that liberates 1 micromol inorganic orthophosphate/min from $0.0051 \mathrm{~mol} \mathrm{~L}-1$ sodium phytate at $\mathrm{pH} 5.5$ and a temperature of $37^{\circ} \mathrm{C}$ [54]. In order to dephosphorylate phytate and liberate $\mathrm{P}$, the 
inclusion of exogenous phytase in pig and poultry rations is increasingly routine [55]. In some situations, as previously mentioned, phytase addition is mandated by state governments.

In a review on microbial phytase in poultry nutrition, Selle and Ravindran report that dietary inclusions of phytase feed enzymes economically generates bioavailable $\mathrm{P}$ and reduces the $\mathrm{P}$ load on the environment [56]. dos Santos and cohorts describe phytase as an enzyme that is able to hydrolyze phytate, releasing $\mathrm{P}$ for absorption and reducing the antinutritional effects of phytate [57]. The level of phytate in a diet affects the ability of phytase to hydrolyze said phytate, which may be related to the kinetics and enzyme characteristics of individual phytases [57]. Additionally, Boney and Moritz discussed the variety of cereals and by-products in today's broiler diets. These dietary variations can dictate substrate type and enzyme accessibility [58]. These speculations help to explain the diversity of commercial phytase enzymes available to poultry nutritionists.

\section{Alternative phytase products}

Advances in biotechnology have led to the study of various cereal grains and plant sources and their capabilities to express enzymatic activity. Chen et al. speculated that successful production of grains expressing phytase would reduce feed costs, as microbial fermentation utilized in the production of common phytase enzymes has an associated cost [59]. These authors proposed an over-expression of Aspergillus niger phyA2 gene in corn seeds to improve $\mathrm{P}$ availability and to reduce the environmental impact of animal production [59]. Hong and cohorts successfully expressed two bacterial phytases in germinated transgenic rice seeds, in vitro, which yielded high activity over broad $\mathrm{pH}$ ranges [60]. Researchers in The Netherlands encoded a DNA fragment of mature enzyme from A. niger into a sequence encoding the signal peptide of the tobacco PR-S protein [61]. After determining enzyme stability over a one year 
period, transgenic tobacco seeds were applied to a broiler diet. Broiler performed similarly to both a commercially available Aspergillus phytase and a P sufficient diet [61]. These findings demonstrate the potential to transform phytase expressing genes into various plant sources. Denbow and coauthors attempted to express enzymatic activity in a more traditional feed ingredient, such as soybeans [62]. An A. niger phytase sequence was stably introduced into raw soybeans without significant interference to enzyme activity. An in vivo broiler experiment revealed similar body weights when comparing 1,200 units of transgenic soybean phytase to a $\mathrm{P}$ sufficient diet.

\section{Feed Safety}

\section{A. Food Safety Modernization Act}

The Food Safety Modernization Act (FSMA) was passed into law on January $4^{\text {th }}, 2011$ in an effort to improve feed, food, and consumer safety. The FSMA gives the Food and Drug Administration (FDA) a modern mandate to improve the safety of the country's food supply [63]. These provisions establish science-based minimum standards to minimize the risk of serious adverse health consequences or death [64]. This legislation shifts food-safety focus from reaction and response to prevention [63], providing a more effective proactive policy [65]. A greater focus has been given to the development, maintenance, and improvement of prerequisite programs, which should contribute to FSMA compliance [66].

Coglianese and Lazer describe three regulatory strategies that may be used when applying new regulations: Performance-based regulation, which specifies a particular outcome; Technology-based regulation, which defines specific rules, procedures, or behaviors that should achieve a desired outcome; and Management-based regulation, which requires plans to comply with general criteria designed to promote targeted social goals [67]. In regard to the FSMA, 
Humphrey claims that management-based regulation allows customized risk-based controls to the specific circumstances of the farm or facility, reducing unnecessary controls [68]. Humphrey also explains management-based regulations requires a facility to have the capacity to develop a site/product specific assessment of risks and implement a food safety plan adequate to identified risks [68]. The American Feed Industry Association (AFIA) [69] has developed training webinars and information packets to assist feed producers, integrators, and ingredient suppliers. Members of AFIA are also provided weekly FSMA updates in an effort ensure FSMA compliance among animal feed and animal feed ingredient suppliers. Currently, all sectors of food production are being affected by the FSMA which is in place to continually provide the world's safest food supply.

\section{B. Animal Feed Contamination}

Cochrane et al. reported that the most prevalent biological hazard in all animal feeds is undoubtedly Salmonella [70]. In support, Baxter-Jones reported that feed is a major source of introduction of Salmonella into commercial production situations [71]. Park et al. further supported these claims by reporting that feed is a leading source of contamination in poultry; however, detection is complicated due to low concentrations [72]. These speculations are supported with scientific evidence of worldwide Salmonella-derived animal feed contamination.

In 1996, Harris presented data at the first international symposium on the ecology of Salmonella in pork production where the first findings of Salmonella in poultry feeds in the U.S. and Great Britain dates back to 1948 [73-74]. Veldman et al. sampled animal feedstuffs in Dutch feed mills and reported $21 \%$ of poultry meals were contaminated with Salmonella [75]. Davies and Wray studied feed manufacturing facilities in Great Britain and reported Salmonella contamination rates ranging from 1.1 to $41.7 \%$ [76]. These authors were only able to isolate a 
few serovars of $S$. Enteritidis and $S$. Typhimurium; however, this confirms that contaminated ingredients were utilized in feed production [76]. Others reported that animal and plant-derived protein meals are frequently contaminated with Salmonella [77]. A survey conducted in the United States in 1991 identified Salmonella in feed ingredients, mash feed, breeder houses, yolk sacs from chicks at the hatchery, fecal droppings, live haul trucks, and whole processed broiler carcasses [78]. Supporting literature from Crump et al. notes incidents in which human illness was traced back to contaminated animal feed [79]. These authors speculate that human foodborne illness may be reduced by ensuring that animal feed is free of bacterial pathogens [79].

\section{Salmonella}

Salmonella is a genus of the family Enterobacteriaceae [80]. Salmonella species are Gram-negative, flagellated facultative anaerobic, non-spore forming bacilli, characterized by O, $\mathrm{H}$, and Vi antigens [81]. Guthrie reported Salmonella growth between $8^{\circ} \mathrm{C}$ and $45^{\circ} \mathrm{C}$ in a pH range of 4-9 and require water activity above 0.94 [82]. Additionally, Mani-Lopez et al. suggested that Salmonella are heat-sensitive and may die if temperatures exceed $70^{\circ} \mathrm{C}$; however, Salmonella are resistant to drying and may survive for long periods of time in dust and dirt [80]. In 1996, there were over 1,800 known serotypes of Salmonella [81]. As of December, 2016 The World Health Organization reported over 2,500 serotypes of Salmonella [83]. Salmonella has the ability to infect a large number of animal species making identification of the source of environmental contamination very difficult [84]. The ubiquitous nature of Salmonella allows cycling between host and nonhost environments as well as the ability to survive for long periods of time on diverse materials [85]. Chicken manure and other abundant, moist, organic materials may serve as reservoirs in which Salmonella species can survive and grow for long periods of 
time [86]. Results from the 1991 Salmonella survey demonstrates the need for comprehensive efforts to control Salmonella [78]. As a result, the USDA created the Food Safety and Inspection Service (FSIS) which organized a Salmonella Action Plan [87] to encompass a comprehensive strategy to reduce Salmonella.

Milner and Shaffer studied salmonellosis in chicks in 1952 and reported that very small oral doses could readily infect day old chicks [88]. These authors also reported that susceptibility to infection by the oral route rapidly decreased as bird age increased [88]. When adult chickens are infected by Salmonella enterica serovars Typhimurium or Enteritidis, there is a risk for public health because these two pathogens are often silent, showing no significant clinical signs or mortality [89-90]. Often present in feces excreted by healthy animals, these bacteria frequently contaminate raw foods of animal origin through fecal contact during production and slaughter [91]. Furthermore, following Salmonella enterica outbreaks in the 1970's, researchers confirmed transovarian transmission when pathogen-free birds were orally inoculated with Salmonella Heidelberg [92]. In 2009, a review on mechanisms of action associated with transovarian transmission, Ganois et al. demonstrated that Salmonella serotypes can pass from the intestine of the chicken into the bloodstream and then into the reproductive tract [93]. These authors concluded that Salmonella enterica possessed the capacity to survive attacks from inherent antimicrobial molecules during the formation of the egg in the oviduct of the hen [93]. These data support continued research in Salmonella mitigation.

\section{Mitigation Techniques}

Microbiological safety is a major concern for both consumers and industry, and a wide range of chemical and physical treatments have been developed to eliminate pathogens [94]. These developments are essential due to potential Salmonella introduction through feed 
following negative Salmonella results. Negative results may be associated with the culture itself [95], where viable but non-culturable cells may be masked. Understanding pathogen mitigation potential in commercial feed production and integrated operations may assist with obtaining desired performance. This is especially important as the United States transitions to antibiotic free production. In 2003, Ricke speculated an inevitable decrease in the use of antibiotics in animal management [96]. In an effort to minimize production setbacks, antibiotic alternatives became an area of research interests. Ricke coined this research interest as the discovery and application of nonantibiotic chemical compounds capable of killing or retarding the growth of microorganisms [96]. However, feed additive support, as a means of antibiotic alternatives, may not be sufficient. Mateos et al. concluded that adequate management and improvement of hygienic conditions are required to minimize the influence of enteric disorders in antibiotic free flocks [97].

Hygiene improvements have been attempted utilizing several methods. In 1996, avian pathologists studied heat treating Salmonella enterica in a laboratory setting. These scientists used regression analysis and predicted that heat treatment of $93^{\circ} \mathrm{C}$ for 90 seconds would cause a 10,000 fold reduction of viable Salmonella in feed with 15\% moisture [98]. Although beneficial on a basic level, the laboratory conditions that were utilized to draw these conclusions do not mimic feed manufacturing conditions. McCapes et al. studied a pelleting process that included conditioning mash feed with steam and other hot gases generated by direct combustion. These authors concluded $100 \%$ mitigation effectiveness when this $14.5 \%$ moisture feed had been conditioned at $85.7^{\circ} \mathrm{C}$ for 4.1 minutes [99]. Each of these experiments suggest improved hygiene with increased conditioning barrel retention time. Another pathogen mitigation option is irradiation. Leeson and Marcotte reported complete destruction of Salmonella and no adverse 
performance from birds eating irradiated feed [100]. Food scientists explain that electron beam (E-beam) irradiation may be an alternative to thermal processing [101]. Additionally, Matak and Jaczynski discussed how E-beam irradiation can reduce the number of probable microbiological hazards that may be present while the food remains generally unaffected [102]. Cost effective mitigation strategies that maintain nutrient digestibility will be at the forefront as poultry nutrition continues to develop.

Organic acids have a long history of use as a food additive and preservative. Paster studied the commercial use of organic acids, specifically propionic acid and calcium propionate, as a fungistat, concluding that propionic acid served as a valid fungistat for commercial poultry feed [103]. Later, in 1981, Dixon and Hamilton claim that the commercial fungistat market was dominated by organic acids, mainly propionic acid [104]. In 2003, Ricke summarized that for the several decades, these acids have been examined for potential bactericidal activity in feed and feed ingredients [96]. Mani-Lopez et al. supported the continued use of organic acids as antimicrobials because they are generally regarded as safe, have no limited acceptable daily intake, and are cheap to apply [80].

Another mitigation approach is to apply formic acid to the feed. This approach coincides with the FSMA's proactive and preventative approach, as opposed to a reactive approach. Formic acid treatment has indicated protection against Salmonella recontamination of feed [105]. In a separate experiment, formic acid treated feed reduced isolation rates of Salmonella, as well as reducing the incidence of infection in newly hatched chicks [106]. These authors concluded that formic acid treatment of chicken feed could have important benefits to public health [106]. When using these acids there are perceptions of human health concerns. A study was conducted to study the effects of formaldehyde inhalation and these results suggested that at airborne levels, 
risks of respiratory tract cancer are considered to be negligibly low [107]. Additionally, commercial formaldehyde-based products are approved for use by the FDA and are available in both liquid and dry powder forms. Israelsen et al. reported that most feed contamination occurred as a result of growth within feed manufacturing systems [108]. Therefore, additive support that is known to decrease recontamination risks, such as formaldehyde-based additive support, would be ideal.

\section{E. Surrogate Organisms}

In an effort to minimize risks associated with studying pathogen mitigation, the use of a nonpathogenic surrogate organism may be appropriate. A surrogate has been defined as organisms, particles, or substances used to study the fate of a pathogen in a specific environment [109]. Sinclair et al. claimed that safety is the major benefit of using nonpathogenic surrogate organisms and their use reduces the uncertainties associated with exposure assessment [109]. Busta et al. claim that surrogate microorganisms are useful in validating effectiveness of microbial control measures, such as responses to specific processing treatments [110]. In regard to feed mills, the use of a surrogate organisms to study process mitigation effects is prudent.

Thermally inactivating Salmonella has been a goal of food and feed processors for some time. The need for inactivation of these pathogens in low moisture products led to numerous funded research projects. In 2007, the Almond Board of California reported that Enterococcus faecium NRRL B-2354 was accepted as a Salmonella surrogate for heat process validation [111]. In 2014, the Almond Board of California funded a project to validate the appropriateness of Enterococcus faecium NRRL B-2354 in thermal processing validations [112]. Kopit et al. conducted this work and reported that E. faecium displayed similar thermal tolerance to that of Salmonella enterica on almonds [113]. These authors concluded that E. faecium NRRL B-2354 
and its clonal representative ATCC 8459 are acceptable surrogate organisms in thermal process validation of food products [113]. Then, in 2015, researches at Kansas State University utilized E. faecium (ATCC 8459) to examine mitigation potential in poultry feed utilizing various concentrations of a novel feed additive, as well as steam conditioning and pelleting [114]. Rachon et al. studied various surrogate organisms and there application to low moisture foods. These authors reported that E. faecium NRRL B-2354 was a suitable surrogate in pet foods [115]. Enache et al. further confirmed the effectiveness of E. faecium as a conservative and suitable surrogate for Salmonella [116]. Finally, in 2016, researchers studying commercial food safety reported that $E$. faecium 8459 could serve as a conservative surrogate to validate thermal process lethality [117].

Experiments utilizing other surrogate organisms for thermal processing validation in poultry feed has been conducted. In 2006, Okelo et al. claimed that spores of B. stearothermophilus were more suitable organisms than cells of $S$. Typhimurium in a surrogate feed matrix [118]. Later, in 2008, Okelo et al. concluded that Nalidixic acid-resistant $S$. Typhimurium nal ${ }^{\mathrm{r}}$ was not an acceptable surrogate organism for monitoring sterilization efficiency during feed extrusion; however, dry feed inocula of $B$. stearothermophilus spores were capable of monitoring sterilization efficiency [119]. Other researchers determined that elevated levels of Enterobacteriaceae is an indication of likely Salmonella contamination [120]. Uneven distribution of Salmonella [121] demonstrates the potential benefit of monitoring Enterobacteriaceae. However, Cox et al. contradicted this when they reported that Enterobacteriaceae is not a reliable indicator of Salmonella in feed [122]. Perhaps the uneven distribution of Salmonella contributed to the results presented by Cox and cohorts. Martinez et al. studied the heat resistance of an E. faecium strain (ATCC 49624) to gather data on its 
usefulness in pasteurization procedure monitoring. These authors reported differing heat resistance throughout progressing growth phases [123]. In conclusion, these data demonstrate the importance of adequate selection of an appropriate surrogate organism for process validation.

\section{Conclusion}

This literature review was designed to properly introduce the research that is presented in the following chapters of this dissertation. The phytase enzyme research was conducted in conjunction with allied industry partners which helped to provide funding for the novel steam conditioning manipulation and antimicrobial inclusion work.

\section{Literature Review References}

1. National Chicken Council. http://www.nationalchickencouncil.org

2. USPOULTRY. https://www.uspoultry.org/

3. United States Department of Agriculture- Economic Research Service. 2017. Poultry and Eggs Overview. https://www.ers.usda.gov/topics/animal-products/poultry-eggs/

4. United States Department of Agriculture- Foreign Agricultural Services. 2017. Livestock and Poultry: World Markets and Trade. https://apps.fas.usda.gov/psdonline/circulars/livestock_poultry.pdf

5. Emmert, J.L., and D.H. Baker. 1997. Use of the Ideal Protein Concept for precision formulation of amino acid levels in broiler diets. J. Appl. Poult. Res. 6:462-470.

6. Dari, R.L., A.M. Penz Jr., A.M. Kessler, and H.C. Jost. 2005. Use of digestible amino acids and the concept of ideal protein in feed formulation for broilers. J. Appl. Poult. Res. 14:195-203.

7. Buchanan, N.P., K.G.S. Lilly, C.K. Gehring, and J.S. Moritz. 2010. The effects of altering diet formulation and manufacturing technique on pellet quality. J. Appl. Poult. Res. 19:112-120.

8. Kidd, M.T., P.B. Tillman, P.W. Waldroup, and W. Holder. 2013. Feed-grade amino acid use in the United States: The synergetic inclusion history with linear programming. J. Appl. Poult. Res. 22:583-590.

9. Corey, A.M., K.G.S. Wamsley, T.S. Winowiski, and J.S. Moritz. 2014. Effects of calcium lignosulfonate, mixer-added fat, and feed form on feed manufacture and broiler performance. J. Appl. Poult. Res. 23:418-428.

10. Abdollahi, M.R., V. Ravindran, and B. Svihus. 2013. Pelleting of broiler diets: An overview with emphasis on pellet quality and nutritional value. Anim. Feed Sci. Technol. 179:1-23.

11. Behnke, K.C. 1996. Feed manufacturing technology: current issues and challenges. Anim. Feed Sci. Tech. 62:49-57. 
12. Patton, J.W., H.H. Buskirk, L.A. Rauls. 1937. A study of the relative merits of pellets and mash poultry feeds. Vet. Med. 32:423-427.

13. Jensen, L.S., L.H. Merrill, C.V. Reddy, and J. McGinnis. 1962. Observation on Eating Patterns and Rate of Food Passage of Birds Fed Pelleted and Unpelleted Diets. Poult. Sci. 41:1414-1419.

14. Scheideler, S.E. 1991. Pelleting is Important for Broilers. Pages 1-7 Proc. $18^{\text {th }}$ Annu. Carolina Poult. Nutr. Conf., Charlotte, NC. North Carolina State Univ., Raleigh.

15. Behnke, K.C. 1994. Factors affecting pellet quality. Proc. Maryland Nutrition Conference, 20-25 March 1994. Department of Poultry Science and Animal Science, College of Agriculture, University of Maryland, College Park.

16. Thomas, M. and A.F.B. van der Poel. 1996. Physical quality of pelleted animal feed 1. Criteria for pellet quality. Anim. Feed Sci. Tech. 61:89-112.

17. Briggs, J.L., D.E. Maier, B.A. Watkins, and K.C. Behnke. 1999. Effects of Ingredients and Processing Parameters on Pellet Quality. Poult. Sci. 78:1464-1471.

18. Loar II, R.E., K.G.S. Wamsley, A. Evans, J.S. Moritz, and A. Corzo. 2014. Effects of varying conditioning temperature and mixer-added fat on feed manufacturing efficiency, 28- to 42- day broiler performance, early skeletal effect, and true amino acid digestibility. J. Appl. Poult. Res. 23:444-4555.

19. Cox, N.A., D. Burdick, J.S. Bailey, and J.E. Thomson. 1986. Effect of the Steam Conditioning and Pelleting Process on the Microbiology and Quality of CommercialType Poultry Feeds. Poult. Sci. 65:704-709.

20. van der Poel, A.F.B., H.M.P. Fransen, and M.W. Bosh. 1997. Effect of expander conditioning and/ or pelleting of a diet containing tapioca, pea and soybean meal on the total tract digestibility in growing pigs. Anim. Feed Sci. Technol. 66:289-295.

21. Lundbald, K.K., S. Issa, J.D. Hancock, K.C. Behnke, L.J. McKinney, S. Alavi, E. Prestlokken, J. Fledderus, and M. Sorensen. 2011. Effects of steam conditioning at low and high temperature, expander conditioning and extruder processing prior to pelleting on growth performance and nutrient digestibility in nursery pigs and broiler chickens. Anim. Feed Sci. Technol. 169:208-217.

22. Cutlip, S.E., J.M. Hott, N.P. Buchanan, A.L. Rack, J.D. Latshaw, and J.S. Moritz. 2008. The Effect of Steam-Conditioning Practices on Pellet Quality and Growing Broiler Nutritional Value. J. Appl. Poult. Res. 17:249-261.

23. Huang, X., C. Christensen, and P. Yu. 2015. Effects of conditioning temperature and time during the pelleting process on feed molecular structure, pellet durability index, and metabolic features of co-products from bio-oil processing in dairy cows. J. Dairy Sci. 98:4869-4881.

24. Wamsley, K.G.S. and J.S. Moritz. 2013. Resolving poor pellet quality and maintaining amino acid digestibility in commercial turkey diet feed manufacture. J. Appl. Poult Res. 22:439-446.

25. Gehring, C.K., J. Jaczynski, and J.S. Moritz. 2009. Improvements of pellet quality with proteins recovered from whole fish using isoelectric solubilization-perception. J. Appl. Poult. Res. 18:418-431

26. Boney, J.W. and J.S. Moritz. 2017. The effects of Spirulina algae inclusion and conditioning temperature on feed manufacturing, pellet quality, and true amino acid digestibility. Ani. Feed Sci. Technol. 224:20-29. 
27. Proudfoot, F.G. and H.W. Hulan. 1982. Feed Texture Effects on the Performance of Turkey Broilers. Poult. Sci. 61:327-330.

28. Corzo, A., L. Mejia, and R.E. Loar, II. 2011. Effect of pellet quality on various broiler production parameters. J. Appl. Poult. Res. 20:68-74.

29. Lilly, K.G.S., C.K. Gehring, K.R. Beaman, P.J. Turk, M. Sperow, and J.S. Moritz. 2011. Examining the relationships between pellet quality, broiler performance, and bird sex. J. Appl. Poult. Res. 20:231-239.

30. Lemons, M.E. and J.S. Moritz. 2015. The effect of feeder space access and crumble- or pellet-to-fine ratio on 38 day-old broiler performance. J. Appl. Poult. Res. 25:12-20.

31. Glover, B.G., K.L. Foltz, I. Holaskova, and J.S. Moritz. 2015. Effects of modest improvements in pellet quality and experiment pen size on broiler chicken performance. J. Appl. Poult. Res. 25:21-28.

32. Leeson, S., and J.D. Summers. 2001. Phosphorus. Pages 358-363 in Nutrition of the Chicken. 4th Edition. University Books. Guelph, Ontario Canada.

33. Fritts, C.A. and P.W. Waldroup. 2006. Modified Phosphorus Program for Broilers Based on Commercial Feeding Intervals to Sustain Live Performance and Reduce Total and Water-Soluble Phosphorus in Litter. J. Appl. Poult. Res. 15:207-218.

34. Angel, R., N.M. Tamim, T.J. Applegate, A.S. Dhandu, and L.E Ellestad. 2002. Phytic Acid Chemistry: Influence on Phytin-Phosphorus Availability and Phytase Efficacy. J. Appl. Poult. Res. 11:471-480.

35. Adeola, O. 2017. Expressing feed phosphorus and requirement on a digestible basis. Poult. Sci. Vol. 96 (E-Suppl. 1): 593S.

36. Bedford, M. 2017. Evaluation of phosphorus digestibility response to exogenous phytases. Poult. Sci. Vol. 96 (E-Suppl. 1): 595S.

37. Mutucumarana, R.K., V. Ravindran, G. Ravindran, and A.J. Cowieson. 2014. Measurement of true ileal digestibility and total tract retention of phosphorus in corn and canola meal for broiler chickens. Poult. Sci. 93:412-419.

38. Summers, J.D. 1997. Precision Phosphorus Nutrition. J. Appl. Poult. Res. 6:495-500.

39. Bougouin, A., J.A.D.R.N. Appuhamy, E. Kebreab, J. Dijkstra, R.P. Kwakkel, and J. France. 2014. Effects of phytase supplementation on phosphorus retention in broilers and layers: a meta-analysis. Poult. Sci. 93:1981-1992.

40. Sharpley, A., B. Foy, and P. Withers. 2000. Practical and innovative measures for the control of agricultural phosphorus losses to water: An overview. J. Environ. Qual. 29:1-9.

41. Sims, J.T. 1999. Delaware's State Nutrient Management Program: An Overview of the 1999 Delaware Nutrient Management Act. Fact Sheet NM-01. College of Agric. Nat. Res., Univ. of DE, Newark, DE.

42. Simpson, T.W. 1998. A Citizen's Guide to Maryland's Water Quality Improvement Act. Univ. of MD Coop. Extension, College Park, MD.

43. Beegle, D., L.E. Lanyon, and D. Ligenfelter. 1997. Nutrient management legislation in Pennsylvania: A summary of the final regulations. Argon. Facts 40. Pennsylvania State Univ., University Park, PA.

44. Hansen, D., J. Nelson, G. Binford, T. Sims, and B. Saylor. 2005. Phosphorus in Poultry Litter: New Guidelines from the University of Delaware. Fact Sheet NM-07. College of Agric. Nat. Res., Univ. of DE, Newark, DE. 
45. Sims, J.T., R.O. Maguire, A.B. Leytem, K.L. Gartley, and M.C. Pautler. 2002. Evaluation of Mehlich 3 as an Agri-Environmental Soil Phosphorous Test for the Mid-Atlantic United States of America. Soil Sci. Soc. Am. J. 66:2016-2032.

46. Evans, A.M., J.W. Boney, and J.S. Moritz. 2016. The effect of poultry litter biochar on pellet quality, one to $21 \mathrm{~d}$ broiler performance, digesta viscosity, bone mineralization, and apparent ileal amino acid digestibility. J. Appl. Poult. Res. 26:89-98.

47. Maga, J.A. 1982. Phytate: Its Chemistry, Occurrence, Food Interactions, Nutritional Significance, and Method of Analysis. J. Agric. Food Chem. 30:1-9.

48. O’Dell, B.L., A.R. de Boland, and S.R. Koirtyohann. 1972. Distribution of Phytate and Nutritionally Important Elements among the Morphological Components of Cereal Grains. J. Agr. Food Chem. 20:718-721.

49. Nelson, T. S. 1966. The Utilization of Phytate Phosphorus by Poultry- A Review. Poult. Sci. 46:862-871.

50. Cowieson, A.J., T. Acamovic, and M.R. Bedford. 2006. Phytic acid and phytase: Implications for protein utilization by poultry. Poult. Sci. 85:878-885.

51. Cosgrove, D.J. 1966. The chemistry and biochemistry of inositol phosphates. Rev. Pure Appl. Chem. 16:209-224.

52. Warden, W. K. and P. Schaible. 1962. Preliminary investigations concerning utilization of phytin phosphorus by the chick. Poult. Sci. 41:1692.

53. Nelson, T.S., T.R. Shieh, and R. J. Wodzinski. 1971. Effects of supplemental phytase on the utilization of phytate phosphorus by chicks. J. Nutrition. 101:1289-1294.

54. Engelen, A.J., F.C. van der Heeft, P.H. Randsdorp, and E.L. Smit. 1994. Simple and rapid determination of phytase activity. J. AOAC Int. 77:760-764.

55. Selle, P.H., A. J. Cowieson, and V. Ravindran. 2009. Consequences of calcium interactions with phytate and phytase for poultry and pigs. Livestock Sci. 124:126-141.

56. Selle, P.H and V. Ravindran. 2007. Microbial phytase in poultry nutrition. Animal Feed Science and technology. 135:1-41.

57. Dos Santos, T.T., C.L. Walk, and S. Srinongkote. 201.4. Influence of phytate level on broiler performance and the efficacy of 2 microbial phytases from 0 to 21 days of age. J. Appl. Poult. Res. 23:181-187.

58. Boney, J.W. and J.S. Moritz. 2017. Phytase dose effects in practically formulated diets that vary in ingredient composition on fees manufacturing and broiler performance. $\mathrm{J}$. Appl. Poult. Res. 26:273-285.

59. Chen, R., G. Xue, P. Chen, B. Yao, W. Yang, Q. Ma, Y. Fan, Z. Zhao, M.C. Tarczynski, and J. Shi. 2007. Transgenic maize plants expressing a fungal phytase gene. Transgenic Res. 17:633-643.

60. Hong, C.Y., K.J. Cheng, T.H. Tseng, C.S. Wang, L.F. Lui, and S.M. Yu. 2004. Production of two highly active bacterial phytases with broad $\mathrm{pH}$ optima in germinated transgenic rice seeds. Transgenic Res. 13:29.

61. Pen, J., T.C. Verwoerd, P.A. van Paridon, R.F. Beudeker, P.J.M. van den Elzen, K. Geerse, J.D. van der Klis, H.A.J. Versteegh, A. J.J. van Ooyen, and A. Hoekema. 1993. Phytase-containing transgenic seeds as a novel feed additive for improved phosphorus utilization. Bio/Technology 11:811-814. 
62. Denbow, D.M., E.A Grabau, G.H. Lacy, E.T. Kornegay, D.R. Russell, and P.F. Umbeck. 1998. Soybeans transformed with a fungal phytase gene improve phosphorus availability for broilers. Poult. Sci. 77:878-881.

63. Taylor, M.R. 2011. Will the Food Safety Modernization Act help prevent Outbreaks of Foodborne Illness?. N. Eng. J. Med. 365:e18. DOI: 10.0156/NEJMp1109388.

64. Paggi, M.S., F. Yamazaki, L. Ribera, M. Palma, and R. Knutson. 2013. Domestic and Trade Implications of Leafy Green Marketing Agreement Type Policies and the Food Safety Modernization Act for the Southern Produce Industry. J. Appl. Agric. And Appl. Econ. 45:453-464.

65. Strauss, D.M. 2011. An Analysis of the FDA Food Safety Modernization Act: Protection for Consumers and Boon for Business. Food and Drug Law Journal. 66:353-376.

66. Kheradia, A. and K. Warriner. 2013. Understanding the Food Safety Modernization Act and the role of quality practitioners in the management of food safety and quality systems. The TQM J. 25:347-370.

67. Coglianese, C. and D. Lazer. 2003. Management-Based Regulation: Prescribing Private Management to Achieve Public Goals. Law and Society Review. 37:691-730.

68. Humphrey, J. 2012. Convergence of US and EU Production Practices Under the New FDA Food Safety Modernization Act. The World Economy. 35:994-1005.

69. The American Feed Industry Association. 2101 Wilson Blvd, Suite 810, Arlington, VA 22201. http://www.afia.org/

70. Cochrane, R.A., S.S. Dritz, J.C. Woodworth, C.R. Stark, A.R. Huss, J.P. Cano, R.W. Thompson, A. C. Fahrenholz, and C.K. Jones. 2016. Feed mill biosecurity plans: A systematic approach to prevent biological pathogens in swine feed. J. Swine Health Prod. 24:154-164.

71. Baxter-Jones, C. 1996. Latest thoughts on Salmonella control. Pages 19-26 in International Hatchery Practice, International Poultry Production. Positive Action Publications, Ltd., North Humberside, UK.

72. Park, S.H., R. Jarquin, I. Hanning, G. Almeida, and S.C. Ricke. 2011. Detection of Salmonella spp. survival and virulence in poultry feed by targeting the hilA gene. J. Appl. Micro. 111:426-432.

73. Harris, I.T. 1996. Salmonella in Swine Feed and Feed Ingredients: A Review. Pg 104118. Proc. Ecology of Salmonella in Pork Production. March 11-13. Ames, IA. National Animal Disease Center.

74. Williams, J.E. 1981. Salmonellas in Poultry Feeds- A Worldwide Review. World's Poultry Sci. J. 37:97-105.

75. Veldman, A., H.A. Vahl, G.J. Borggreve, and D.C. Fuller. 1995. A survey of the incidence of Salmonella species and Enterobacteriaceae in poultry feeds and feed components. Vet. Rec. 136:169-172.

76. Davies, R.H. and C. Wray. 1997. Distribution of Salmonella contamination in ten feedmills. Vet. Microbiol. 51:159-169.

77. Wales, A.D., V.M. Allen, and R.H. Davies. 2010. Chemical treatment of animal feed and water for the control of Salmonella. Foodborne Path. And Dis. 7:3-15. 
78. Jones, F.T., R.C. Axtell, D.V. Rives, S.E. Scheideler, F.R. Tarver, Jr., R.L. Walker, and M.J. Wineland. 1991. A Survey of Salmonella Contamination in Modern Broiler Production. J. Food Prot. 54:502-507.

79. Crump, J.A., P.M. Griffin, and F.J. Angulo. 2002. Bacterial contamination of animal feed and its relationship to human foodborne illness. Clin. Infect. Dis. 35:859-865.

80. Mani-Lopez, E., H.S. Garcia, and A. Lopez-Malo. 2012. Organic acids as antimicrobials to control Salmonella in meat and poultry products. Food Res. Int. 45:713-721.

81. Giannella RA. Salmonella. In: Baron S, editor. Medical Microbiology. 4th edition. Galveston (TX): University of Texas Medical Branch at Galveston; 1996. Chapter 21. Available from: https://www.ncbi.nlm.nih.gov/books/NBK8435/

82. Guthrie, R.K. 1992. Salmonella. Boca Raton, FL. CRC Press, Inc.

83. World Health Organization. Salmonella fact sheet. Available from: http://www.who.int/mediacentre/factsheets/fs139/en/

84. Winfield, M.D. and E.A. Groisman. 2003. Role of Nonhost Environments in the Lifestyles of Salmonella and Escherichia coli. Appl. Environ. Microbiol. 69:3687-3694.

85. Jones, F.T. 2011. A review of practical Salmonella control measures in animal feed. J. Appl. Poult. Res. 20:102-113.

86. Braden, C.R. 2006. Salmonella enterica Serotype Enteritidis and Eggs: A National Epidemic in the United States. Clin. Infect. Dis. 43:512-517.

87. United States Department of Agriculture: Food Safety and Inspection Service. 2016. Salmonella Action Plan. https://www.fsis.usda.gov/wps/portal/fsis/topics/food-safetyeducation/get-answers/food-safety-fact-sheets/foodborne-illness-anddisease/salmonella/sap

88. Milner, K.C. and M.F. Shaffer. 1952. Bacteriologic studies of experimental Salmonella infections in chicks. J. Infect. Dis. 90:8186-8189.

89. Leveque, G., V. Forgetta, S. Morroll, A.L. Smith, N. Bumstead, P. Barrow, J.C. LoredoOsti, K. Morgan, and D. Malo. 2003. Allelic Variation in TLR4 Is Linked to Susceptibility to Salmonella enterica Serovar Typhimurium Infection in Chickens. Infection and Immunity. 71:1116-1124.

90. Guard-Peter, J. 2001. The chicken, the egg and Salmonella enteritidis. Environ. Microbiol. 3:421-430.

91. Sanchez, S., C.L. Hofacre, M.D. Lee, J.L. Maurer, and M.P. Doyle. 2002. Animal sources of salmonellosis in humans. J. American Vet. Med. Assoc. 221:492-497.

92. Gast, R.K., J. Guard-Bouldin, and P.S. Holt. 2004. Colonization of reproductive organs and internal contamination of eggs after experimental infection of laying hens with Salmonella Heidelberg and Salmonella Enteritidis. Avian Dis. 48:863-869.

93. Gantois, I., R. Ducatelle, F. Pasmans, F. Haesebrouck, R. Gast, T.J. Humphrey, and F.V. Immerseel. 2009. Mechanisms of egg contamination by Salmonella Enteritidis. Microbio. Reviews. 33:718-738.

94. Kim, S.A., and M.S. Rhee. 2013. Marked Synergisitic Bactericidal Effects and Mode of Action of Medium Chain Fatty Acids in Combination with Organic Acids against Escherichia coli O157:H7. Appl. Environ. Microbiol. 79:6552-6560. 
95. Carrique-Mas, J.J., S. Bedford and R.H. Davies. 2006. Organic acid and formaldehyde treatment of animal feeds to control Salmonella: efficacy and masking during culture. J. of Appl. Micro. 103:88-96.

96. Ricke, S.C. 2003. Perspectives on the Use of Organic Acids and Short Chain Fatty acids as Antimicrobials. Poult. Sci. 82:632-639.

97. Mateos, G.G., R. Lazaro, and M.I. Gracia. 2002. The feasibility of using nutritional modifications to replace drugs in poultry feed. J. Appl. Poult. Res. 11:437-452.

98. Himathongkham, S., M. das Gracas Pereira, and H. Riemann. 1996. Heat Destruction of Salmonella in Poultry Feed: Effect of Time, Temperature, and Moisture. Avian Dis. 40:72-77.

99. McCapes, R.H., H.E. Ekperigin, W.J. Cameron, W.L. Ritchie, J. Slagter, V. Stangeland, and K.V. Nagaraja. 1989. Effect of a New Pelleting Process on the Level of Contamination of Poultry Mash by Escherichia coli and Salmonella. Avian Dis. 33:103111.

100. Leeson, S. and M. Marcotte. 1993. Irradiation of poultry feed I. Microbial status and bird response. World's Poult. Sci. J. 49:19-33.

101. Matak, K.E., A.L. Hvizdzak, S. Beamer, and J. Jaczynski. 2010. Recovery of Salmonella enterica Serovars Typhimurium and Tennessee in Peanut Butter after Electron Beam Exposure. J. Food Sci. 75:M462-M467.

102. Matak, K.E. and J. Jaczynski. 2009. Food preservation with electron beam. In: Hulsen I, Ohenesorge E, editors, Food science research and technology. New York, N.Y.: Nova Sciences Publishers, Inc. p229-245.

103. Paster, N. 1979. A Commercial Scale Study of the Efficiency of Propionic Acid and Calcium Propionate as Fungistats in Poultry Feed. Poult. Sci. 58:572-576.

104. Dixon, R.C and P.B. Hamilton. 1981. Effect of Feed Ingredients on the Antifungal Activity of Propionic Acid. Poult. Sci. 60:2407-2411.

105. Hinton, M. and A.H. Linton. 1988. Control of Salmonella infections in broiler chickens by the acid treatment of their feed. Vet. Rec. 123:416-421.

106. Humphrey and Lanning. 1988. The vertical transmission of salmonella and formic acid treatment of chicken feed: A possible strategy for control. Epid. Inf. 100:43-49.

107. Arts, J.H., M.A. Rennen, and C. de Heer. 2006. Inhaled formaldehyde: evaluation of sensory irritation in relation to carcinogenicity. Regul. Toxicol. Pharmacol. 44: 144160.

108. Israelsen, M., I.D. Hansen, and E. Jacobsen. 1996. Don't grow Salmonella in the pellet cooler. Feed Int. 17:34-38.

109. Sinclair, R.G., J.B. Rose, S. A. Hashsham, C.P. Gerba, and C.N. Haas. 2012. Criteria for Selection of Surrogates Used to Study the Fate and control of Pathogens in the Environment. Appl. Environ. Microbiol. 78:1969-1977.

110. Busta, F.F., T.V. Suslow, M.E. Parish, L.R. Beuchat, J.N. Farber, E.H. Garrett, and L.J. Harris. 2003. The use of indicators and surrogate microorganisms for the evaluation of pathogens in fresh and fresh-cut produce. Comp. Rev. in Food Sci. and Food Safety. 2(supplement):179-185. 
111. Almond Board of California. 2007. Guidelines for validation of dry roasting processes. http://www.almonds.com/sites/default/files/content/attachments/dry-roastvalidation-guidelines.pdf

112. Almond Board of California. 2014. Guidelines for using Enterococcus faecium NRRL B-2354 as a surrogate microorganism in almond process validation. http://www.almonds.com/sites/default/files/content/attachments/guidelines_for_using_ent erococcus_faecium_nrrl_b2354_as_a_surrogate_microorganism_in_almond_process_validation.pdf

113. Kopit, L.M, E.B. Kim, R.J. Siezen, L.J. Harris, and M.L. Marco. 2014. Safety of the Surrogate Microorganism Enterococcus faecium NRRL B-2354 for Use in Thermal Process Validation. Appl. Environ. Microbiol. 80:1899-1909.

114. Cochrane, R.A., C.R. Stark, A. R. Huss, G. Aldrich, C.J. Knueven, C.K. Jones, and J.S. Pitts. 2015. Salmonella surrogate mitigation in poultry feed using a dry acid powder. American Society of Animal Science, Midwest section. Accepted Abstract 89.

115. Rachon, G., W. Penaloza, and P.A. Gibbs. 2016. Inactivation of Salmonella, Listeria monocytogenes and Enterococcus faecium NRRL B-2354 in a selection of low moisture foods. Int. J. Food Micro. 231:16-25.

116. Enache, E., A. Kataoka, D.G. Black, C.D. Napier, R. Podolak, and M.M. Hayman. 2015. Development of a Dry Inoculation Method for Thermal Challenge Studies in low-Moisture Foods by Using Talc as a Carrier for Salmonella and a Surrogate (Enterococcus faecium). J. Food Prot. 78:1106-1112.

117. Channaiah, L.H, E. S. Holmgren, M. Michael, N.J. Sevart, D. Milke, C.L. Schwan, M. Krug, A. Wilder, R.K. Phebus, H. Thippareddi, and G. Milliken. 2016. Validation of Baking To Control Salmonella Serovars in Hamburger Bum Manufacturing, and Evaluation of Enterococcus faecium ATCC 8459 and Sacharomyces cerevisiae as Nonpathogenic Surrogate Indicators. J. Food Prot. 79:544-552.

118. Okelo, P.O., D.D. Wagner, L.E. Carr, F.W. Wheaton, L.W. Douglass, and S.W. Joseph. 2006. Optimization of extrusion conditions for elimination of mesophilic bacteria during thermal processing of animal feed mash. Anim. Feed Sci. technol. 129:116-137.

119. Okelo, P.O., S.W. Joseph, D.D. Wagner, F.W. Wheaton, L.W. Douglas, and L.E. Carr. 2008. Improvements in Reduction of Feed Contamination: An Alternative Monitor of Bacterial Killing During Feed Extrusion. J. Appl. Poult. Res. 17:219-228.

120. Jones, F.T. and K.E. Richardson. 2004. Salmonella in commercially manufactured feeds. Poult. Sci. 83:384-391.

121. Malorny, B., C. Lofstrom, M. Wagner, N. Kramer, and J. Hoorfar. 2008. Enumeration of Salmonella Bacteria in Food and Feed Samples by Real-Time PCR for Quantitative Microbial Risk Assessment. Appl. Environ. Micribiol. 74:1299-1304.

122. Cox, N.A., J.S. Bailey, J.E. Thompson, B.J. Juven. 1983. Salmonella and Other Enterobacteriaceae Found in Commercial Poultry Feed. Poult. Sci. 62:2169-2175.

123. Martinez, S., M. Lopez, and A. Bernardo. 2003. Thermal inactivation of Enterococcus faecium: effect of growth temperature and physiological state of microbial cells. Letters in Applied Microbiology. 37:475-481. 


\title{
CHAPTER 2
}

The Effects of Steam Conditioning Manipulations and Antimicrobial Inclusion on Feed Manufacturing and Salmonella Surrogate Mitigation

\author{
J.W. Boney ${ }^{1}$, J.L Weidhaas ${ }^{2}$, J. Jaczynski ${ }^{1}$, and J.S. Moritz ${ }^{1, ¥}$ \\ ${ }^{1}$ Division of Animal and Nutritional Sciences, West Virginia University, Morgantown, West \\ Virginia, 26506 \\ Phone: (304) 293-1911 \\ Fax: (304) 293-2232 \\ ${ }^{2}$ Department of Civil and Environmental Engineering, University of Utah, Salt Lake City, Utah, \\ 84112 \\ Phone: (801) 585-1228
}

¥Corresponding Author: Joe.Moritz@mail.wvu.edu

Primary Audience: Feed Manufacturers, Nutritionists, Researchers 
SUMMARY Animal well-being, evolving feed manufacturing regulatory programs, and consumer perception drive the continued need to provide safe feed to animals. Two experiments were conducted, using both short-term (ST) and long-term (LT) steam conditioning, to determine the effects of antimicrobial inclusion and conditioning temperature variations on feed manufacturing metrics (EXP1) and the mitigation of a Salmonella surrogate (EXP2). A split-plot design was utilized where ST (10s) or LT (60s) steam conditioning served as whole plot units. Whole plots consisted of either 2x3 (EXP1) or 2x4 (EXP2) factorial arrangements varying in mixer-added antimicrobial inclusion (With or Without) and degree of thermal processing ((Unprocessed Mash), $\left.71,82,88^{\circ} \mathrm{C}\right)$. Manufacturing of dietary treatments was replicated three times. A basal diet was used to obtain desired conditioning temperature, after which surrogate inoculated feed was exposed to either ST or LT conditioning. In EXP1, conditioning time and antimicrobial inclusion interacted $(\mathrm{P}=0.03)$ by decreasing pellet durability when antimicrobial was included to diets subjected to ST conditioning. Durability was not affected when LT conditioning was utilized. In EXP2, conditioning time, antimicrobial inclusion, and degree of thermal processing interacted $(\mathrm{P}<0.0001)$. Surrogate mitigation was detected with $\mathrm{ST}$ conditioning at $71^{\circ} \mathrm{C}$ relative to higher conditioning temperatures and for ST and LT conditioning applied to antimicrobial treated feed. Within the parameters of this study, both ST and LT steam conditioning display surrogate mitigation potential, 3-log and 4-log reductions, respectively. However, degree of surrogate mitigation and pellet quality are dependent on specific manufacturing and antimicrobial additive strategies.

KEYWORDS: Salmonella, mitigation, surrogate, conditioning temperature, antimicrobial 


\section{DESCRITION OF PROBLEM}

Increasing regulations from the United States Food and Drug Administration have resulted in the removal of growth promoting antibiotics in production agriculture and mandated efforts to increase feed and food safety. In regard to feed hygiene, feed producers need to understand the mitigation capabilities of their manufacturing processes. Furthermore, these producers must make a concerted effort to improve management strategies to reduce the introduction of harmful agents, formerly controlled with unrestricted sub-therapeutic or therapeutic antibiotic inclusions. Nutrition and antibiotic alternatives, feed manufacturing strategies, improved biosecurity, and on-farm management practices will continue to be integral to successful poultry production.

Currently, there are no feed manufacturing guidelines that dictate feed manufacturing techniques. Resultantly, techniques differ based on throughput demands, geographical and climate restrictions, ambient conditions, diet formulation, ingredient availability, and various feed processing equipment. Perhaps, understanding the effects of steam conditioning time and temperature manipulations could assist producers with maintaining hygienic, physical, and nutritional quality of feed.

The use of surrogate organisms has been studied and utilized to reduce the uncertainties associated with pathogen exposure assessment [1]. The selection of an adequately characterized, nonpathogenic surrogate organism is essential. However, selection may be limited due to the few bacterial surrogate strains that qualify to validate processes used in the control of foodborne pathogens [2]. For example, Okelo et al. concluded that Nalidixic acid-resistant Salmonella Typhimurium nal ${ }^{\mathrm{r}}$ was not an acceptable surrogate organism for monitoring sterilization efficiency during feed extrusion; however, dry feed inocula of B. stearothermophilus spores were 
capable of monitoring sterilization efficiency [3]. Properly sampling and monitoring Salmonella contamination can be difficult. Jones and Richardson determined that elevated levels of Enterobacteriaceae is an indication of likely Salmonella contamination [4]. Due to the uneven distribution of Salmonella, monitoring this family of bacteria that contains Salmonella may be more effective.

Conversely, simply inoculating feed with a non-pathogenic surrogate organism may be an ideal platform for determining mitigation potential. Following extensive experimentation, Kopit et al. concluded that E. faecium ATCC 8459 is an acceptable bacterial surrogate to be utilized in thermal processing validation experiments [2]. Researchers studying commercial food safety reported that E. faecium could serve as a conservative surrogate to validate thermal process lethality [5]. Bianchini et al. reported that E. faecium was inactivated at higher temperatures than Salmonella, indicating an appropriate margin of error in thermal process validation studies [6]. Furthermore, Cochrane et al. utilized E. faecium 8459 as a Salmonella surrogate organism while studying mitigation effects of a dry acid powder in poultry diets [7], confirming its acceptability for use in poultry feed processing validation experiments.

Steam conditioning temperature manipulations have been studied extensively [8-13], while comparative analysis of steam conditioning time is limited due to the complexity of altering steam conditioning systems. Concerns pertaining to steam conditioning manipulations include pellet quality, nutrient digestibility, protein denaturation, manufacturing parameters such as pelleting efficiency, and mixer-added enzyme activity retention. Inborr and Bedford reported that the magnitude of enzyme inactivation increases as temperature increases and conditioning time is prolonged [14]. However, increasing processing time at a given temperature can also lead to a better efficacy of hydrothermal treatment in terms of decontamination [15]. 
Furthermore, increasing steam conditioning temperature has been shown to consistently improve pellet quality [8].

As animal feeding legislation continues to evolve, the need for antibiotic alternatives continues to rise. Merriam-Webster defines an antimicrobial as an agent that destroys or inhibits the growth of microorganisms and especially pathogenic microorganisms [16]. Organic acids can broadly be classified as antimicrobials and were originally added to animal feeds to serve as fungistats; however, formic acid, propionic acid, and various organic acid combinations have been considered for their bactericidal activity in contaminated feed and feed ingredients [17]. Furthermore, formic, acetic, and propionic acids have been shown to reduce the colonization of Salmonella and Campylobacter colonization in the gut of poultry [18]. The objective of the current study was to determine the effects of mixer-added antimicrobial inclusion and steam conditioning temperature variations, in both short-term (ST) and long-term (LT) steam conditioning systems, on feed manufacturing metrics and the viability of Enterococcus faecium (ATCC 8459), an appropriate non-pathogenic surrogate for Salmonella.

\section{MATERIALS AND METHODS}

\section{Experimental Design}

Two experiments were conducted to examine feed manufacturing metrics and Salmonella surrogate mitigation potential. Treatments were arranged in a split-plot design in which whole plot units differed by feed residence time in the conditioning barrel. One whole plot unit consisted of short-term (ST) steam conditioning with a 10 second conditioning barrel retention time. The additional whole plot unit consisted of long-term (LT) steam conditioning with a 60 second conditioning barrel retention time. For simplicity, whole plot units will be referred to 
herein as conditioning times. In order to properly manipulate conditioning time, the ST and LT trails were conducted separately and then both feed manufacturing and surrogate mitigation experiments were nested within the split-plot design for analyses.

\section{EXP 1: Feed Manufacturing}

Treatments comprised a 2 × 3 factorial arrangement in a completely randomized design (CRD) with treatments nested within the aforementioned whole plot units. The main effects were mixer-added antimicrobial inclusion [19] (With or Without) and steam conditioning temperature $\left(71^{\circ} \mathrm{C}, 82^{\circ} \mathrm{C}\right.$, and $\left.88^{\circ} \mathrm{C}\right)$. Manufacturing of each treatment combination was replicated three times.

\section{EXP 2: Enterococcus faecium ATCC 8459 Mitigation}

Treatments comprised a $2 \times 4$ factorial arrangement in a CRD and were nested within the aforementioned whole plot units. The main effects were mixer-added antimicrobial inclusion [19] (With or Without) and degree of thermal processing (Unconditioned Mash, $71^{\circ} \mathrm{C}$ pellets, $82^{\circ} \mathrm{C}$ pellets, and $88^{\circ} \mathrm{C}$ pellets). Manufacturing of each treatment combination was replicated three times. EXP1 and EXP2 utilized identical feed allotments, differing only by the addition of unprocessed mash feed samples in EXP2.

\section{Surrogate Organism}

Enterococcus faecium (ATCC 8459) was selected as the non-pathogenic surrogate organism based on its acceptable margin of error in thermal processing studies and its long history of use [2, 6-7]. This E. faecium bacteria strain was obtained from American Type Culture Collection (ATCC) located in Manassas, Virginia [20]. Brain-heart infusion (BHI) broth was prepared by dissolving BHI powder in deionized water by heating. The broth was 
autoclaved at $121^{\circ} \mathrm{C}$ for 15 minutes. A freeze-dried E. faecium pellet was rehydrated in sterile BHI broth. A portion of the rehydrated bacteria was then aseptically transferred to tryptic soy broth (TSB) with $5 \%$ defibrinated sheep blood and incubated for 24 hours at $26^{\circ} \mathrm{C}$. A stock culture collection was prepared by combining equal parts glycerol and young growing bacteria and stored at $-80^{\circ} \mathrm{C}$.

\section{Feed Inoculum Propagation}

Tryptic soy broth powder was dissolved in deionized water and sterilized by autoclaving at $121^{\circ} \mathrm{C}$ for 15 minutes. The sterile medium was allowed to cool to approximately $47^{\circ} \mathrm{C}$ before defibrinated sheep blood was added at a five percent inclusion and then gently mixed. An inoculation loop was sterilized, inserted into the stock culture collection tube, and then aseptically transferred to the TSB solution to initiate propagation. Inoculated media was placed in an incubator shaker [21] for 24 hours at $26^{\circ} \mathrm{C}$.

\section{Diet Formulation, Batching, and Feed Inoculation}

A basal diet was formulated to AgriStat recommendations [22] to meet growing broilers nutritional needs. A master batch was created and split into $113 \mathrm{~kg}$ allotments. Ten kilograms of the master batch was collected from each allotment to which E. faecium inoculum broth was applied. It is important to note that unprocessed mash feed was not sterilized prior to inoculation. This $10 \mathrm{~kg}$ allotment was placed in a horizontal ribbon mixer, inoculum was poured onto the feed at a 5\% (wt/wt) inclusion, and allowed to mix for five minutes. When appropriate, the mixer-added antimicrobial was applied to surrogate inoculated feed and mixed for an additional five minutes. Subsequent mixed mash feed samples were collected and submerged in liquid nitrogen to maintain bacterial integrity and stored $\left(-80^{\circ} \mathrm{C}\right)$ until analysis. 


\section{Feed Manufacture}

All feed was manufactured at the West Virginia University pilot feed mill located in Morgantown, West Virginia. Pellets were manufactured using a 40 HP California Pellet Mill [23] and were extruded through a 4.7 x $38 \mathrm{~mm}$ pellet die. Whole plot units differed between ST and LT steam conditioning times. In regard to the current experiment, ST steam conditioning had a 10 second conditioning barrel retention time while LT steam conditioning had a 60 second conditioning barrel retention time. These conditioning times were obtained using identical equipment. Currently, the West Virginia University pilot feed mill is designed to utilize ST steam conditioning. In order to create a production system that provided LT conditioning, manual power switches were manipulated to hold conditioned feed in the conditioning barrel for 60 seconds at a desired temperature. It is important to note that additional steam was not applied when LT conditioned feed was being held at the desired temperature in the conditioning barrel.

One allotment of basal diet, $103 \mathrm{~kg}$, was placed into a one ton vertical screw mixer, mixed for 10 minutes before conveyance to a surge bin above the pellet mill, and then used to obtain and maintain desired steam conditioning temperature. After desired conditioning temperature was achieved and all feed had passed through the feed screw auger chamber that fed directly into the conditioning barrel, the $10 \mathrm{~kg}$ allotment of inoculated or inoculated and antimicrobial treated feed was poured into a feed input chute that directly fed into the feed screw auger chamber. Here, 30 seconds of pelleting elapsed in order to ensure that the appropriate feed was passing through the conditioning barrel. Additionally, a pellet mill motor amperage range was recorded during this time. Following $30 \mathrm{~s}$ of pellet extrusion, ST or LT steam conditioning was employed and subsequent pellet samples were collected directly from the stream of extruded pellets. Pellet samples were placed on cheesecloth and then placed on a large agricultural fan 
which pulled ambient air across the pellets for 12 minutes to cool and dry the pellets, following methodologies reported by Reese et al. [24]. This particular methodology decreased the opportunity for cross contamination of basal diet pellets and inoculated pellets.

Following pellet cooling and drying, pelleted samples were collected and flash frozen in liquid nitrogen to maintain bacterial integrity. Following flash freezing, samples were stored ($80^{\circ} \mathrm{C}$ ) until analysis. Additionally, pelleted feed samples were maintained for pellet quality analyses.

\section{Pellet Quality Analysis}

Pellet quality was determined 24 hours post-pelleting, utilizing a New Holmen pellet tester (NHPT) [25]. A pelleted feed sample from each treatment combination was sifted using a No. 6 W.S. Tyler testing sieve [26]. One hundred grams of sifted pellets were placed in the NHPT perforated chamber. Forced air was applied for $30 \mathrm{~s}$ and the remaining pellet sample was weighed and recorded as a percentage. Pellet quality analyses were conducted in duplicate for each treatment combination and results reflect average pellet durability.

\section{Enumeration of Enterococcus faecium in Mash and Pelleted Feed}

The following procedures were conducted to enumerate E. faecium:

1. Pelleted feed samples were pulverized using a sterile mortar and pestle to minimize bacteria encapsulation.

2. A 2 gram sample of either unconditioned mash or pulverized pellet was weighed and aseptically placed in a sterile, $50 \mathrm{ml}$ conical tube.

3. Phosphate buffered saline (1xPBS) was added to the conical tube containing either mash or pulverized pellets to create a $50 \mathrm{ml}$ solution. 
4. The solution was agitated by hand to suspend E. faecium in the 1xPBS solution.

5. Following agitation, serial dilutions were prepared by placing $9 \mathrm{ml}$ of $1 \times \mathrm{PBS}$ in five sterilized, $20 \mathrm{ml}$ glass tubes.

6. A quantity of $1,000 \mu \mathrm{l}$ of the feed and PBS solution was transferred to a serial dilution tube, covered with parafilm, and inverted multiple times, creating a 1:10 dilution.

7. Subsequent serial dilutions were carried out $(1: 10-1: 1,000,000)$.

8. Contents from each dilution tube were passed through a $0.45 \mu \mathrm{m}$ gridded membrane filter using vacuum filtration.

9. Post vacuum filtration, each filter was placed on an m-Enterococcus agar plate, inverted, and placed in an incubator for 48 hours at $35^{\circ} \mathrm{C}$.

10. Following incubation, pink/purple E. faecium colonies were counted and recorded.

\section{Statistical Analysis}

A split-plot design was utilized for both EXP1 and EXP2 where ST and LT whole plot units were based on feed retention time in the conditioning barrel. For EXP 1, treatments comprised a $2 \times 3$ factorial arrangement in a CRD. For EXP 2, treatments comprised a $2 \times 4$ factorial arrangement in a CRD. Manufacturing of dietary treatments was replicated three times and one allotment of feed served as the experimental unit. Data were analyzed using the GLM procedure of SAS [27] and alpha was designated to be $\mathrm{P} \leq 0.05$. Significant main effects and interactions were further explored via post hoc F protected Fisher's least significant difference tests. 


\section{RESULTS AND DISCUSSION}

\section{EXP 1: Feed Manufacture}

The basal diet formulation utilized in the current study can be found in Table 1. Feed manufacturing results are depicted in Table 2. Conditioning time and antimicrobial inclusion interacted $(\mathrm{P}=0.0316)$ to decrease pellet durability when the antimicrobial was included to feed subjected to ST steam conditioning. When the antimicrobial was added to diets subjected to LT steam conditioning pellet durability differences were not apparent (Figure 1). An 11 percentage point decrease in pellet durability was apparent when the antimicrobial was utilized in conjunction with ST steam conditioning. Additionally, Figure 1 demonstrates that these differences diminish to only 2 percentage points when LT steam conditioning was employed. These data indicate that increasing conditioning time may negate pellet durability detriments associated with mixer-added antimicrobial inclusion. Peer-reviewed literature pertaining to similar antimicrobials is available $[18,27]$; however, pellet quality data was not presented in these articles. The authors speculate that since this particular antimicrobial contains formaldehyde that it may interfere with hydrogen bonding and subsequent particle agglomeration. Water may hydrogen bond to one of the carbonyl oxygen lone pairs of formaldehyde [29]. Perhaps, this water and formaldehyde interaction is inhibiting hydrogen bonding between feed groups that may otherwise be active in pellet binding. Therefore, increasing conditioning barrel retention time may allow for additional hydrogen bonding potential stemming from increased water absorption, ultimately reducing pellet quality detriments. Pellet durability was affected by conditioning temperature, improving pellet durability as steam conditioning temperature increased $(\mathrm{P}<0.0001)$, which is supported throughout the literature $[8-9,11,13]$. Increasing steam conditioning temperature ultimately 
increases moisture content, providing lubrication as conditioned feed is formed into pellet via the pellet die. This increase in moisture provides an opportunity for increased starch gelatinization and subsequent pellet quality improvements.

Conditioning time affected pellet mill motor amperage $(\mathrm{P}=0.0002)$ and hot pellet temperature $(\mathrm{P}<0.0001)$. Feed exposed to ST steam conditioning increased motor amperage relative to feed that was exposed to LT steam conditioning (Table 2). Gilpin et al. reported that a long retention time resulted in the lowest energy consumption [30]. Although relative energy consumption was not determined in the current study, noted motor amperage decreases during LT steam conditioning would indicate decreased energy consumption. Furthermore, ambient temperature differences could contribute to these differences. Hot pellet temperature decreased with LT steam conditioning, as this design inherently induced heat dissipation from the input and output regions of the conditioning barrel. Perhaps, successive experiments using in-line LT steam conditioning, rather than a modified ST conditioning system, may affect hot pellet temperature results differently.

Steam conditioning temperature affected pellet mill motor amperage $(\mathrm{P}=0.0002)$, hot pellet temperature $(\mathrm{P}<0.0001)$, and pellet durability $(\mathrm{P}<0.0001)$. Pellet mill motor amperage decreased when feed was conditioned at either $82^{\circ} \mathrm{C}$ or $88^{\circ} \mathrm{C}$, relative to feed conditioned at $71^{\circ} \mathrm{C}$ $(\mathrm{P}<0.05)$. Past literature suggests that increasing steam conditioning temperature results in a greater lubrication action at the mash-die interface, reducing friction and decreasing motor amperage [8,31]. Recently, Boney and Moritz reported findings [8] that supports current study findings of hot pellet temperature and pellet durability increases as steam conditioning temperatures increase. 


\section{EXP 2: Enterococcus faecium 8459 Mitigation}

Enterococcus faecium mitigation results are displayed in Table 3 and a depiction of interactive effects can be found in Figure 2. Conditioning time, antimicrobial inclusion effects, and degree of thermal processing effects interacted $(\mathrm{P}<0.0001)$ to affect mitigation of the nonpathogenic surrogate organism, E. faecium 8459. The antimicrobial decreased E. faecium colony counts in unprocessed mash $(\mathrm{P}<0.05)$ while steam conditioning further reduced E. faecium colony counts $(\mathrm{P}<0.05)$. The antimicrobial enhanced the reduction of E. faecium colonies in conditioned feed, only when ST steam conditioning was applied at $71^{\circ} \mathrm{C}(\mathrm{P}<0.05$; Figure 2$)$. These results essentially coincide with broadly stated claims that pelleting destroys pathogenic organisms [32]. Current study results may be useful in determining the degree of destruction that is achievable given differing manufacturing systems. It is important to note these data are specific to feed microbial levels immediately after manufacture and do not predict microbial levels post feed storage. This model also provides a platform for testing other pathogenic bacteria that may be present in animal feeds.

The Salmonella surrogate inoculum differed in concentration between the ST and LT steam conditioning times $(\mathrm{P}<0.0001)$. The $\mathrm{ST}$ steam conditioning experiment was carried out prior to the LT steam conditioning experiment. Ambient temperatures and unprocessed mash temperatures may have played another role in this concentration difference. Additionally, Martinez et al. worked with Enterococcus faecium and reported a complex interaction between growth temperature and growth phase of the cells [33]. Although methodology for inoculum preparation for both ST and LT experiments were identical, ambient temperature and inoculum transport conditions were different. The amount of time between transport and feed inoculation may have also contributed to those concentration differences. The authors speculate that these 
variables may have interacted to affect bacteria concentrations in the inoculum. However, the specificity of the m-Enterococcus media used for this culture-based method may have contributed to viable but non-culturable cells. As previously mentioned, feed was not sterilized prior to inoculation. Therefore, media specificity was appropriate in order to distinguish specific bacteria strains. Regardless of how these whole plot units differed, initial surrogate concentrations provided a viable platform for studying E. faecium mitigation.

Main effects did not interact to affect relative reduction of E. faecium $(\mathrm{P}>0.05)$. Interestingly, relative reduction of $E$. faecium differed between conditioning times $(\mathrm{P}=0.0142)$ where ST steam conditioning provided a 3-log reduction and LT steam conditioning provided a 4-log reduction of the Salmonella surrogate organism (Table 3). Cochrane et al. reported a 3-log reduction of E. faecium when poultry feed was steam conditioned at $70^{\circ} \mathrm{C}$ and subsequently pelleted [7]. However, these authors did not disclose the conditioning barrel retention time. Within the parameters of this study that utilized ST and LT steam conditioning and a nonpathogenic surrogate organism for pathogenic Salmonella, high quality feed production, in regards to physical quality and hygiene, may be achieved.

\section{CONCLUSIONS AND APPLICATIONS}

1. Increasing conditioning time may negate pellet durability detriments associated with inclusions of this particular antimicrobial.

2. Antimicrobial inclusion decreased E. faecium colony counts when applied to unprocessed mash feed that was inoculated with a Salmonella surrogate organism.

3. Mitigation potential was apparent when ST steam conditioning was applied to inoculated feed steam conditioned at $71^{\circ} \mathrm{C}$; however, mitigation increased when steam conditioning temperatures increased to either 82 or $88^{\circ} \mathrm{C}$. Antimicrobial inclusion and ST steam conditioning improved surrogate mitigation, regardless of steam conditioning temperature. 
4. Within the parameters of this study, short-term steam conditioning (10s) demonstrated a 3 -log surrogate organism reduction while long-term steam conditioning (60s) resulted in a 4-log reduction of the Salmonella surrogate organism.

\section{REFERENCES AND NOTES}

1. Sinclair, R.G., J.B. Rose, S. A. Hashsham, C.P. Gerba, and C.N. Haas. 2012. Criteria for Selection of Surrogates Used to Study the Fate and control of Pathogens in the Environment. Appl. Environ. Microbiol. 78:1969-1977.

2. Kopit, L.M, E.B. Kim, R.J. Siezen, L.J. Harris, and M.L. Marco. 2014. Safety of the Surrogate Microorganism Enterococcus faecium NRRL B-2354 for Use in Thermal Process Validation. Appl. Environ. Microbiol. 80:1899-1909.

3. Okelo, P.O., S.W. Joseph, D.D. Wagner, F.W. Wheaton, L.W. Douglas, and L.E. Carr. 2008. Improvements in Reduction of Feed Contamination: An Alternative Monitor of Bacterial Killing During Feed Extrusion. J. Appl. Poult. Res. 17:219-228.

4. Jones, F.T. and K.E. Richardson. 2004. Salmonella in commercially manufactured feeds. Poult. Sci. 83:384-391.

5. Channaiah, L.H, E. S. Holmgren, M. Michael, N.J. Sevart, D. Milke, C.L. Schwan, M. Krug, A. Wilder, R.K. Phebus, H. Thippareddi, and G. Milliken. 2015. Validation of Baking To Control Salmonella Serovars in Hamburger Bum Manufacturing, and Evaluation of Enterococcus faecium ATCC 8459 and Sacharomyces cerevisiae as Nonpathogenic Surrogate Indicators. J. Food Protec. 79:544-552.

6. Bianchini, A., J. Stratton, S. Weier, T. Hartter, B. Plattner, G. Rokey, G. Hertzel, L. Gompa, B. Martinez, and K.M. Eskridge. 2014. Use of Enterococcus fecium as a surrogate for Salmonella enterica during Extrusion of a Balanced Carbohydrate-Protein Meal. J. Food. Prot. 77:75-82.

7. Cochrane, R.A., C.R. Stark, A. R. Huss, G. Aldrich, C.J. Knueven, C.K. Jones, and J.S. Pitts. 2015. Salmonella surrogate mitigation in poultry feed using a dry acid powder. American Society of Animal Science, Midwest section. Accepted Abstract 89.

8. Boney, J.W. and J.S. Moritz. 2017. The effects of Spirulina algae inclusion and conditioning temperature on feed manufacture, pellet quality, and true amino acid digestibility. Anim. Feed Sci. Technol. 224:20-29.

9. Loar, R.E., K.G.S. Wamsley, A. Evans, J.S. Moritz, and A. Corzo. 2014. Effects of varying conditioning temperature and mixer-added fat on feed manufacturing efficiency, 28- to 42- day broiler performance, early skeletal effect, and true amino acid digestibility. J. Appl. Poult. Res. 23:444-455. 
10. Wilkinson, S.J., C.L. Walk, M.R. Bedford, and A.J. Cowieson. 2013. Influence of conditioning temperature on the postpellet recovery and efficacy of 2 microbial phytases for broiler chicks. J. Appl. Poult. Res. 22:308-313.

11. Beaman, K.R., K.G.S. Lily, C.K. Gehring, P.J. Turk, and J.S. Moritz. 2012. Influence of pelleting on the efficacy of an exogenous enzyme cocktail using broiler performance and metabolism. J. Appl. Poult. Res. 21:744-756.

12. Gehring, C.K., K.G.S. Lily, L.K. Shires, K.R. Beaman, S.A. Loop, and J.S. Moritz. 2011. Increasing mixer-added fat reduces the electrical energy required for pelleting and improves exogenous enzyme efficacy for broilers. J. Appl. Poult. Res. 20:75-89.

13. Cutlip, S.E., J.M. Hott, N.P. Buchanan, A.L. Rack, J.D. Latshaw, and J.S. Moritz. 2008. The effect of steam-conditioning practices on pellet quality and growing broiler nutritional value. J. Appl. Poult. Res. 17:249-261.

14. Inborr, J. and M.R. Bedford. 1994. Stability of feed enzymes to steam pelleting during feed processing. Ani. Feed Sci. Technol. 46:179-196.

15. Boroojeni, F.G., B. Svihus, H.G. von Reichenbach, and J. Zentek. 2016. The effects of hydrothermal processing on feed hygiene, nutrient availability, intestinal microbiota and morphology in poultry- A review. Ani. Feed Sci. Technol. 220:187-215.

16. Merriam-Webster Dictionary. https://www.merriamwebster.com/dictionary/antimicrobial.

17. Ricke, S.C. 2003. Perspectives on the Use of Organic Acids and Short Chain Fatty Acids and Antimicrobials. Poult. Sci. 82:632-639.

18. Griggs, J.P. and J.P. Jacob. 2005. Alternatives to Antibiotics for Organic Poultry Production. J. Appl. Poult. Res. 14:750-756.

19. Termin-8. Anitox Corp., Lawrenceville, GA, USA.

20. ATCC. The Global Bioresource Center. https://www.atcc.org/

21. Classic Series C24 Incubator Shaker. New Brunswick Scientific Co., INC. Edison, NJ.

22. AgriStats Inc., Fort Wayne, IN.

23. Master Model Pellet Mill, California Pellet Mill Company, Crawfordsville, IN. 
24. Reese, D.A., K.L. Foltz, and J.S. Moritz. 2017. Effect of mixing and sampling method on pelleted feed nutrient analysis and diet formulation validation. J. Appl. Poult. Res. 26:219-225.

25. New Holmen Portable Pellet Durability Tester, Lignotech USA, Inc., Rothschild, WI.

26. U.S.A. Standard Test Sieve. No. 6. W.S. Tyler. Mentor, Ohio.

27. SAS Institute. 2017. The SAS System for Windows 2017. Release 9.4. SAS Inst. Inc., Cary, NC.

28. Dos Santos, T.T., G.A. Gomes, C.L. Walk, B.V. Freitas, and L.F. Araujo. 2013. Effect of formaldehyde inclusion on phytase efficiency in broilers. J. Appl. Poult. Res. 22:204-210.

29. Kumpf, R.A. and J.R. Damewood Jr. 1989. Interaction of Formaldehyde with water. J. Phys. Chem. 93:4478-4486.

30. Gilpin, A.S., T.J. Herman, K.C. Behnke, and F.J. Fairchild. 2002. Feed moisture, retention time, and steam as quality and energy utilization determinants in the pelleting process. Appl. Eng. Agric. 18:331-338.

31. Corey, A. M., K.G.S. Wamsley, T.S. Winowiski, and J.S. Moritz. 2014. Effects of calcium lignosulfonate, mixer-added fat, and feed form on feed manufacture and broiler performance. J. Appl. Poult. Res. 23:418-428.

32. Behnke, K.C. 1994. Factors affecting pellet quality. Proc. Maryland Nutrition Conference. 20-25 March 1994. Department of Poultry Science and Animal Science, College of Agriculture, University of Maryland, College Park.

33. Martinez, S., M. Lopez, and A. Bernardo. 2003. Thermal inactivation of Enterococcus faecium: effect of growth temperature and physiological state of microbial cells. Letters in Applied Microbiology. 37:475-481. 


\section{Figures}

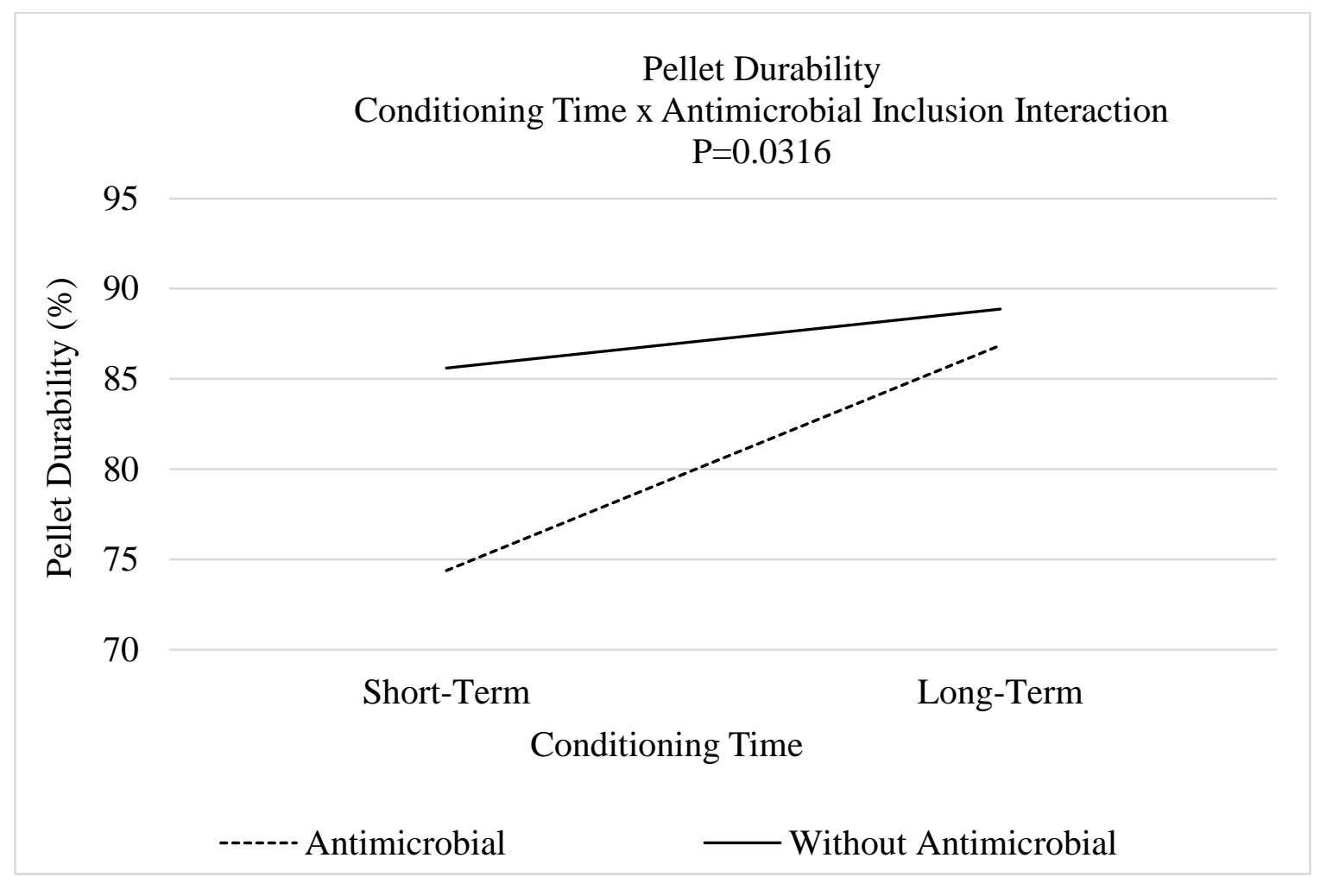

Figure 1. Interactive effects of conditioning time and antimicrobial inclusion on pellet durability. 
Enterococcus faecium 8459 Mitigation

Conditioning Time $\mathrm{x}$ Antimicrobial Inclusion $\mathrm{x}$ Degree of Thermal Processing Interaction $\mathrm{P}<0.0001$

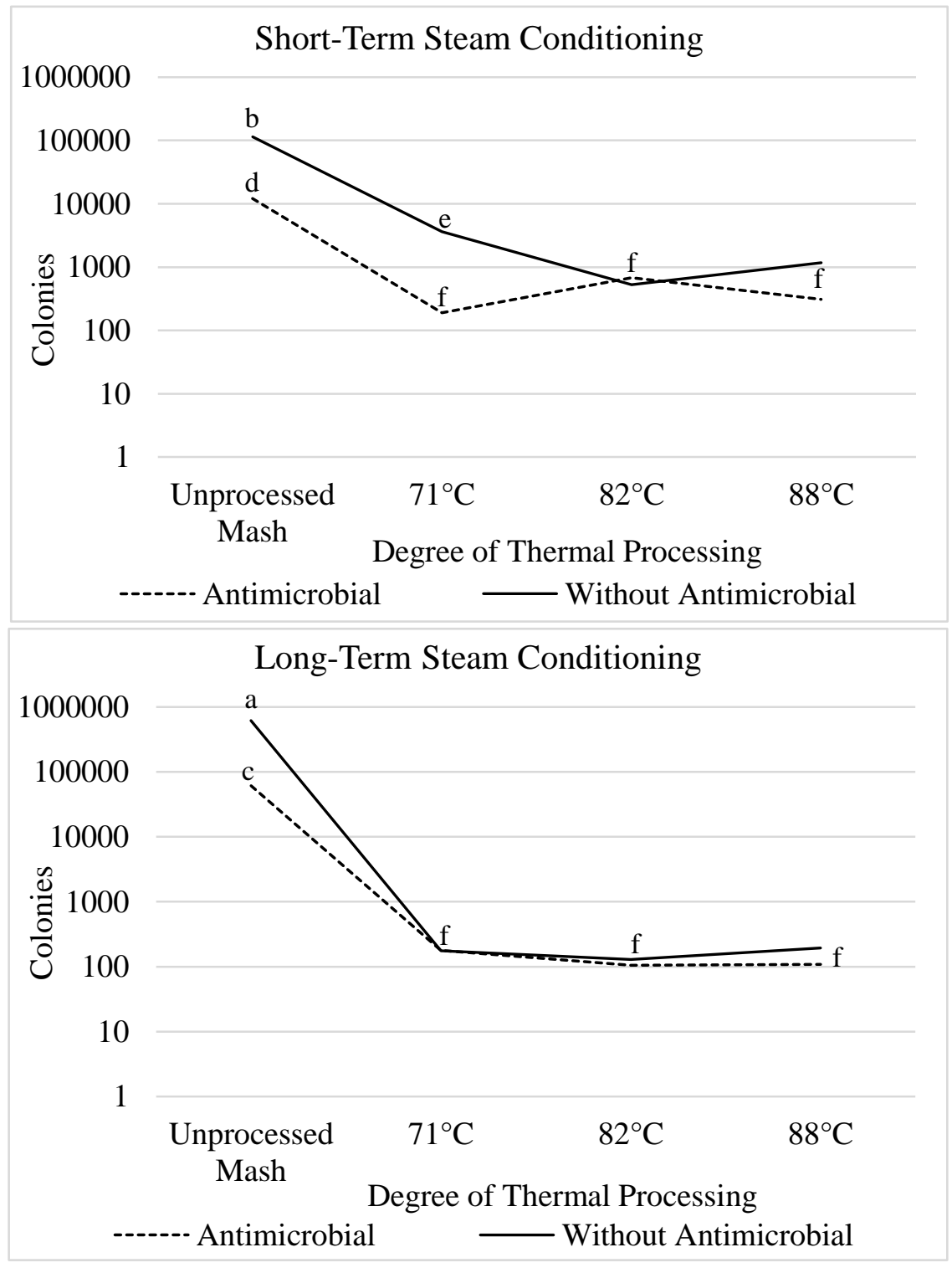

Figure 2. Interactive effects of conditioning time, antimicrobial inclusion, and degree of thermal processing on Enterococcus faecium 8459 mitigation. 


\section{Tables}

Table 1. Dietary composition and calculated nutrients of the basal diet used during inoculation

\begin{tabular}{|c|c|}
\hline Ingredient & Inclusion (\%) \\
\hline Corn & 57.52 \\
\hline Soybean Meal (48\%) & 30.82 \\
\hline Wheat Middlings & 5.00 \\
\hline Soybean Oil & 2.18 \\
\hline Dicalcium Phosphate & 1.68 \\
\hline Limestone & 1.31 \\
\hline DL-Methionine & 0.36 \\
\hline White Salt & 0.35 \\
\hline L-Lysine HCl & 0.27 \\
\hline Vitamin/Mineral Premix & 0.25 \\
\hline Sodium Bicarbonate & 0.15 \\
\hline L-Threonine & 0.12 \\
\hline ME (kcal/kg) & $3,030.5$ \\
\hline Crude Protein (\%) & 20.71 \\
\hline Digestible Lysine (\%) & 1.18 \\
\hline Digestible Met+Cys (\%) & 0.89 \\
\hline Digestible Threonine (\%) & 0.77 \\
\hline Calcium (\%) & 0.96 \\
\hline Available Phosphorus (\%) & 0.45 \\
\hline Sodium (\%) & 0.20 \\
\hline
\end{tabular}

${ }^{1}$ Supplied per kilogram of diet: $0.02 \%$ manganese; $0.02 \%$ zinc; $0.01 \%$ iron; $0.0025 \%$ copper; $0.0003 \%$ iodine; $0.00003 \%$ selenium; $0.69 \mathrm{mg}$ of folic acid; $386 \mathrm{mg}$ of choline; $6.61 \mathrm{mg}$ of riboflavin; $0.03 \mathrm{mg}$ of biotin; $1.38 \mathrm{mg}$ of vitamin B6; $27.56 \mathrm{mg}$ of niacin; $6.61 \mathrm{mg}$ of pantothenic acid; $2.20 \mathrm{mg}$ of thiamine; $0.83 \mathrm{mg}$ of menadione; $0.01 \mathrm{mg}$ of vitamin B12; $16.53 \mathrm{IU}$ of vitamin E; 2,133 IU of vitamin D3; and 7,716 of vitamin A.

${ }^{2}$ AgriStats Inc., Fort Wayne, IN. 
Table 2. Conditioning Time, Antimicrobial Inclusion, and Steam Conditioning Temperature Effects on Feed Manufacturing Metrics

\begin{tabular}{|c|c|c|c|c|c|}
\hline Conditioning Time ${ }^{1}$ & Antimicrobial Inclusion & $\begin{array}{l}\text { Steam Conditioning Temperature } \\
\qquad\left({ }^{\circ} \mathrm{C}\right)\end{array}$ & $\begin{array}{c}\text { Motor } \\
\text { Amperage }^{2} \\
\text { (A) }\end{array}$ & $\begin{array}{l}\text { Hot Pellet Temperature }{ }^{3} \\
\qquad\left({ }^{\circ} \mathrm{C}\right)\end{array}$ & $\begin{array}{l}\text { Pellet Durability }{ }^{4} \\
(\%)\end{array}$ \\
\hline \multirow{6}{*}{$\begin{array}{l}\text { Short-Term Steam } \\
\text { Conditioning }\end{array}$} & \multirow{3}{*}{ With } & 71 & 20.4 & 77.1 & 61.185 \\
\hline & & 82 & 19.1 & 83.9 & 76.658 \\
\hline & & 88 & 18.9 & 87.3 & 85.310 \\
\hline & \multirow{3}{*}{ Without } & 71 & 20.2 & 76.1 & 77.080 \\
\hline & & 82 & 19.0 & 81.8 & 87.885 \\
\hline & & 88 & 19.0 & 87.3 & 91.851 \\
\hline \multirow{6}{*}{$\begin{array}{l}\text { Long-Term Steam } \\
\text { Conditioning }\end{array}$} & \multirow{3}{*}{ With } & 71 & 19.0 & 71.8 & 80.966 \\
\hline & & 82 & 18.2 & 78.0 & 86.833 \\
\hline & & 88 & 18.1 & 81.8 & 92.783 \\
\hline & \multirow{3}{*}{ Without } & 71 & 19.3 & 72.0 & 83.933 \\
\hline & & 82 & 18.1 & 78.4 & 89.633 \\
\hline & & 88 & 18.0 & 82.5 & 93.066 \\
\hline \multicolumn{6}{|c|}{ Conditioning Time Means } \\
\hline Short-Term & --- & --- & $19.5^{\mathrm{a}}$ & $82.3^{\mathrm{a}}$ & $79.995^{\mathrm{b}}$ \\
\hline Long-Term & --- & --- & $18.5^{\mathrm{b}}$ & $77.4^{\mathrm{b}}$ & $87.869^{\mathrm{a}}$ \\
\hline \multicolumn{3}{|c|}{ Conditioning Time SEM $^{5}$} & 0.158 & 0.403 & 1.425 \\
\hline \multicolumn{6}{|c|}{ Antimicrobial Inclusion Means } \\
\hline--- & With & --- & 18.9 & 80.0 & $80.623^{\mathrm{b}}$ \\
\hline--- & Without & --- & 18.9 & 79.7 & $87.242^{\mathrm{a}}$ \\
\hline \multicolumn{3}{|c|}{ Antimicrobial Inclusion $\mathrm{SEM}^{5}$} & 0.158 & 0.403 & 1.425 \\
\hline \multicolumn{6}{|c|}{$\begin{array}{ll}\text { Steam Conditioning Temperature Means } \\
\end{array}$} \\
\hline--- & --- & $71^{\circ} \mathrm{C}$ & $19.8^{\mathrm{a}}$ & $74.2^{\mathrm{c}}$ & $75.791^{\mathrm{c}}$ \\
\hline--- & --- & $82^{\circ} \mathrm{C}$ & $18.6^{\mathrm{b}}$ & $80.5^{\mathrm{b}}$ & $85.253^{\mathrm{b}}$ \\
\hline--- & --- & $88^{\circ} \mathrm{C}$ & $18.6^{\mathrm{b}}$ & $84.8^{\mathrm{a}}$ & $90.753^{\mathrm{a}}$ \\
\hline \multicolumn{3}{|c|}{ Steam Conditioning Temperature SEM $^{5}$} & 0.194 & 0.493 & 1.745 \\
\hline \multicolumn{6}{|c|}{ Probability } \\
\hline \multicolumn{3}{|c|}{ Conditioning Time } & 0.0002 & $<0.0001$ & 0.0007 \\
\hline \multicolumn{3}{|c|}{ Antimicrobial Inclusion } & 0.9512 & 0.5933 & 0.0031 \\
\hline \multicolumn{3}{|c|}{ Conditioning Time*Antimicrobial inclusion } & 0.7973 & 0.2099 & 0.0316 \\
\hline \multicolumn{3}{|c|}{ Steam Conditioning Temperature } & 0.0002 & $<0.0001$ & $<0.0001$ \\
\hline \multicolumn{3}{|c|}{ Conditioning Time* Steam Conditioning Temperature } & 0.8578 & 0.9253 & 0.1750 \\
\hline \multicolumn{3}{|c|}{ Antimicrobial Inclusion*Steam Conditioning Temperature } & 0.9763 & 0.6968 & 0.4821 \\
\hline \multicolumn{3}{|c|}{ Conditioning Time*Antimicrobial Inclusion*Steam Conditioning Temperature } & 0.7573 & 0.7871 & 0.7905 \\
\hline
\end{tabular}

${ }^{1}$ Conditioning Time refers to the conditioning barrel retention time; Short-term $=10 \mathrm{~s}$; Long-term $=60 \mathrm{~s}$.

${ }^{2}$ Motor amperage was determined by recording the average of an amperage range from the digital output from a square-D meter.

${ }^{3}$ Hot Pellet Temperature was determined by collecting pellets from the stream of extruded pellets in an insulated container and obtaining a temperature reading from a thermocouple thermometer.

${ }^{4}$ Pellet durability was determined 24 hours post-pelleting using the New Holmen Portable Pellet durability Tester, Lignotech USA, INC., Rothschild, WI.

${ }^{5} \mathrm{SEM}=$ Pooled Standard error of the mean. 
Table 3. Conditioning Time, Antimicrobial Inclusion, and Degree of Thermal Processing Effects on E. faecium 8459 mitigation

\begin{tabular}{|c|c|c|c|c|}
\hline Conditioning Time $^{1}$ & Antimicrobial Inclusion & Degree of Thermal Processing & E. faecium Mitigation ${ }^{2}$ (Colonies) & Relative Reduction $^{3}(\%)$ \\
\hline \multirow{8}{*}{$\begin{array}{l}\text { Short-Term Steam } \\
\text { Conditioning }\end{array}$} & \multirow{4}{*}{ With } & Unprocessed Mash & $12,093^{\mathrm{d}}$ & --- \\
\hline & & $71^{\circ} \mathrm{C}$ & $190^{\mathrm{f}}$ & 99.984 \\
\hline & & $82^{\circ} \mathrm{C}$ & $677^{f}$ & 99.944 \\
\hline & & $88^{\circ} \mathrm{C}$ & $311^{\mathrm{f}}$ & 99.974 \\
\hline & \multirow{4}{*}{ Without } & Unprocessed Mash & $114,228^{b}$ & --- \\
\hline & & $71^{\circ} \mathrm{C}$ & $3,638^{\mathrm{e}}$ & 99.968 \\
\hline & & $82^{\circ} \mathrm{C}$ & $528^{\mathrm{f}}$ & 99.995 \\
\hline & & $88^{\circ} \mathrm{C}$ & $1,165^{\mathrm{f}}$ & 99.989 \\
\hline \multirow{8}{*}{$\begin{array}{l}\text { Long-Term Steam } \\
\text { Conditioning }\end{array}$} & \multirow{4}{*}{ With } & Unprocessed Mash & $61,015^{\mathrm{c}}$ & --- \\
\hline & & $71^{\circ} \mathrm{C}$ & $178^{\mathrm{f}}$ & 99.997 \\
\hline & & $82^{\circ} \mathrm{C}$ & $105^{\mathrm{f}}$ & 99.998 \\
\hline & & $88^{\circ} \mathrm{C}$ & $108^{\mathrm{f}}$ & 99.998 \\
\hline & \multirow{4}{*}{ Without } & Unprocessed Mash & $616,444^{\mathrm{a}}$ & --- \\
\hline & & $71^{\circ} \mathrm{C}$ & $176^{\mathrm{f}}$ & 99.999 \\
\hline & & $82^{\circ} \mathrm{C}$ & $129^{\mathrm{f}}$ & 99.999 \\
\hline & & $88^{\circ} \mathrm{C}$ & $195^{\mathrm{f}}$ & 99.999 \\
\hline \multicolumn{5}{|c|}{ Conditioning Time Means } \\
\hline Short-Term & --- & --- & $16,604^{\mathrm{b}}$ & $99.975^{\mathrm{b}}$ \\
\hline Long-Term & --- & --- & $84,794^{\mathrm{a}}$ & $99.998^{\mathrm{a}}$ \\
\hline \multicolumn{3}{|c|}{ Conditioning Time SEM ${ }^{4}$} & 253 & 0.006 \\
\hline \multicolumn{5}{|c|}{ Antimicrobial Inclusion Means } \\
\hline--- & With & --- & $9,335^{\mathrm{b}}$ & 99.982 \\
\hline--- & Without & --- & $92,063^{\mathrm{a}}$ & 99.992 \\
\hline \multicolumn{3}{|c|}{ Antimicrobial Inclusion $\mathrm{SEM}^{4}$} & 253 & 0.006 \\
\hline \multicolumn{5}{|c|}{ Degree of Thermal Processing Means } \\
\hline--- & --- & Unprocessed Mash & $200,945^{\mathrm{a}}$ & --- \\
\hline--- & --- & $71^{\circ} \mathrm{C}$ & $1,046^{\mathrm{b}}$ & 99.987 \\
\hline--- & --- & $82^{\circ} \mathrm{C}$ & $360^{\mathrm{b}}$ & 99.984 \\
\hline--- & --- & $88^{\circ} \mathrm{C}$ & $445^{\mathrm{b}}$ & 99.990 \\
\hline \multicolumn{3}{|c|}{ Degree of Thermal Processing SEM ${ }^{4}$} & 358 & 0.007 \\
\hline \multicolumn{5}{|c|}{ Probability } \\
\hline \multicolumn{3}{|c|}{ Conditioning Time } & $<0.0001$ & 0.0142 \\
\hline \multicolumn{3}{|c|}{ Antimicrobial Inclusion } & $<0.0001$ & 0.2871 \\
\hline \multicolumn{3}{|c|}{ Conditioning Time*Antimicrobial Inclusion } & $<0.0001$ & 0.3919 \\
\hline \multicolumn{3}{|c|}{ Degree of Thermal Processing } & $<0.0001$ & 0.8463 \\
\hline \multicolumn{3}{|c|}{ Conditioning Time* Degree of Thermal Processing } & $<0.0001$ & 0.8416 \\
\hline \multicolumn{3}{|c|}{ Antimicrobial Inclusion*Degree of Thermal Processing } & $<0.0001$ & 0.3085 \\
\hline \multicolumn{3}{|c|}{ Conditioning Time*Antimicrobial Inclusion*Degree of Thermal Processing } & $<0.0001$ & 0.2861 \\
\hline
\end{tabular}

${ }^{1}$ Conditioning Time refers to the conditioning barrel retention time; Short-term $=10 \mathrm{~s} ;$ Long-term $=60 \mathrm{~s}$.

${ }^{2}$ E. faecium Mitigation= Determined using serial dilutions, vacuum filtration, bacteria specific m-ENT media, and incubation. Pink/Purple colonies were counted following $35^{\circ} \mathrm{C}$ incubation for 48 hours

${ }^{3}$ Relative Reduction $=100-($ Pellet Colony Count/Mash Colony Count)

${ }^{4} \mathrm{SEM}=$ Pooled Standard error of the mean 


\title{
CHAPTER 3
}

The Effects of Corn-Expressed Phytase Varying in Particle Size, Concentration, and Coating on D1-38 Broiler Performance and Tibia Ash Analysis

\author{
J.W. Boney ${ }^{1}$, B.G. Glover ${ }^{1}$, J.N. Broomhead ${ }^{2}$, and J.S. Moritz ${ }^{1, ¥}$ \\ ${ }^{1}$ Division of Animal and Nutritional Sciences, West Virginia University, Morgantown, West \\ Virginia, 26506 \\ Phone: (304) 293-1911 \\ Fax: (304) 293-2232
}

${ }^{2}$ Agrivida Inc, Medford, Massachusetts, 02155

${ }^{\ddagger}$ Corresponding Author: Joe.Moritz@mail.wvu.edu

Primary Audience: Feed Manufacturers, Nutritionists, Researchers 
Summary Transgenic grains expressing phytase provide an alternative method to support dietary phosphorus requirements in broilers. However, variables common to enzymes expressed in grains must be studied to optimize product efficacy. The objective of this study was to describe the effect of phosphorus deficient diets supplemented with Corn-Expressed Phytase (CEP) varying in particle size, concentration, and coating on $38 \mathrm{~d}$ broiler performance and tibia mineralization. Treatments were arranged in a $3 \times 2 \times 2$ factorial varying in CEP particle size $(1.5$, 2.0 , or $2.5 \mathrm{~mm}$ ), concentration (500 or 3,000 FTU/kg), and coating (with or without). A commercial phytase product supplemented at 500 or $3,000 \mathrm{FTU} / \mathrm{kg}$, as well as positive and negative control diets were also manufactured and fed. Diets were steam conditioned at $85^{\circ} \mathrm{C}$ for $10 \mathrm{~s}$, extruded through a $4.7 \times 38 \mathrm{~mm}$ pellet die, and provided as crumbles or intact pellets, based on age. Six replicate pens of 23 straight-run Hubbard x Cobb 500 broilers were fed each dietary treatment. Data were analyzed as a factorial that included 12 treatments and a multiple comparison that included 16 treatments. Broilers fed CEP at 3,000 FTU/kg demonstrated improved live weight gain (LWG), feed conversion ratio (FCR), and bone mineralization compared to broilers fed CEP at 500 FTU/kg $(\mathrm{P}<0.05)$. Broilers fed CEP of $2.0 \mathrm{~mm}$ had improved FCR compared to broilers fed CEP of $2.5 \mathrm{~mm}(\mathrm{P}<0.05)$. Coating did not affect broiler performance or tibia mineralization. The efficacy of CEP was comparable to the positive control diet and commercial phytase product when particle size and concentration was optimized.

KEYWORDS: corn-expressed phytase, particle size, concentration, coating, tibia ash 


\section{DESCRIPTION OF PROBLEM}

Although the major role of phosphorus $(\mathrm{P})$ is as a component of bone, $\mathrm{P}$ is also an essential component of organic compounds involved in almost every aspect of metabolism [1]. A large portion of the $\mathrm{P}$ of seed based ingredients used in poultry diets is stored as phytate, making $\mathrm{P}$ poorly available. Phytic acid (myo-inositol 1,2,3,4,5,6-hexakisphosphate; $\mathrm{InsP}_{6}$ ), consisting of phytate bound to mineral cations, and phytin, a complex of phytate and proteins, constitute the storage forms of the generally unavailable $\mathrm{P}$ in cereal grains [2]. Inorganic phosphates may be included to growing broiler diets to ensure adequate $\mathrm{P}$ availability. However, bound P may be excreted in the manure, which is often applied to the land as fertilizer. Leaching of nitrogen and $\mathrm{P}$ to waterways, stemming from manure application concentrated with minerals, is thought to be associated with eutrophication [3]. Additionally, a variety of phytase enzymes have been developed to liberate bound P for uptake by the bird. Phytases are a special class of phosphatases that catalyze the sequential hydrolysis of phytic acid to produce less phosphorylated myo-inostiol derivatives and inorganic phosphates [4]. Phytase inclusions reduce inorganic phosphate inclusions and aid in reduction of $\mathrm{P}$ excreted in the litter.

Alternative sources of phytase enzymes, such as transgenic grains expressing enzymatic activity in the seed, have been developed. Hong and coauthors determined that germinated transgenic rice seeds may provide phytase and improve phytate-phosphorus digestibility [5]. Pen et al. reported comparable growth performance when broilers were provided transgenic tobacco seeds expressing phytase compared to broilers provided diets supplemented with fungal phytase [6]. Denbow et al. reported that phytase expressed in raw soybeans and applied to phosphorus deficient diets improved broiler growth performance [7]. Additionally, Chen et al. proposed an over-expression of Aspergillus niger phyA2 gene in corn seeds to improve phosphorus 
availability and to reduce the environmental impact of animal production [8]. Furthermore, Chen et al. speculated that successful production of grains expressing phytase would reduce feed costs, as microbial fermentation utilized in the production of common phytase enzymes has an associated cost [8].

Particle size of dietary components can affect overall diet mixability. Literature on enzyme particle size is limiting but may become more important as grain-expressed enzymes become more readily available. Foltz reported that $2 \mathrm{~mm}$ transgenic phytase corn (TPC) provided more opportunity for uptake by small chicks when compared to $3 \mathrm{~mm}$ TPC [9]. Amerah et al. report that relationships of feed particle size and diet uniformity warrants investigation in order to optimize broiler performance, gut health, and pellet quality [10].

Dietary phytase concentration continues to be an area of interest in poultry nutrition. Phytase super-doses reportedly provide an extraphosphoric effect by enhancing nutrient digestibility and improving broiler performance [11]. Literature suggests that super-doses of phytase may alleviate anti-nutritional effects of phytate $\mathrm{P}$ [12] in part by reducing phytate phosphorus gut irritation [13]. Evans et al. speculated that a super-dose of phytase may contribute to decreasing energy dedicated to the energy expensive immune response [14]. Therefore, product optimization should include the study of optimal phytase concentrations, based on nutrient digestibility and subsequent broiler performance metrics.

Enzyme manufacturers have explored carbohydrate-lipid coating techniques to address denaturation concerns [15]. Patented coating techniques limit specificity in the literature. However, Ward et al. suggest that the mode of action is reduction of enzyme exposure to moisture, a major concern during pelleting [16]. Other work by Ward and cohorts suggest that coating mixer-added phytase products supports bird performance equivalent to post-pellet 
applied phytase without coating [17]. Regardless of phytase application technique, knowledge of enzyme activity retention is essential to meeting bird phosphorus requirements. The objectives of this study were to describe the effects of phosphorus deficient diets supplemented with CEP varying in particle size, concentration, and coating on $38 \mathrm{~d}$ broiler performance and tibia mineralization.

\section{MATERIALS AND METHODS}

Experimental diets were corn and soybean meal based and varied in non-phytate phosphorus (nPP), experimental phytase product, and concentration. Treatments were arranged in a $3 \times 2 \times 2$ factorial arrangement with the main effects of phytase particle size, concentration, and coating. Positive control (PC) and negative control (NC) diets were formulated for treatment comparisons. The NC diet was formulated to be $0.15 \%$ deficient in $\mathrm{nPP}$, to which experimental CEP products were applied. Targeted phytase activity for experimental diets was either 500 or 3,000 FTU/kg. Additionally, a commercially available phytase product [18] was applied to the $\mathrm{NC}$ diet at targeted inclusions of 500 and 3,000 FTU/kg, respectively. Overall, 16 dietary treatments were utilized in the study.

All feed was manufactured at the West Virginia University pilot feed mill in Morgantown, West Virginia, utilizing a 40 HP California Pellet Mill [19]. On the day of feed manufacture, a master batch of the NC diet was prepared and split into 15 equal allotments. A small portion of feed was removed from each allotment and individually placed in a Hobart mixer [20] with the appropriate concentration of experimental CEP, and allowed to mix for 10 minutes. Remaining feed from each negative control feed allotment was individually placed in a vertical screw mixer along with the portion of feed mixed with the appropriate experimental CEP and was allowed to mix for 10 minutes. Mixed feed was then conveyed to the pellet mill where 
diets were conditioned at $85^{\circ} \mathrm{C}$ for 10 seconds and extruded through a $4.7 \times 38 \mathrm{~mm}$ pellet die. Hot pellet temperature (HPT) was measured by collecting extruded pellets in an insulated container and using a thermocouple thermometer [21] and an 80PK-24 temperature probe. Pellet survivability was determined 24 hours post-pelleting using a New Holmen Pellet Tester [22], for all treatments, across all three growth periods. Starter (d1-10) and grower (d11-22) period diets were passed through a roller mill and provided as crumbled pellets while finisher (d23-38) period diets were provided as intact pellets. Feed samples for each treatment and growth period were collected and utilized for phytase activity determination [23] using the AOAC 2000.12 method [24] and mineral analyses [25].

Particle size was determined in duplicate for all treatments in the starter and grower periods [26]. Percentage of intact pellets was determined in duplicate for finisher period treatments in accordance to the Feed Manufacturing Technology textbook [27]. Briefly, as-fed pellets were passed through an American Society for Testing and Materials (ASTM) \# 5 sieve. After sieving, sample remaining on the sieve were considered intact pellets and sample passing through the sieve was considered fines. Pellet and fine weights were used to calculate average percent pellets per treatment.

A total of 2,208 Hubbard x Cobb straight-run day old chicks were obtained from a commercial hatchery [28], weighed, and placed in one of 96 floor pens at a count of 23 broilers per pen. The 16 dietary treatments were randomly allotted to adjacent pens blocked by location within the barn located at the West Virginia University Animal Science Farm. Each dietary treatment was applied to six replicate pens of broilers. Commercial lighting and temperature manipulations were applied throughout the $38 \mathrm{~d}$ experiment. Feed and water were applied ad libitum. Broilers were weighed as a pen at the end of the starter and grower periods. On d 38 
broilers were separated by sex and weighed individually. Three male broilers $\pm 100 \mathrm{~g}$ of the male broiler mean weight were euthanized via cervical dislocation and the left tibia was excised. Tibiae were dried at $105^{\circ} \mathrm{C}$ for 48 hours after which the lipid content was extracted using petroleum ether in a soxhlet tube apparatus for 16 hours. Dried and fat extracted tibiae were then placed in a muffle furnace at $600^{\circ} \mathrm{C}$ for 18 hours. All animals were reared in accordance with protocols established by the West Virginia University Animal Care and Use Committee [ACUC 15-0408].

\section{Statistical Analysis}

Corn-expressed phytase variables were arranged as a 3 (particle size) x 2 (concentration) x 2 (coating) factorial. Positive and negative control diets and diets containing commercial phytase were included for treatment comparisons. All 16 treatments were arranged in a randomized complete block design and analyzed using the GLM procedure of SAS [29]. Blocking criterion was location within the research facility. Alpha was designated as 0.05. Main effect interactions were also considered. A Fisher's LSD test was employed to further explore significant multiple comparisons of all 16 treatments.

\section{RESULTS AND DISCUSSION}

\section{Feed Manufacture}

The positive control diet was formulated to meet or exceed the nutritional requirements of small growing broilers [30-31] while the negative control diet was formulated to be $0.15 \%$ deficient in nPP. The experimental CEP products were applied to the NC diet (Table 1). Feed manufacture was not replicated and all corresponding feed manufacturing and pellet quality data should be considered descriptive (Table 2). Pellet durability was highest in the starter period and 
decreased sequentially in the grower and finisher periods, likely explained by increasing metabolizable energy through soybean oil inclusion. Past research coincides with the current study results that depict decreased pellet durability as soybean oil inclusions increase [32-33]. Starter and grower period diets were crumbled prior to feeding. Average particle size of starter diets was $1,198 \mu \mathrm{m}$ while average particle size of grower diets was $1,930 \mu \mathrm{m}$. Finisher period diets were provided as intact pellets and averaged $62.8 \%$ pellets (Table 2). Table 2 displays considerably low values for finisher period pellet durability, determined using the New Holmen Pellet Tester. This rapid pellet durability analysis is aggressive in nature and represents the rigors of handling, transporting, and augering that feed endures in a commercial setting. In this controlled research setting the percentage of pellets should be considered since feed handling was minimal.

\section{Phytase Activity}

Phytase activity values determined using finisher period mash and pelleted samples are presented in Table 3. In general, phytase activity of pelleted diets was lower than the targeted value across all treatments. Analyzed phytase activity for pelleted diets formulated to contain phytase at $500 \mathrm{FTU} / \mathrm{kg}$ averaged $278 \mathrm{FTU} / \mathrm{kg}$ while those formulated to contain CEP at 3,000 FTU/kg averaged 1,426 FTU/kg. Loop et al. eluded to variability of the phytase activity assay, reporting considerable relative standard deviation for repeatability and reproducibility [15]. More importantly, phytase activity differed by an average 1,148 FTU/kg between the targeted $500 \mathrm{FTU} / \mathrm{kg}$ and 3,000 FTU/kg CEP inclusions. 


\section{Overall (d1-38) Period Live Performance}

Overall (d1-38) period main effects (Table 4) did not interact $(\mathrm{P}>0.05)$. The main effect of CEP coating did not affect overall broiler performance $(\mathrm{P}>0.05)$. Feed intake (FI) was not affected by CEP main effects throughout the 38 day growth out $(\mathrm{P}>0.05)$. The main effect of CEP concentration affected LWG and FCR $(\mathrm{P}<0.05)$; increasing LWG by $38 \mathrm{~g}$ per bird and improving FCR by 3.9 points when broilers were provided CEP at 3,000 FTU/kg compared to birds provided CEP at $500 \mathrm{FTU} / \mathrm{kg}$. Shirley and Edwards reported performance improvements when broilers were provided graded levels of phytase, with graded levels ranging between 0 and 12,000 FTU/kg [34]. The main effect of CEP particle size improved d1-38 FCR by 4.4 point when birds were provided 2.0 mm CEP compared to birds provided $2.5 \mathrm{~mm}$ CEP ( $\mathrm{P}=0.0476)$. Birds provided the $1.5 \mathrm{~mm}$ CEP were intermediate (Table 4). As the particle size of CEP products is reduced, the total number of particles expressing phytase activity theoretically increases, suggesting more particles expressing phytase. Wondra et al. eluded to increased nutrient digestibility as mean particle size diameter is reduced; however nutritional implications are not completely understood [35]. Decreasing CEP particle size increases surface area and provides greater opportunities for enzyme degradation during the pelleting process. This speculation is supported with descriptive data found in Table 3. Average phytase activity decreased when the diets contained $1.5 \mathrm{~mm}$ CEP. Phytase activity was highest when provided as $2.0 \mathrm{~mm}$ CEP. Furthermore, the authors speculate that phytase mixability was affected by variations in particle size. Therefore, decreased analyzed phytase activity for diets that contained $2.5 \mathrm{~mm}$ CEP may be explained by decreased homogeneity and varying phytase particles in feed samples collected for analysis. However, Timmons et al. stated that variations 
in ingredient mixability may not produce detrimental performance effects [36]. Future experiments should analyze homogeneity of phytase particles distribution prior to feeding.

Multiple comparison analysis for the $38 \mathrm{~d}$ grow out (Table 4) resulted in similar FI across all dietary treatments $(\mathrm{P}>0.05)$. Similar intake results were reported by Shaw and coauthors when broilers were provided diets varying in nPP and phytase inclusions from d0 to 21 [37]. Birds that were provided the commercial product at 3,000 FTU/kg showed the highest LWG across the $38 \mathrm{~d}$ grow out while birds that were provided the commercial product at $500 \mathrm{FTU} / \mathrm{kg}$, PC, and uncoated 2.0 mm CEP at 3,000 FTU/kg had similar LWG. Birds provided all other treatment combinations had decreased LWG, similar to birds provided the NC $(\mathrm{P}=0.0019)$. Finally, birds provided 3,000 FTU/kg of the commercial product improved FCR by 12.7 points compared to birds provided uncoated $2.5 \mathrm{~mm} \mathrm{CEP}$ at $500 \mathrm{FTU} / \mathrm{kg}(\mathrm{P}=0.0037)$, although FCR was not different between the PC and NC fed birds ( $\mathrm{P}>0.05)$.

\section{D1-38 Bone Mineralization}

Main effects for the overall (d1-38) growth period did not interact $(\mathrm{P}>0.05)$ to affect tibia mineralization (Table 5). Neither main effect of particle size nor coating affected tibia ash results $(\mathrm{P}>0.05)$. The main effect of CEP concentration increased both tibia ash percentage $(\mathrm{P}=0.0015)$ and $\mathrm{mg}$ tibia ash per bird $(\mathrm{P}=0.0011)$ when birds were provided $\mathrm{CEP}$ at 3,000 FTU $/ \mathrm{kg}$ compared to birds provided CEP at $500 \mathrm{FTU} / \mathrm{kg}$. Shaw et al. reported similar increases in tibia mineralization when feeding increasing levels of phytase to broilers [37].

Multiple comparison analysis of bone mineralization variables are displayed in Table 5. Birds provided the PC diet resulted in the highest percentage of tibia ash; however, birds provided coated $1.5 \mathrm{~mm} \mathrm{CEP}$ at 3,000 FTU/kg, uncoated 2.0 and $2.5 \mathrm{~mm} \mathrm{CEP}$ at 3,000 FTU/kg, 
and the commercial product at 3,000 FTU/kg revealed similar tibia ash percentages. Birds provided the NC and the coated $2.5 \mathrm{~mm}$ CEP at $500 \mathrm{FTU} / \mathrm{kg}$ revealed the lowest percentage of tibia ash $(\mathrm{P}<0.0001)$. When considering $\mathrm{mg}$ tibia ash per bird, birds provided the commercial product at 3,000 FTU/kg deposited the greatest amount of mineral in the tibia while birds provided the PC and uncoated 2.0 and $2.5 \mathrm{~mm} \mathrm{CEP}$ at 3,000 FTU/kg resulted in similar mg tibia ash per bird (Table 5). Birds provided uncoated 2.0 and $2.5 \mathrm{~mm}$ CEP at $500 \mathrm{FTU} / \mathrm{kg}$ deposited the least amount of mineral in the tibia $(\mathrm{P}=0.0007)$.

\section{Starter (d1-10) Period Live Performance}

Improvements to LWG and FCR were apparent when phytase was provided at 3,000 FTU/kg in the starter (d1-10) period (Table 6). These data support D1-38 performance results. Main effects interacted to affect starter period FI ( $\mathrm{P}=0.0063)$. However, feed was placed in flat bottom trays from d1-7. This increased the opportunity for feed spillage and likely contributed to this interaction. Furthermore, main effects did not interact to affect FI during any other growth period.

Multiple comparison analysis of starter period LWG supports the LWG results for the overall d1-38 grow out. Gains were highest when birds were provided the commercial product at $3,000 \mathrm{FTU} / \mathrm{kg}$ while birds provided the commercial product at $500 \mathrm{FTU} / \mathrm{kg}$ or uncoated $2.0 \mathrm{~mm}$ CEP at 3,000 FTU/kg demonstrated similar LWG. Birds provided the uncoated $2.5 \mathrm{~mm}$ CEP at $500 \mathrm{FTU} / \mathrm{kg}$ had the lowest starter period LWG $(\mathrm{P}=0.0003)$ (Table 6).

\section{Grower (d11-22) Period Live Performance}

Grower (d11-22) period main effects did not interact ( $\mathrm{P}>0.05)$. Additionally, neither the main effects of particle size nor coating affected grower period broiler performance. In support 
of d1-38 period and starter period findings, birds provided CEP at 3,000 FTU/kg increased FI by 28 g per bird and LWG by 33 grams per bird when compared to birds provided a 500 FTU/kg inclusion during the grower period (Table 7). These findings coincide with previous literature that suggests improvement in broiler performance when provided elevated inclusions of phytase $[11,34,38]$.

Grower period multiple comparison analysis demonstrate improved FI and LWG when broilers were provided the commercial product at 3,000 FTU/kg. Birds provided the uncoated $2.5 \mathrm{~mm} \mathrm{CEP}$ at $500 \mathrm{FTU} / \mathrm{kg}$ decreased FI by $90 \mathrm{~g}$ per bird and LWG by $95 \mathrm{~g}$ per bird relative to birds provided the commercial product at 3,000 FTU/kg. Furthermore, birds that were provided the NC diet gained $34 \mathrm{~g}$ per bird less than those provided the PC (Table 7).

\section{Finisher (d23-38) Period Live Performance}

Main effects did not interact $(\mathrm{P}>0.05)$ during the finisher $(\mathrm{d} 23-38)$ period (Table 8$)$. The main effect of CEP coating did not affect broiler performance $(\mathrm{P}>0.05)$. Similar to the overall d1-38 period, the main effect of CEP particle size affected d23-38 FCR demonstrating that birds provided a diet containing $2.0 \mathrm{~mm}$ CEP product improved FCR by 7.7 points compared to birds consuming a diet with $2.5 \mathrm{~mm}$ CEP $(\mathrm{P}=0.0391)$. Birds provided the $1.5 \mathrm{~mm}$ CEP product were intermediate (Table 8). Literature on particle size of grains in pelleted diets and subsequent broiler performance is contradicting [10]. Particle sizes that are too large may lead to an underdeveloped gizzard that is not able to physically break down large particles [39]. Others speculate that coarse particles slow passage rate through the gizzard and increase exposure time of nutrients to digestive enzymes [40]. Perhaps phytase particle size contributes to interactions between mixer uniformity, thermal stability, and particles ingested per bird to optimize broiler performance. Phytase concentration trended towards a 4.6 point FCR improvement when 
broilers were provided phytase at 3,000 FTU/kg $(\mathrm{P}=0.0591)$. Similar feed intake across

treatments during the finisher period likely contributed to the lack of FCR differences for the main effect of phytase concentration.

Multiple comparison analysis of finisher (d23-38) period treatments demonstrated similar FI across all treatments ( $\mathrm{P}>0.05)$ (Table 8$)$. These data support d1-38 period results. LWG and FCR were also similar during the finisher period. However, birds provided 3,000 FTU/kg of the commercial product trended towards an improved FCR when compared to birds provided uncoated 2.5mm CEP at $500 \mathrm{FTU} / \mathrm{kg}(\mathrm{P}=0.0627)$, similar to $\mathrm{d} 1-38$ period findings (Table 8).

\section{CONCLUSIONS AND APPLICATIONS}

1. Coating CEP did not affect D1-38 broiler performance or tibia mineralization.

2. The efficacy of CEP was comparable to the positive control diet and commercial phytase product when both particle size and concentration were optimized.

3. D1-38 broiler performance and bone mineralization improved when broilers were provided CEP at 3,000 FTU/kg compared to those provided CEP at $500 \mathrm{FTU} / \mathrm{kg}$.

4. Broilers provided 2.0 mm CEP demonstrated D1-38 broiler performance improvements compared to those provided CEP at $2.5 \mathrm{~mm}$. However, CEP particle size did not affect tibia mineralization.

\section{REFERENCES AND NOTES}

1. Leeson, S., and J.D. Summers. 2001. Phosphorus. Pages 358-363 in Nutrition of the Chicken. $4^{\text {th }}$ Edition. University Books. Guelph, Ontario Canada.

2. Angel, R., N.M. Tamim, T.J. Applegate, A.S. Dhandu, and L.E. Ellestad. 2002. Phytic Acid Chemistry: Influence on Phytin-Phosphorus Availability and Phytase Efficacy. J. Appl. Poult. Res. 11:471-480. 
3. Evans, A.M., S.A. Loop, and J.S. Moritz. 2015. Effect of poultry litter biochar duet inclusion on feed manufacture and 4- to 21-d broiler performance. J. Appl. Poult. Res. 24:380-386.

4. Wyss, M., R.A. Kronenberger, R. Remy, R. Fimbel, G. Oesterhelt, M. Lehmann, and A.P. van Loon. 1999. Biophysical characterization of fungal phytases (myo-inositol hexakisphosphate phosphohydrolases): molecular size, glycosylation pattern, and engineering of proteolytic resistance. Appl. Environ. Microbiol. 65:359-366.

5. Hong, C.Y., K.J. Cheng, T.H. Tseng, C.S. Wang, L.F. Lui, and S.M. Yu. 2004. Production of two highly active bacterial phytases with broad $\mathrm{pH}$ optima in germinated transgenic rice seeds. Transgenic Res. 13:29.

6. Pen, J., T.C. Verwoerd, P.A. van Paridon, R.F. Beudeker, P.J.M. van den Elzen, K. Geerse, J.D. van der Klis, H.A.J. Versteegh, A. J.J. van Ooyen, and A. Hoekema. 1993. Phytase-containing transgenic seeds as a novel feed additive for improved phosphorus utilization. Bio/Technology 11:811-814.

7. Denbow, D.M., E.A Grabau, G.H. Lacy, E.T. Kornegay, D.R. Russell, and P.F. Umbeck. 1998. Soybeans transformed with a fungal phytase gene improve phosphorus availability for broilers. Poult. Sci. 77:878-881.

8. Chen, R., G. Xue, P. Chen, B. Yao, W. Yang, Q. Ma, Y. Fan, Z. Zhao, M.C. Tarczynski, and J. Shi. 2007. Transgenic maize plants expressing a fungal phytase gene. Transgenic Res. 17:633-643.

9. Foltz, K.L. 2016. Nutritional consequences of various feed ingredients in broilers, turkeys, and swine. MS Thesis. West Virginia University, Morgantown.

10. Amerah, A.M., V. Ravindran, R.G. Lentle, and D.G. Thomas. 2007. Feed particle size: Implications on the digestion and performance of poultry. World's Poult. Sci. 63:439455.

11. Campasino, A., T. York, C. Wyatt, M.R. Bedford, and W.A. Dozier III. 2014. Effect of increasing supplemental phytase concentration in diets fed to Hubbard x Cobb 500 male broilers from 1 to 42 days of age. J. Appl. Poult. Res. 23:705-714.

12. dos Santos, T.T., S. Srinongkote, M.R. Bedford, and C.L. Walk. 2013. Effect of high phytase inclusion rates on performance of broilers fed diets not severely limited in available phosphorus. Asian-Australian J. Anim. Sci. 26:227-232.

13. Boney, J.W. and J.S. Moritz. 2017. Phytase dose effects in practically formulated diets that vary in ingredient composition on feed manufacturing and broiler performance. $\mathrm{J}$. Appl. Poult. Res. 26:273-285.

14. Evans, A.M., J.W. Boney, and J.S. Moritz. 2016. The effect of poultry litter biochar on pellet quality, one to $21 \mathrm{~d}$ broiler performance, digesta viscosity, bone mineralization, and apparent ileal amino acid digestibility. J. Appl. Poult. Res. 26:89-98.

15. Loop, S.A., K.G.S. Lilly, L.K. Shires, C.K. Gehring, K.R. Beaman, M.E. Persia, and J.S. Moritz. 2012. The phytase analytical activity of pelleted diets may not adequately describe efficacy in the bird. J. Appl. Poult. Res. 21:492-501.

16. Ward, N.E. and J.W. Wilson. 2001. Pelleting stability of Ronozyme P CT phytase in commercial feedmills. Poult. Sci. 80 (Suppl 1):1968.

17. Ward, N.E., J.W. Wilson, and J. McNaughton. 2001. Comparison of Ronozyme P CT, Ronozyme P Liquid and Natuphos Liquid in a commercial broiler pelleted feed. Poult. Sci. 80 (Suppl 1): 1969.

18. Quantum Blue 5G. AB Vista Feed Ingredients, Marlborough, UK. 
19. Master Model Pellet Mill, California Pellet Mills Company, Crawfordsville, IN.

20. Hobart paddle mixer (model 4146) Hobart Corp., Troy, OH.

21. Fluke 51 II, Everette, WA.

22. Pellet quality was determined 24 hours post-pelleting using a New Holmen Portable Pellet Durability Tester, Lignotech USA, Inc., Rothschild, WI.

23. Eurofins Nutrition Analysis Center. Des Moines, IA.

24. AOAC. 2000. Method 2000.12: Phytase activity in feed: Colorimetric enzymatic method. In Official Methods of Analysis of AOAC International. 17 ${ }^{\text {th }}$ ed. Assoc. Off. Anal. Chem., Arlington, VA. A 50-g sample was extracted with $500 \mathrm{~mL}$ of distilled water containing $0.01 \%$ Tween 20 . A $100-\mu \mathrm{L}$ extract was diluted with $300 \mathrm{~mL}$ of acetate buffer until reaching $\mathrm{pH} 5.5$. After pre-incubation of the diluted extract at $37^{\circ} \mathrm{C}, 0.8 \mathrm{~mL}$ of sodium phytate was added, and the sample was incubated for $30 \mathrm{~min}$ at $37^{\circ} \mathrm{C}$. The reaction was stopped via addition of $0.8 \mathrm{~mL}$ of molybdate-vanadate stop reagent. A blank was included, and after its pre-incubation, the stop reagent was added before the addition of the substrate. The yellow complex was measured colorimetrically at $415 \mathrm{~nm}$. The value obtained from the blank was then subtracted from the sample value, and the phosphate released was quantified with a phosphate standard curve.

25. NP Analytical Laboratories, St. Louis, MO.

26. Ro-Tap particle size analyzer model RX-29 type 110V 60H2, WS Tyler, Mentor, OH. One hundred grams of each ground treatment was placed in a dust-tight enclosed series of stacked (N0. 4, 6, etc.) American Society for Testing and Materials (ASTM) screens affixed to the Ro-Tap particle size analyzer and shaken for 10 minutes. The screens were then separated and weighed. Particle size was calculated by subtracting the weight of the screen from the final weight of screen and sample after shaking. The mean geometric particle size and log normal geometric SD were calculated as described by McEllhiney (McEllhiney, R. R. 1994. Determining and expressing particle size. Pages 545-547 in Feed Manufacture Technology IV. Am. Feed Ind. Assoc. Inc., Arlington, VA.)

27. E.K. Schofield (ed.). Feed Manufacture Technology V. 2005. Table F-2. Screen Sizes for Pellet and Crumble Durability Tests. Pg 631. American Feed Industry Association.

28. Pilgrim's Pride Inc., Moorefield, WV

29. SAS Institute. 2017. The SAS System for Windows 2000. Release 8.1. SAS Inst. Inc., Cary, NC.

30. M. Donohue. 2013. The Challenges in Feeding Broilers in Times of High and Volatile Feed Ingredient Costs: How to Cover the Costs?. 2013 Mid-Atlantic Nutrition Conference proceedings.

31. P. B. Tillman and W.A. Dozier. 2013. Current Amino Acid Considerations for Broilers: Requirements, Ratios, Economics. www.thepoultryfederation.com

32. Gehring, C.K., K.G.S. Lilly, L.K. Shires, K.R. Beaman, S.A. Loop, and J.S. Moritz. 2011. Increasing mixer-added fat reduces the electrical energy required for pelleting and improves exogenous enzyme efficacy for broilers. J. Appl. Poult. Res. 20:75-89.

33. Wamsley, K.G.S. and J.S. Moritz. 2013. Resolving poor pellet quality and maintaining amino acid digestibility in commercial turkey diet feed manufacture. J. Appl. Poult. Res. 22:439-446.

34. Shirley, R.B., and H.M. Edwards. 2003. Graded Levels of Phytase Past Industry Standards Improves Broiler Performance. Poult. Sci. 82:671-680 
35. Wondra, K.J., J.D. Hancock, K.C. Behnke, R.H. Hines, and C.R. Stark. 1995. Effects of particle size and pelleting on growth performance, nutrient digestibility, and stomach morphology in finishing pigs. J. Anim. Sci. 73:757-763.

36. Timmons, J.R., J.M. Harter-Dennis, and A.E. Sefton. 2004. Evaluation of Nonuniform Application of Phytase (Simulated) on Growth Performance and Bone Quality in Broiler Chicks. J. Appl. Poult. Res. 13:311-318.

37. Shaw, A.L., J.B. Hess, J.P Blake, and N.E. Ward. 2011. Assessment of an experimental phytase enzyme product on live performance, bone mineralization, and phosphorus excretion in broiler chickens. J. Appl. Poult. Res. 20:561-566.

38. Cowieson, A.J., P. Wilcock, and M.R. Bedford. 2011. Super-dosing effects of phytase in poultry and other monogastrics. World's Poultry Science Journal. Volume 67, Issue 2, pp $225-236$.

39. Covasa, M. and J.M. Forbes. 1996. Effect of prior experience and training on diet selection of broiler chicken using wheat. Applied Animal Behaviour Science 46:229-242.

40. Nir, I., G. Shefet, and Y. Aaroni. 1994. Effect of particle size on performance. 1. Corn. Poult sci. 73:45-49.

41. Angel, R., N.M. Tamim, T.J. Applegate, A.S. Dhandu, and L.E. Ellestad. 2002. Phytic acid chemistry: Influence on phytin-phosphorus availability and phytase efficacy. J. Appl. Poult. Res. 11: 471-480. 
Table 1. Diet composition of positive and negative control ${ }^{1}$ diets for starter, grower, and finisher periods

\begin{tabular}{|c|c|c|c|c|c|c|}
\hline \multirow{3}{*}{ Ingredient } & \multicolumn{2}{|c|}{ Starter (D1-10) } & \multicolumn{2}{|c|}{ Grower (D11-22) } & \multicolumn{2}{|c|}{ Finisher (D23-38) } \\
\hline & $\begin{array}{l}\text { Positive } \\
\text { Control }\end{array}$ & $\begin{array}{l}\text { Negative } \\
\text { Control }\end{array}$ & $\begin{array}{l}\text { Positive } \\
\text { Control }\end{array}$ & $\begin{array}{l}\text { Negative } \\
\text { Control }\end{array}$ & $\begin{array}{l}\text { Positive } \\
\text { Control }\end{array}$ & $\begin{array}{l}\text { Negative } \\
\text { Control }\end{array}$ \\
\hline & \multicolumn{2}{|c|}{$\%$} & \multicolumn{2}{|c|}{$\%$} & \multicolumn{2}{|c|}{$\%$} \\
\hline Corn & 51.24 & 51.87 & 55.27 & 55.87 & 60.42 & 61.05 \\
\hline Soybean Meal (48\%) & 35.07 & 34.99 & 30.78 & 30.73 & 25.64 & 25.56 \\
\hline Corn DDGS & 5.00 & 5.00 & 5.00 & 5.00 & 5.00 & 5.00 \\
\hline Soybean Oil & 4.09 & 3.90 & 4.61 & 4.42 & 4.82 & 4.63 \\
\hline Limestone & 1.31 & 1.77 & 1.22 & 1.68 & 1.22 & 1.68 \\
\hline DL-Methionine & 0.45 & 0.45 & 0.43 & 0.43 & 0.39 & 0.39 \\
\hline Dicalcium Phosphate & 1.77 & 0.96 & 1.59 & 0.78 & 1.41 & 0.60 \\
\hline Salt & 0.24 & 0.24 & 0.29 & 0.29 & 0.26 & 0.26 \\
\hline $\begin{array}{l}\text { Vitamin/Mineral } \\
\text { Premix }^{2}\end{array}$ & 0.25 & 0.25 & 0.25 & 0.25 & 0.25 & 0.25 \\
\hline Sodium Bicarbonate & 0.15 & 0.15 & 0.15 & 0.15 & 0.15 & 0.15 \\
\hline L-Lysine $\mathrm{HCl}$ & 0.19 & 0.19 & 0.20 & 0.20 & 0.23 & 0.23 \\
\hline L-Threonine & 0.14 & 0.14 & 0.12 & 0.12 & 0.11 & 0.11 \\
\hline Sand & 0.10 & 0.10 & 0.10 & 0.10 & 0.10 & 0.10 \\
\hline \multicolumn{7}{|c|}{ Calculated Nutrients } \\
\hline $\mathrm{ME}^{3}(\mathrm{kcal} / \mathrm{kg})$ & 3,000 & 3,000 & 3,072 & 3,072 & 3,132 & 3,132 \\
\hline Crude Protein (\%) & 22.00 & 22.00 & 20.16 & 20.17 & 18.00 & 18.00 \\
\hline $\begin{array}{l}\text { Digestible Lysine }{ }^{4} \\
(\%)\end{array}$ & 1.20 & 1.20 & 1.10 & 1.10 & 1.00 & 1.00 \\
\hline $\begin{array}{l}\text { Digestible } \\
\text { Methionine }^{4}(\%)\end{array}$ & 0.54 & 0.54 & 0.51 & 0.51 & 0.47 & 0.47 \\
\hline $\begin{array}{l}\text { Digestible Met }+ \text { Cys }^{4} \\
(\%)\end{array}$ & 1.10 & 1.10 & 1.05 & 1.05 & 0.98 & 0.98 \\
\hline $\begin{array}{l}\text { Digestible Threonine } 4 \\
\text { (\%) }\end{array}$ & 0.84 & 0.84 & 0.76 & 0.76 & 0.68 & 0.68 \\
\hline $\begin{array}{l}\text { Digestible } \\
\text { Tryptophan }{ }^{4}(\%)\end{array}$ & 0.22 & 0.22 & 0.20 & 0.20 & 0.17 & 0.17 \\
\hline Calcium (\%) & 0.96 & 0.96 & 0.88 & 0.88 & 0.83 & 0.83 \\
\hline $\mathrm{nPP}^{5}(\%)$ & 0.46 & 0.31 & 0.42 & 0.27 & 0.38 & 0.23 \\
\hline Sodium (\%) & 0.17 & 0.17 & 0.19 & 0.19 & 0.18 & 0.18 \\
\hline
\end{tabular}

${ }^{1}$ Calculated inclusions of experimental CEP or commercial phytase was added to the negative control diet at the expense of sand

${ }^{2}$ Supplied per kilogram of diet: $0.02 \%$ manganese; $0.02 \%$ zinc; $0.01 \%$ iron; $0.0025 \%$ copper; $0.0003 \%$ iodine; $0.00003 \%$ selenium; $0.69 \mathrm{mg}$ of folic acid; $386 \mathrm{mg}$ of choline; $6.61 \mathrm{mg}$ of riboflavin; $0.03 \mathrm{mg}$ of biotin; $1.38 \mathrm{mg}$ of vitamin B6; $27.56 \mathrm{mg}$ of niacin; $6.61 \mathrm{mg}$ of pantothenic acid; $2.20 \mathrm{mg}$ of thiamine; $0.83 \mathrm{mg}$ of menadione; $0.01 \mathrm{mg}$ of vitamin B12; $16.53 \mathrm{IU}$ of vitamin E; 2,133 IU of vitamin D3; and 7,716 of vitamin A.

${ }^{3}$ Metabolizable Energy and Available Phosphorus were based on Agristat values as suggested by M. Donohue. 2013 [30]. Available Phosphorus in the $\mathrm{NC}$ was reduced by 0.15 of the US average.

${ }^{4}$ Digestible amino acids were based on the digestible lysine values suggested by P. B. Tillman and W.A. Dozier. 2013 [31]. Digestible amino acid to digestible lysine ratios followed further recommendations of this communication.

${ }^{5} \mathrm{nPP}=$ non-phytate phosphorus 
Table 2. Descriptive Feed Manufacturing Data for Starter, Grower, and Finisher Growth Periods

\begin{tabular}{|c|c|c|c|c|c|c|c|c|c|c|c|}
\hline \multirow{2}{*}{\multicolumn{3}{|c|}{ Treatment }} & \multicolumn{9}{|c|}{ Growth Period } \\
\hline & & & \multicolumn{3}{|c|}{ Starter (D1-10) } & \multicolumn{3}{|c|}{ Grower (D11-22) } & \multicolumn{3}{|c|}{ Finisher (D23-38) } \\
\hline Particle Size & Concentration & Coating & $\begin{array}{c}\text { Hot Pellet } \\
\text { Temperature }^{1}\end{array}$ & $\mathrm{NHPT}^{2}$ & $\begin{array}{l}\text { Particle } \\
\text { Size }^{3}\end{array}$ & $\begin{array}{c}\text { Hot Pellet } \\
\text { Temperature }^{1}\end{array}$ & $\mathrm{NHPT}^{2}$ & $\begin{array}{l}\text { Particle } \\
\text { Size }^{3}\end{array}$ & $\begin{array}{c}\text { Hot Pellet } \\
\text { Temperature } \\
1\end{array}$ & $\mathrm{NHPT}^{2}$ & $\begin{array}{l}\text { Percent } \\
\text { Pellet }^{4}\end{array}$ \\
\hline \multirow{3}{*}{1.5} & \multirow{2}{*}{500} & With & 88.28 & 81.02 & $1,138.4$ & 86.89 & 54.76 & $2,157.4$ & 84.17 & 35.87 & 69.95 \\
\hline & & Without & 85.83 & 72.11 & $1,177.5$ & 87.94 & 54.06 & $1,944.4$ & 83.39 & 30.04 & 59.55 \\
\hline & 3,000 & Without & 87.17 & 69.01 & $1,221.6$ & 87.83 & 48.44 & $2,065.4$ & 82.94 & 26.53 & 65.55 \\
\hline \multirow{4}{*}{2.0} & \multirow{2}{*}{500} & With & 85.94 & 70.54 & $1,233.3$ & 87.06 & 52.30 & $1,970.5$ & 84.33 & 24.05 & 66.95 \\
\hline & & Without & 85.17 & 78.38 & $1,236.3$ & 85.72 & 49.43 & $1,667.1$ & 85.06 & 27.88 & 67.95 \\
\hline & \multirow{2}{*}{3,000} & With & 87.06 & 67.71 & $1,163.9$ & 86.67 & 51.86 & $2,106.0$ & 84.94 & 25.26 & 51.60 \\
\hline & & Without & 85.28 & 70.37 & $1,234.9$ & 85.44 & 56.04 & $1,822.3$ & 85.06 & 32.62 & 62.65 \\
\hline \multirow{3}{*}{2.5} & \multirow{2}{*}{500} & With & 85.72 & 70.88 & $1,188.4$ & 86.28 & 54.80 & $1,934.2$ & 85.22 & 22.19 & 66.05 \\
\hline & & Without & 86.22 & 70.48 & $1,190.5$ & 85.94 & 52.26 & $1,887.4$ & 83.11 & 23.38 & 58.35 \\
\hline & 3,000 & Without & 86.61 & 72.08 & $1,328.6$ & 86.17 & 55.86 & $2,160.7$ & 84.06 & 23.50 & 62.20 \\
\hline \multicolumn{3}{|c|}{ Commercial Phytase at 500 FTU/kg } & 86.39 & 75.63 & $1,215.0$ & 88.06 & 58.23 & $1,570.6$ & 84.39 & 20.66 & 58.05 \\
\hline \multicolumn{3}{|c|}{ Commercial Phytase at 3,000 FTU/kg } & 87.00 & 74.08 & $1,221.2$ & 87.94 & 55.14 & $1,796.6$ & 84.39 & 22.37 & 64.90 \\
\hline \multicolumn{3}{|c|}{ Negative Control } & 87.28 & 72.04 & $1,135.1$ & 88.72 & 59.55 & $1,702.9$ & 84.94 & 22.86 & 58.40 \\
\hline \multicolumn{3}{|c|}{ Positive Control } & 86.17 & 73.32 & $1,130.3$ & 87.39 & 64.37 & $1,751.2$ & 85.00 & 19.33 & 58.15 \\
\hline
\end{tabular}

${ }^{1}$ Hot Pellet Temperature was determined by collecting pellets from the stream of extruded pellets in an insulated container and obtaining a temperature reading from a thermocouple thermometer.

${ }^{2}$ Pellet survivability was determined 24 hours post-pelleting using the New Holmen Portable Pellet Durability Tester, Lignotech USA, INC., Rothschild, WI.

${ }^{3}$ Particle size was determined using a Ro-Tap particle size analyzer model RX-29 type $110 \mathrm{~V} 60 \mathrm{H} 2$.

${ }^{4}$ Percent pellet was determined by placing a unit of feed on a \#5 ASAE testing sieve. After sieving, pellets remaining on the sieve were considered pellets and feed passing through were considered

fines. The weight of remaining pellets were used to calculate percent pellets. 
Table 3. Phytase Activity ${ }^{1}$ and Mineral Analysis for the Finisher (d23-38) Growth Period

\begin{tabular}{|c|c|c|c|c|c|c|c|c|}
\hline \multicolumn{3}{|c|}{ Treatment } & \multirow{2}{*}{$\begin{array}{c}\text { Unconditioned Mash } \\
\text { Phytase Activity } \\
\text { (FTU/kg) }\end{array}$} & \multirow{2}{*}{$\begin{array}{c}\text { Pelleted Feed } \\
\text { Phytase Activity } \\
\text { (FTU/kg) }\end{array}$} & \multirow{2}{*}{$\begin{array}{c}\text { Total } \\
\text { Phosphorous } \\
(\%) \\
\end{array}$} & \multirow{2}{*}{$\begin{array}{l}\text { Phytic } \\
\text { Acid } \\
(\%)\end{array}$} & \multirow{2}{*}{$\begin{array}{c}\mathrm{nPP}^{4} \\
(\%)\end{array}$} & \multirow{2}{*}{$\begin{array}{l}\text { Calcium } \\
(\%)\end{array}$} \\
\hline $\begin{array}{l}\text { Particle Size } \\
(\mathrm{mm})\end{array}$ & $\begin{array}{c}\text { Concentration } \\
(\mathrm{FTU} / \mathrm{kg})\end{array}$ & Coating & & & & & & \\
\hline \multirow{4}{*}{1.5} & \multirow{2}{*}{500} & With & 550 & 210 & 0.435 & 0.861 & 0.192 & 0.955 \\
\hline & & Without & 650 & 170 & 0.457 & 0.873 & 0.211 & 0.847 \\
\hline & \multirow{2}{*}{3,000} & With & 1,800 & 980 & 0.442 & 0.846 & 0.203 & 0.854 \\
\hline & & Without & 2,000 & 1,200 & 0.440 & 0.818 & 0.209 & 0.846 \\
\hline \multirow{4}{*}{2.0} & \multirow{2}{*}{500} & With & 300 & 520 & 0.445 & 0.866 & 0.201 & 0.782 \\
\hline & & Without & 340 & 320 & 0.433 & 0.856 & 0.192 & 0.819 \\
\hline & \multirow{2}{*}{3,000} & With & 2,000 & 1,600 & 0.437 & 0.886 & 0.187 & 0.741 \\
\hline & & Without & 2,100 & 1,500 & 0.436 & 0.858 & 0.194 & 0.796 \\
\hline \multirow{4}{*}{2.5} & \multirow{2}{*}{500} & With & 690 & 250 & 0.433 & 0.821 & 0.211 & 0.860 \\
\hline & & Without & 180 & 270 & 0.445 & 0.836 & 0.209 & 0.862 \\
\hline & \multirow{2}{*}{3,000} & With & 1,300 & 1,400 & 0.445 & 0.782 & 0.224 & 0.786 \\
\hline & & Without & 1,800 & 1,400 & 0.449 & 0.881 & 0.201 & 0.855 \\
\hline \multicolumn{3}{|c|}{ Commercial Phytase @ 500 FTU/kg } & 380 & 360 & 0.440 & 0.847 & 0.201 & 0.815 \\
\hline \multicolumn{3}{|c|}{ Commercial Phytase @ 3,000 FTU/kg } & 1,900 & 1,900 & 0.456 & 0.843 & 0.218 & 0.853 \\
\hline \multicolumn{3}{|c|}{ Negative Control } & 330 & 84 & 0.449 & 0.875 & 0.202 & 0.867 \\
\hline \multicolumn{3}{|c|}{ Positive Control } & 180 & 82 & 0.564 & 0.903 & 0.309 & 0.899 \\
\hline
\end{tabular}

${ }^{1}$ Phytase activity was determined at a commercial laboratory using the AOAC 2000.12 method.

${ }^{2}$ Unconditioned mash samples were collected directly from the feed screw auger immediately before entering the steam conditioning barrel.

${ }^{3}$ Pelleted feed samples were collected as pellets exited the horizontal belt cooler

${ }^{4} \mathrm{nPP}=$ Total Phosphorus $-($ Phytic acid *0.282) [41] 
Table 4. Overall (d1-38) effects of feeding diets supplemented with corn-expressed phytase varying in particle size, concentration, and coating on Hubbard x Cobb 500 broiler performance

\begin{tabular}{|c|c|c|c|c|c|}
\hline \multirow{2}{*}{\multicolumn{3}{|c|}{ Treatment }} & \multicolumn{3}{|c|}{ D1-38 } \\
\hline & & & \multirow{2}{*}{$\begin{array}{c}\mathrm{FI}^{1} \\
(\mathrm{~kg} / \mathrm{bird})\end{array}$} & \multirow{2}{*}{$\begin{array}{c}\mathrm{LWG}^{2} \\
\text { (kg/bird) }\end{array}$} & \multirow{2}{*}{$\begin{array}{c}\mathrm{FCR}^{3} \\
(\mathrm{~kg}: \mathrm{kg})\end{array}$} \\
\hline $\begin{array}{l}\text { Particle Size } \\
(\mathrm{mm})\end{array}$ & $\begin{array}{c}\text { Concentration } \\
(\text { FTU } / \mathrm{kg})\end{array}$ & Coating & & & \\
\hline \multirow{4}{*}{1.5} & \multirow{2}{*}{500} & With & 3.898 & $2.301^{\mathrm{cd}}$ & $1.727^{\mathrm{ab}}$ \\
\hline & & Without & 3.803 & $2.342^{\text {bcd }}$ & $1.639^{\mathrm{de}}$ \\
\hline & \multirow{2}{*}{3,000} & With & 3.841 & $2.343^{\mathrm{bcd}}$ & $1.655^{\mathrm{cde}}$ \\
\hline & & Without & 3.802 & $2.346^{\mathrm{bcd}}$ & $1.635^{\mathrm{de}}$ \\
\hline \multirow{4}{*}{2.0} & \multirow{2}{*}{500} & With & 3.862 & $2.345^{\mathrm{bcd}}$ & $1.671^{\text {bcde }}$ \\
\hline & & Without & 3.741 & $2.290^{\mathrm{d}}$ & $1.637^{\mathrm{de}}$ \\
\hline & \multirow{2}{*}{3,000} & With & 3.828 & $2.353^{\mathrm{bcd}}$ & $1.639^{\mathrm{de}}$ \\
\hline & & Without & 3.895 & $2.405^{\mathrm{ab}}$ & $1.623^{\mathrm{e}}$ \\
\hline \multirow{4}{*}{2.5} & \multirow{2}{*}{500} & With & 3.820 & $2.284^{\mathrm{d}}$ & $1.689^{\mathrm{abcd}}$ \\
\hline & & Without & 3.892 & $2.294^{\mathrm{cd}}$ & $1.737^{\mathrm{a}}$ \\
\hline & \multirow{2}{*}{3,000} & With & 3.780 & $2.292^{\mathrm{d}}$ & $1.658^{\text {cde }}$ \\
\hline & & Without & 3.870 & $2.341^{\mathrm{bcd}}$ & $1.658^{\text {cde }}$ \\
\hline \multicolumn{3}{|c|}{ Commercial Phytase @ 500 FTU/kg } & 3.909 & $2.413^{\mathrm{ab}}$ & $1.633^{\mathrm{de}}$ \\
\hline \multicolumn{3}{|c|}{ Commercial Phytase @ 3,000 FTU/kg } & 3.906 & $2.438^{\mathrm{a}}$ & $1.610^{\mathrm{e}}$ \\
\hline \multicolumn{3}{|c|}{ Negative Control } & 3.853 & $2.284^{\mathrm{d}}$ & $1.707^{\mathrm{abc}}$ \\
\hline \multicolumn{3}{|c|}{ Positive Control } & 3.887 & $2.375^{\mathrm{abc}}$ & $1.652^{\text {cde }}$ \\
\hline \multicolumn{3}{|c|}{ P-Value } & 0.6582 & 0.0019 & $\mathbf{0 . 0 0 3 7}$ \\
\hline \multicolumn{3}{|c|}{$\mathrm{SEM}^{4}$} & 0.055 & 0.0291 & 0.0230 \\
\hline \multicolumn{6}{|c|}{ Particle Size Means } \\
\hline $1.5 \mathrm{~mm}$ & -- & -- & 3.836 & 2.333 & $1.664^{\mathrm{ab}}$ \\
\hline $2.0 \mathrm{~mm}$ & -- & -- & 3.831 & 2.348 & $1.642^{\mathrm{b}}$ \\
\hline $2.5 \mathrm{~mm}$ & -- & -- & 3.841 & 2.303 & $1.686^{\mathrm{a}}$ \\
\hline \multicolumn{3}{|c|}{ Particle Size SEM ${ }^{4}$} & 0.027 & 0.0153 & 0.0121 \\
\hline \multicolumn{6}{|c|}{ Concentration Means } \\
\hline-- & $500 \mathrm{FTU} / \mathrm{kg}$ & -- & 3.836 & $2.309^{\mathrm{b}}$ & $1.683^{\mathrm{a}}$ \\
\hline-- & 3,000 FTU/ks & -- & 3.836 & $2.347^{\mathrm{a}}$ & $1.644^{\mathrm{b}}$ \\
\hline \multicolumn{3}{|c|}{ Concentration SEM ${ }^{4}$} & 0.022 & 0.0125 & 0.0099 \\
\hline \multicolumn{6}{|c|}{ Coating Means } \\
\hline-- & -- & With & 3.838 & 2.320 & 1.673 \\
\hline-- & -- & Without & 3.834 & 2.336 & 1.655 \\
\hline \multicolumn{3}{|c|}{ Coating SEM $^{4}$} & 0.022 & 0.0125 & 0.0099 \\
\hline \multicolumn{6}{|c|}{ Probability } \\
\hline & Particle Size & & 0.9732 & 0.1130 & 0.0476 \\
\hline & Concentratior & & 0.9999 & 0.0391 & 0.0071 \\
\hline & Coating & & 0.8854 & 0.3559 & 0.1966 \\
\hline Parti & ize $x$ Concentrat & ating & 0.3008 & 0.6155 & 0.2540 \\
\hline
\end{tabular}


Table 5. Overall (d1-38) effects of feeding diets supplemented with corn-expressed phytase varying in particle size, concentration, and coating on Hubbard x Cobb 500 tibia mineralization

\begin{tabular}{|c|c|c|c|c|}
\hline \multirow{2}{*}{\multicolumn{3}{|c|}{ Treatment }} & \multicolumn{2}{|c|}{ D38 } \\
\hline & & & \multirow{2}{*}{$\begin{array}{c}\text { Tibia Ash } \\
(\%)\end{array}$} & \multirow{2}{*}{$\begin{array}{c}\mathrm{Mg} \mathrm{Ash} / \text { Bird } \\
(\mathrm{mg})\end{array}$} \\
\hline $\begin{array}{l}\text { Particle Size } \\
(\mathrm{mm})\end{array}$ & $\begin{array}{c}\text { Concentration } \\
(\mathrm{FTU} / \mathrm{kg})\end{array}$ & Coating & & \\
\hline \multirow{4}{*}{1.5} & \multirow{2}{*}{500} & With & $38.88^{\text {def }}$ & $3,110.7^{\text {cde }}$ \\
\hline & & Without & $38.62^{\mathrm{ef}}$ & $3,103.3^{\text {cde }}$ \\
\hline & \multirow{2}{*}{3,000} & With & $39.90^{\mathrm{ab}}$ & $3,222.2^{\text {bcde }}$ \\
\hline & & Without & $39.27^{\text {bcdef }}$ & $3,168.3^{\text {cde }}$ \\
\hline \multirow{4}{*}{2.0} & \multirow{2}{*}{500} & With & $38.76^{\mathrm{ef}}$ & $3,233.3^{\text {bcde }}$ \\
\hline & & Without & $38.68^{\mathrm{ef}}$ & $3,044.1^{\mathrm{e}}$ \\
\hline & \multirow{2}{*}{3,000} & With & $38.79^{\mathrm{ef}}$ & $3,144.9^{\text {cde }}$ \\
\hline & & Without & $39.55^{\text {abcde }}$ & $3,414.3^{\mathrm{ab}}$ \\
\hline \multirow{4}{*}{2.5} & \multirow{2}{*}{500} & With & $38.91^{\text {cdef }}$ & $3,145.0^{\text {cde }}$ \\
\hline & & Without & $37.59^{\mathrm{g}}$ & $3,024.5^{\mathrm{e}}$ \\
\hline & \multirow{2}{*}{3,000} & With & $39.17^{\text {bcdef }}$ & $3,280.4^{\text {bcd }}$ \\
\hline & & Without & $39.81^{\mathrm{abcd}}$ & $3,404.1^{\mathrm{ab}}$ \\
\hline \multicolumn{3}{|c|}{ Commercial Phytase @ 500 FTU/kg } & $39.27^{\text {bcdef }}$ & $3,330.2^{\mathrm{abc}}$ \\
\hline \multicolumn{3}{|c|}{ Commercial Phytase @ 3,000 FTU/kg } & $39.92^{\mathrm{ab}}$ & $3,515.8^{\mathrm{a}}$ \\
\hline \multicolumn{3}{|c|}{ Negative Control } & $38.54^{\mathrm{fg}}$ & $3,082.3^{\mathrm{de}}$ \\
\hline \multicolumn{3}{|c|}{ Positive Control } & $40.39^{\mathrm{a}}$ & $3,317.5^{\mathrm{abc}}$ \\
\hline \multicolumn{3}{|c|}{ P-Value } & $<0.0001$ & 0.0007 \\
\hline \multicolumn{3}{|c|}{ SEM $^{1}$} & 0.353 & 82.648 \\
\hline \multicolumn{5}{|c|}{ Particle Size Means } \\
\hline $1.5 \mathrm{~mm}$ & -- & -- & 39.16 & $3,151.1$ \\
\hline $2.0 \mathrm{~mm}$ & -- & -- & 38.94 & $3,209.1$ \\
\hline $2.5 \mathrm{~mm}$ & -- & -- & 38.86 & $3,213.5$ \\
\hline \multicolumn{3}{|c|}{ Particle Size SEM $^{1}$} & 0.219 & 41.11 \\
\hline \multicolumn{5}{|c|}{ Concentration Means } \\
\hline-- & $500 \mathrm{FTU} / \mathrm{kg}$ & -- & $38.57^{\mathrm{b}}$ & $3,110.1^{\mathrm{b}}$ \\
\hline-- & 3,000 FTU/kg & -- & $39.41^{\mathrm{a}}$ & $3,272.3^{\mathrm{a}}$ \\
\hline \multicolumn{3}{|c|}{ Concentration SEM $^{1}$} & 0.178 & 33.57 \\
\hline \multicolumn{5}{|c|}{ Coating Means } \\
\hline-- & -- & With & 39.06 & $3,189.4$ \\
\hline-- & -- & Without & 38.92 & $3,193.0$ \\
\hline \multicolumn{3}{|c|}{ Coating SEM $^{1}$} & 0.178 & 33.57 \\
\hline \multicolumn{5}{|c|}{ Probabilities } \\
\hline \multicolumn{3}{|c|}{ Particle Size } & 0.6115 & 0.4917 \\
\hline & Concentration & & 0.0015 & 0.0011 \\
\hline & Coating & & 0.5657 & 0.9384 \\
\hline Particle & ize x Concentrati & Coating & 0.2308 & 0.1023 \\
\hline
\end{tabular}

${ }^{\mathrm{a}-\mathrm{g}}$ Means within the same column with no common superscript differ significantly $(\mathrm{P}<0.05)$

${ }^{1} \mathrm{SEM}=$ Pooled standard error of the mean 
Table 6. The effects of feeding starter (d1-10) diets supplemented with corn-expressed phytase varying in particle size, concentration, and coating on Hubbard x Cobb 500 broiler performance

\begin{tabular}{|c|c|c|c|c|c|c|}
\hline \multirow{2}{*}{\multicolumn{3}{|c|}{ Treatment }} & \multirow{3}{*}{$\begin{array}{c}\text { D22 } \\
\text { BW }^{1} \\
\text { (kg/bird) }\end{array}$} & \multicolumn{3}{|c|}{ D11-22 } \\
\hline & & & & & & \\
\hline Particle Size (mm) & $\begin{array}{c}\text { Concentration } \\
(\mathrm{FTU} / \mathrm{kg})\end{array}$ & Coating & & $\begin{array}{c}\mathrm{Fl}^{2} \\
(\mathrm{~kg} / \mathrm{bird})\end{array}$ & $\begin{array}{c}\text { (kg/bird) } \\
\text { (kg }\end{array}$ & $\begin{array}{l}\text { Fg: } \mathrm{kg}) \\
\mathrm{kgR}\end{array}$ \\
\hline \multirow{4}{*}{1.5} & \multirow{2}{*}{500} & With & $0.893^{\mathrm{g}}$ & $0.989^{\mathrm{ef}}$ & $0.667^{\mathrm{g}}$ & 1.515 \\
\hline & & Without & $0.930^{\text {def }}$ & $0.994^{\text {defg }}$ & $0.704^{\text {cde }}$ & 1.414 \\
\hline & \multirow{2}{*}{3,000} & With & $0.954^{\mathrm{bcd}}$ & $1.037^{\mathrm{abc}}$ & $0.722^{\text {bc }}$ & 1.452 \\
\hline & & Without & $0.951^{\mathrm{bcd}}$ & $1.025^{\text {bcde }}$ & $0.726^{\mathrm{bc}}$ & 1.424 \\
\hline \multirow{4}{*}{2.0} & \multirow{2}{*}{500} & With & $0.914^{\mathrm{efg}}$ & $1.016^{\text {bcdef }}$ & $0.693^{\text {def }}$ & 1.472 \\
\hline & & Without & $0.907^{\text {fg }}$ & $0.982^{\mathrm{f}}$ & $0.687^{\text {efg }}$ & 1.437 \\
\hline & \multirow{2}{*}{3,000} & With & $0.934^{\text {cdef }}$ & $1.008^{\text {bcdefg }}$ & $0.713^{\mathrm{bcd}}$ & 1.423 \\
\hline & & Without & $0.962^{\mathrm{bc}}$ & $1.027^{\mathrm{bcd}}$ & $0.729^{\mathrm{bc}}$ & 1.415 \\
\hline \multirow{4}{*}{2.5} & \multirow{2}{*}{500} & With & $0.920^{\text {efg }}$ & $0.993^{\text {def }}$ & $0.696^{\text {def }}$ & 1.437 \\
\hline & & Without & $0.897^{\mathrm{g}}$ & $0.979^{\mathrm{g}}$ & $0.674^{\text {fg }}$ & 1.467 \\
\hline & \multirow{2}{*}{3,000} & With & $0.937^{\text {cde }}$ & $1.003^{\text {cdefg }}$ & $0.714^{\mathrm{bcd}}$ & 1.406 \\
\hline & & Without & $0.941^{\text {bcde }}$ & $1.017^{\text {bcdef }}$ & $0.714^{\mathrm{bcd}}$ & 1.432 \\
\hline \multicolumn{3}{|c|}{ Commercial Phytase @ 500 FTU/kg } & $0.966^{\mathrm{b}}$ & $1.042^{\mathrm{ab}}$ & $0.736^{\mathrm{b}}$ & 1.421 \\
\hline \multicolumn{3}{|c|}{ Commercial Phytase @ 3,000 FTU/kg } & $1.009^{\mathrm{a}}$ & $1.069^{\mathrm{a}}$ & $0.769^{\mathrm{a}}$ & 1.402 \\
\hline \multicolumn{3}{|c|}{ Negative Control } & $0.920^{\mathrm{efg}}$ & $1.001^{\text {cdefg }}$ & $0.690^{\text {defg }}$ & 1.464 \\
\hline \multicolumn{3}{|c|}{ Positive Control } & $0.954^{\mathrm{bcd}}$ & $1.027^{\mathrm{bcd}}$ & $0.724^{\mathrm{bc}}$ & 1.430 \\
\hline \multicolumn{3}{|c|}{ P-Value } & $<0.0001$ & 0.0002 & $<0.0001$ & 0.0811 \\
\hline \multicolumn{3}{|c|}{ SEM $^{5}$} & 0.010 & 0.013 & 0.009 & 0.023 \\
\hline \multicolumn{7}{|c|}{ Particle Size Means } \\
\hline $1.5 \mathrm{~mm}$ & -- & -- & 0.932 & 1.011 & 0.705 & 1.451 \\
\hline $2.0 \mathrm{~mm}$ & -- & -- & 0.929 & 1.008 & 0.705 & 1.437 \\
\hline $2.5 \mathrm{~mm}$ & -- & -- & 0.924 & 0.998 & 0.700 & 1.435 \\
\hline \multicolumn{3}{|c|}{ Particle Size SEM ${ }^{5}$} & 0.0050 & 0.006 & 0.0046 & 0.0126 \\
\hline \multicolumn{7}{|c|}{ Concentration Means } \\
\hline-- & 500 FTU/kg & -- & $0.910^{\mathrm{b}}$ & $0.992^{\mathrm{b}}$ & $0.687^{b}$ & $1.457^{\mathrm{a}}$ \\
\hline-- & 3,000 FTU/kg & -- & $0.946^{\mathrm{a}}$ & $1.020^{\mathrm{a}}$ & $0.720^{\mathrm{a}}$ & $1.425^{b}$ \\
\hline \multicolumn{3}{|c|}{ Concentration $\mathrm{SEM}^{5}$} & 0.0041 & 0.005 & 0.0038 & 0.0103 \\
\hline \multicolumn{7}{|c|}{ Coating Means } \\
\hline-- & -- & With & 0.925 & 1.008 & 0.701 & 1.451 \\
\hline-- & -- & Without & 0.931 & 1.004 & 0.705 & 1.431 \\
\hline \multicolumn{3}{|c|}{ Coating SEM ${ }^{6}$} & 0.0041 & 0.005 & 0.0038 & 0.0103 \\
\hline \multicolumn{7}{|c|}{ Probability } \\
\hline \multicolumn{3}{|c|}{ Particle Size } & 0.5165 & 0.3623 & 0.6514 & 0.6180 \\
\hline & Concentration & & $<0.0001$ & 0.0008 & $<0.0001$ & 0.0342 \\
\hline & Coating & & 0.3152 & 0.6114 & 0.4057 & 0.1920 \\
\hline Particle & x Concentration $\mathrm{x}$ & & 0.0903 & 0.4630 & 0.1024 & 0.2535 \\
\hline $\begin{array}{l}{ }^{\mathrm{a}-\mathrm{g}} \text { Means wi } \\
{ }^{1} \mathrm{BW}=\text { Bird } \\
{ }^{2} \mathrm{FI}=\text { Feed } \mathrm{i} \\
{ }^{3} \mathrm{LWG}=\text { Liv } \\
{ }^{4} \mathrm{FCR}=\text { Mor } \\
{ }^{5} \mathrm{SEM}=\text { Poo }\end{array}$ & $\begin{array}{l}\text { n the same column with no } \\
\text { ight } \\
\text { ke per bird } \\
\text { veight gain per bird } \\
\text { ty corrected feed conversio } \\
\text { standard error of the mean }\end{array}$ & on superscript d & icantly $(\mathrm{P}<0.0$ & & & \\
\hline
\end{tabular}


Table 7. The effects of feeding grower (d11-22) diets supplemented with corn-expressed phytase varying in particle size, concentration, and coating on Hubbard x Cobb 500 broiler performance

\begin{tabular}{|c|c|c|c|c|c|c|}
\hline \multicolumn{3}{|c|}{ Treatment } & \multirow{2}{*}{$\begin{array}{c}\mathrm{D} 22 \\
\mathrm{BW}^{1} \\
(\mathrm{~kg} / \mathrm{bird})\end{array}$} & \multicolumn{3}{|c|}{ D11-22 } \\
\hline Particle Size (mm) & $\begin{array}{l}\text { Concentration } \\
\text { (FTU/kg) }\end{array}$ & Coating & & $\begin{array}{c}\mathrm{FI}^{2} \\
\text { (kg/bird) }\end{array}$ & $\begin{array}{c}\mathrm{LWG}^{3} \\
\text { (kg/bird) }\end{array}$ & $\begin{array}{l}\mathrm{FCR}^{4} \\
(\mathrm{~kg}: \mathrm{kg})\end{array}$ \\
\hline \multirow{4}{*}{1.5} & \multirow{2}{*}{500} & With & $0.893^{\mathrm{g}}$ & $0.989^{\text {ef }}$ & $0.667^{\mathrm{g}}$ & 1.515 \\
\hline & & Without & $0.930^{\mathrm{def}}$ & $0.994^{\text {defg }}$ & $0.704^{\text {cde }}$ & 1.414 \\
\hline & \multirow{2}{*}{3,000} & With & $0.954^{\text {bcd }}$ & $1.037^{\mathrm{abc}}$ & $0.722^{\mathrm{bc}}$ & 1.452 \\
\hline & & Without & $0.951^{\mathrm{bcd}}$ & $1.025^{\text {bcde }}$ & $0.726^{\mathrm{bc}}$ & 1.424 \\
\hline \multirow{4}{*}{2.0} & \multirow{2}{*}{500} & With & $0.914^{\mathrm{efg}}$ & $1.016^{\text {bcdef }}$ & $0.693^{\text {def }}$ & 1.472 \\
\hline & & Without & $0.907^{\mathrm{fg}}$ & $0.982^{\mathrm{f}}$ & $0.687^{\mathrm{efg}}$ & 1.437 \\
\hline & \multirow{2}{*}{3,000} & With & $0.934^{\text {cdef }}$ & $1.008^{\text {bcdefg }}$ & $0.713^{\text {bcd }}$ & 1.423 \\
\hline & & Without & $0.962^{\mathrm{bc}}$ & $1.027^{\mathrm{bcd}}$ & $0.729^{\mathrm{bc}}$ & 1.415 \\
\hline \multirow{4}{*}{2.5} & \multirow{2}{*}{500} & With & $0.920^{\mathrm{efg}}$ & $0.993^{\text {def }}$ & $0.696^{\text {def }}$ & 1.437 \\
\hline & & Without & $0.897^{\mathrm{g}}$ & $0.979^{\mathrm{g}}$ & $0.674^{\mathrm{fg}}$ & 1.467 \\
\hline & \multirow{2}{*}{3,000} & With & $0.937^{\text {cde }}$ & $1.003^{\text {cdefg }}$ & $0.714^{\text {bcd }}$ & 1.406 \\
\hline & & Without & $0.941^{\text {bcde }}$ & $1.017^{\text {bcdef }}$ & $0.714^{\mathrm{bcd}}$ & 1.432 \\
\hline \multicolumn{3}{|c|}{ Commercial Phytase @ 500 FTU/kg } & $0.966^{\mathrm{b}}$ & $1.042^{\mathrm{ab}}$ & $0.736^{\mathrm{b}}$ & 1.421 \\
\hline \multicolumn{3}{|c|}{ Commercial Phytase @ 3,000 FTU/kg } & $1.009^{\mathrm{a}}$ & $1.069^{\mathrm{a}}$ & $0.769^{\mathrm{a}}$ & 1.402 \\
\hline \multicolumn{3}{|c|}{ Negative Control } & $0.920^{\mathrm{efg}}$ & $1.001^{\text {cdefg }}$ & $0.690^{\operatorname{defg}}$ & 1.464 \\
\hline \multicolumn{3}{|c|}{ Positive Control } & $0.954^{\mathrm{bcd}}$ & $1.027^{\mathrm{bcd}}$ & $0.724^{\mathrm{bc}}$ & 1.430 \\
\hline \multicolumn{3}{|c|}{ P-Value } & $<0.0001$ & 0.0002 & $<0.0001$ & 0.0811 \\
\hline \multicolumn{3}{|c|}{ SEM $^{5}$} & 0.010 & 0.013 & 0.009 & 0.023 \\
\hline \multicolumn{7}{|c|}{ Particle Size Means } \\
\hline $1.5 \mathrm{~mm}$ & -- & -- & 0.932 & 1.011 & 0.705 & 1.451 \\
\hline $2.0 \mathrm{~mm}$ & -- & -- & 0.929 & 1.008 & 0.705 & 1.437 \\
\hline $2.5 \mathrm{~mm}$ & -- & -- & 0.924 & 0.998 & 0.700 & 1.435 \\
\hline \multicolumn{3}{|c|}{ Particle Size SEM ${ }^{5}$} & 0.0050 & 0.006 & 0.0046 & 0.0126 \\
\hline \multicolumn{7}{|c|}{ Concentration Means } \\
\hline-- & $500 \mathrm{FTU} / \mathrm{kg}$ & -- & $0.910^{\mathrm{b}}$ & $0.992^{\mathrm{b}}$ & $0.687^{\mathrm{b}}$ & $1.457^{\mathrm{a}}$ \\
\hline-- & $3,000 \mathrm{FTU} / \mathrm{kg}$ & -- & $0.946^{\mathrm{a}}$ & $1.020^{\mathrm{a}}$ & $0.720^{\mathrm{a}}$ & $1.425^{\mathrm{b}}$ \\
\hline \multicolumn{3}{|c|}{ Concentration $\mathrm{SEM}^{5}$} & 0.0041 & 0.005 & 0.0038 & 0.0103 \\
\hline \multicolumn{7}{|c|}{ Coating Means } \\
\hline-- & -- & With & 0.925 & 1.008 & 0.701 & 1.451 \\
\hline-- & -- & Without & 0.931 & 1.004 & 0.705 & 1.431 \\
\hline \multicolumn{3}{|c|}{ Coating SEM ${ }^{6}$} & 0.0041 & 0.005 & 0.0038 & 0.0103 \\
\hline \multirow{2}{*}{\multicolumn{3}{|c|}{ Particle Size }} & lity & & & \\
\hline & & & 0.5165 & 0.3623 & 0.6514 & 0.6180 \\
\hline \multicolumn{3}{|c|}{ Concentration } & $<0.0001$ & 0.0008 & $<0.0001$ & 0.0342 \\
\hline & Coating & & 0.3152 & 0.6114 & 0.4057 & 0.1920 \\
\hline Particle & e x Concentration $\times \mathrm{C}$ & & 0.0903 & 0.4630 & 0.1024 & 0.2535 \\
\hline $\begin{array}{l}{ }^{\mathrm{a}-\mathrm{g}} \text { Means wi } \\
{ }^{1} \mathrm{BW}=\text { Bird } \\
{ }^{2} \mathrm{FI}=\text { Feed } \\
{ }^{3} \mathrm{LWG}=\mathrm{Liv} \\
{ }^{4} \mathrm{FCR}=\text { Mor } \\
{ }^{5} \mathrm{SEM}=\text { Poo }\end{array}$ & $\begin{array}{l}\text { the same column with no } c \\
\text { ght } \\
\text { ke per bird } \\
\text { eight gain per bird } \\
\text { y corrected feed conversion } \\
\text { standard error of the mean }\end{array}$ & on superscript d & cantly $(\mathrm{P}<0.0$ & & & \\
\hline
\end{tabular}


Table 8. The effects of feeding finisher (d23-38) diets supplemented with corn-expressed phytase varying in particle size, concentration, and coating on Hubbard x Cobb 500 broiler performance

\begin{tabular}{|c|c|c|c|c|c|c|}
\hline \multicolumn{3}{|c|}{ Treatment } & \multirow{2}{*}{$\begin{array}{c}\text { D38 } \\
\text { BW }^{1} \\
\text { (kg/bird) }\end{array}$} & \multicolumn{3}{|c|}{ D23-38 } \\
\hline $\begin{array}{l}\text { Particle Size } \\
(\mathrm{mm})\end{array}$ & $\begin{array}{c}\text { Concentration } \\
(\mathrm{FTU} / \mathrm{kg})\end{array}$ & Coating & & $\begin{array}{c}\mathrm{FI}^{2} \\
\text { (kg/bird) }\end{array}$ & $\begin{array}{c}\mathrm{LWG}^{3} \\
\text { (kg/bird) }\end{array}$ & $\begin{array}{c}\mathrm{FCR}^{4} \\
(\mathrm{~kg}: \mathrm{kg})\end{array}$ \\
\hline \multirow{4}{*}{1.5} & \multirow{2}{*}{500} & With & $2.349^{\mathrm{cd}}$ & 2.636 & 1.422 & 1.900 \\
\hline & & Without & $2.388^{\mathrm{bcd}}$ & 2.570 & 1.444 & 1.811 \\
\hline & \multirow{2}{*}{3,000} & With & $2.389^{\mathrm{bcd}}$ & 2.572 & 1.428 & 1.821 \\
\hline & & Without & $2.391^{\mathrm{bcd}}$ & 2.549 & 1.433 & 1.799 \\
\hline \multirow{4}{*}{2.0} & \multirow{2}{*}{500} & With & $2.391^{\mathrm{bcd}}$ & 2.601 & 1.455 & 1.829 \\
\hline & & Without & $2.335^{\mathrm{d}}$ & 2.527 & 1.422 & 1.779 \\
\hline & \multirow{2}{*}{3,000} & With & $2.399^{\mathrm{bcd}}$ & 2.593 & 1.451 & 1.805 \\
\hline & & Without & $2.450^{\mathrm{ab}}$ & 2.637 & 1.489 & 1.773 \\
\hline \multirow{4}{*}{2.5} & \multirow{2}{*}{500} & With & $2.330^{\mathrm{d}}$ & 2.586 & 1.396 & 1.878 \\
\hline & & Without & $2.342^{\mathrm{cd}}$ & 2.635 & 1.405 & 1.948 \\
\hline & \multirow{2}{*}{3,000} & With & $2.338^{\mathrm{d}}$ & 2.540 & 1.387 & 1.845 \\
\hline & & Without & $2.387 b^{c d}$ & 2.615 & 1.438 & 1.825 \\
\hline \multicolumn{3}{|c|}{ Commercial Phytase @ 500 FTU/kg } & $2.452^{\mathrm{ab}}$ & 2.617 & 1.471 & 1.802 \\
\hline \multicolumn{3}{|c|}{ Commercial @ 3,000 FTU/kg } & $2.485^{\mathrm{a}}$ & 2.587 & 1.467 & 1.769 \\
\hline \multicolumn{3}{|c|}{ Negative Control } & $2.331^{\mathrm{d}}$ & 2.593 & 1.390 & 1.896 \\
\hline \multicolumn{3}{|c|}{ Positive Control } & $2.422^{\mathrm{abc}}$ & 2.620 & 1.460 & 1.812 \\
\hline \multicolumn{3}{|c|}{ P-Value } & 0.0028 & 0.8567 & 0.2507 & 0.0627 \\
\hline \multicolumn{3}{|c|}{ SEM $^{5}$} & 0.0292 & 0.043 & 0.0270 & 0.0384 \\
\hline \multicolumn{7}{|c|}{ Particle Size Means } \\
\hline $1.5 \mathrm{~mm}$ & -- & -- & 2.379 & 2.582 & 1.432 & $1.833^{\mathrm{ab}}$ \\
\hline $2.0 \mathrm{~mm}$ & -- & -- & 2.394 & 2.589 & 1.454 & $1.797^{\mathrm{b}}$ \\
\hline $2.5 \mathrm{~mm}$ & -- & -- & 2.349 & 2.594 & 1.407 & $1.874^{\mathrm{a}}$ \\
\hline \multicolumn{3}{|c|}{ Particle Size SEM ${ }^{5}$} & 0.0154 & 0.022 & 0.0145 & 0.0208 \\
\hline \multicolumn{7}{|c|}{ Concentration Means } \\
\hline-- & $500 \mathrm{FTU} / \mathrm{kg}$ & -- & $2.356^{\mathrm{b}}$ & 2.593 & 1.424 & 1.857 \\
\hline-- & 3,000 FTU/kg & -- & $2.392^{\mathrm{a}}$ & 2.584 & 1.438 & 1.811 \\
\hline \multicolumn{3}{|c|}{ Concentration SEM $^{5}$} & 0.0126 & 0.018 & 0.0118 & 0.0170 \\
\hline \multicolumn{7}{|c|}{ Coating Means } \\
\hline-- & -- & With & 2.366 & 2.588 & 1.423 & 1.846 \\
\hline-- & -- & Without & 2.382 & 2.589 & 1.439 & 1.822 \\
\hline \multicolumn{3}{|c|}{ Coating SEM $^{5}$} & 0.0126 & 0.018 & 0.0118 & 0.0170 \\
\hline \multicolumn{7}{|c|}{ Probability } \\
\hline \multicolumn{3}{|c|}{ Particle Size } & 0.1233 & 0.9313 & 0.0742 & 0.0391 \\
\hline & Concentration & & 0.0456 & 0.7445 & 0.4125 & 0.0591 \\
\hline & Coating & & 0.3725 & 0.9701 & 0.3714 & 0.3246 \\
\hline Particle $\mathrm{Si}$ & x Concentration & Coating & 0.6231 & 0.3666 & 0.8600 & 0.6453 \\
\hline $\begin{array}{l}{ }^{\mathrm{a}-\mathrm{d}} \mathrm{Mea} \\
{ }^{1} \mathrm{BW}= \\
{ }^{2} \mathrm{FI}=\mathrm{I} \\
{ }^{3} \mathrm{LWG} \\
{ }^{4} \mathrm{FCR}= \\
{ }^{5} \mathrm{SEM}=\end{array}$ & $\begin{array}{l}\text { within the same colur } \\
\text { ird weight } \\
\text { ed intake per bird } \\
\text { Live weight gain per b } \\
\text { Mortality corrected fee } \\
\text { Pooled standard error }\end{array}$ & $\begin{array}{l}\text { version ratic } \\
\text { mean }\end{array}$ & iipt differ sign & 05) & & \\
\hline
\end{tabular}




\section{CHAPTER 4}

Corn-Expressed Phytase Product Coating and Concentration Effects on D1-38 Broiler Performance, Toe Ash, and Tibia Ash

J.W. Boney ${ }^{1}$, B.G. Glover ${ }^{1}$, A.N. Bergeron ${ }^{1}$, H.L. Baldwin ${ }^{1}$, J.N. Broomhead ${ }^{2}$, and J.S. Moritz ${ }^{1, ¥}$

${ }^{1}$ Division of Animal and Nutritional Sciences, West Virginia University, Morgantown, West Virginia, 26506

Phone: 304-293-1911

Fax: 304-293-2232

${ }^{2}$ Agrivida Inc., Boston, MA

${ }^{\ddagger}$ Corresponding Author: Joe.Moritz@mail.wvu.edu

Primary Audience: Feed Manufacturers, Nutritionists, Researchers 
SUMMARY Cereal grains expressing enzymatic activity may provide integrators with additional options to support dietary phosphorus requirements in growing broilers. The objectives of this study were to describe the effects of phosphorus $(\mathrm{P})$ deficient diets supplemented with various corn-expressed phytase (CEP) product coatings and concentrations on $38 \mathrm{~d}$ broiler performance and bone mineralization. Treatments were arranged in a $5 \times 2$ factorial that varied in proprietary CEP coating technique (Product 1- Product 5) and concentration (500 or 1,500 FTU/kg). Positive and negative control diets, varying in non-phytate $\mathrm{P}\left(0.46 \%\right.$ vs $0.25 \%$ respectively), were also fed. Diets were steam conditioned at $85^{\circ} \mathrm{C}$ for $10 \mathrm{~s}$, extruded through a $4.7 \times 38 \mathrm{~mm}$ pellet die, and provided as crumbles or pellets, based on age. Treatments were provided to eight replicate pens of 26 straight-run Hubbard x Cobb 500 broilers. Data were analyzed as a factorial that included 10 treatments and a multiple comparison that included 12 treatments. Product coating affected FI and LWG, decreasing consumption and gains when broilers were provided either Product 1 or Product $4(\mathrm{P}<0.05)$. Broilers fed CEP at $1,500 \mathrm{FTU} / \mathrm{kg}$ increased FI by $259 \mathrm{~g}$ per bird ( $\mathrm{P}<0.0001)$, LWG by $240 \mathrm{~g}$ per bird $(\mathrm{P}<0.0001)$, and all bone mineralization metrics $(\mathrm{P}<0.05)$, relative to those fed $\mathrm{CEP}$ at 500 FTU/kg. Multiple comparison analyses show PC fed birds improved performance above NC fed birds $(\mathrm{P}<0.05)$. Optimizing proprietary coating techniques and dietary concentrations of CEP may liberate bound $\mathrm{P}$ in the diet, improving both performance and mineralization.

KEYWORDS: phytase, concentration, performance, tibia, toe 


\section{DESCRIPTION OF PROBLEM}

Just as phytase manufacturers have addressed thermal denaturation concerns with the selection of inherently stable enzyme expressing organisms and the addition of carbohydratelipid coatings, grain-expressed phytase manufacturers must address similar issues. Phytase derived broiler performance improvements through increased phosphorus $(\mathrm{P})$ utilization and environmental benefits stemming from decreased excreta mineral are represented throughout the literature [1-7]. Feed additive advancements have resulted in new products that were developed to assist nutritionists in more closely meeting animal requirements. Engineering corn to express phytase activity may provide an alternative to achieving maximal $\mathrm{P}$ utilization and minimal $\mathrm{P}$ excretion.

Denaturation of mixer-added enzymes generally occurs during the feed manufacturing process, more specifically during a variety of thermal processing techniques and subsequent extrusion processes. Denaturation is defined as the unfolding of the enzyme tertiary structure to a disordered polypeptide [8]. The widely accepted Lumry-Eyring approach describes enzyme inactivation as a two-step phenomenon: reversible unfolding of the enzyme and a kinetically irreversible aggregation or covalent change of the enzyme [9]. One technique used to maximize phytase efficacy is the addition of a lipid or carbohydrate coating that encapsulates the phytase to minimize oxidation at high pelleting temperatures [10]. Other techniques included granulation or post-pellet enzyme application. Coating of phytases has been shown to improve heat stability; however, coating may compromise the release and function of the enzyme [11]. Therefore, enzyme application feasibility is dependent on enzyme stability against temperature, $\mathrm{pH}$ extremes, and the presence of salts, alkalis, and surfactant [8]. 
More recently, dietary concentrations of phytase enzymes have been studied. Campasino et al. reported that supplementation beyond the need for $\mathrm{P}$ enhances growth performance and carcass characteristics [4]. Gehring et al. reported FCR improvements with 1,500 FTU/kg of phytase compared to $500 \mathrm{FTU} / \mathrm{kg}$ of phytase, suggesting an extraphosphoric effect [5]. Phytase may reduce the onset of an immune response and improve gut health [12]. Some speculation suggests that performance benefits associated with super-doses of phytase may be a result of reducing phytate $\mathrm{P}$ gastrointestinal irritation [1]. Therefore, understanding phytase dose effects is essential when optimizing grain expressed phytase inclusions.

The concept of determining bone ash has been practiced for many years as a means of determining phytase efficacy. The Association of Official Analytical Chemists (AOAC) method for bone ash determination includes the use of dried and defatted tibia, a process that requires substantial time, labor, and potentially harmful materials. Garcia and Dale explain that this method was simply adopted and never critically compared to other possible assays [13]. In order to reduce labor, time, and the use of harmful chemicals, other mineralization methods, such as foot ash and toe ash have been studied. Comparisons between the various methods suggest similar precision [13-14]. In an effort to expedite data generation, the current study utilized initial toe ash data and later confirmed differences using tibia ash results. The objectives of the current study were to determine the effects of variations to CEP product coating and concentration on d1-38 broiler performance and bone mineralization, determined using both toe ash and tibia ash measures.

\section{MATERIALS AND METHODS}

Experimental diets were corn and soybean meal based and varied in corn-expressed phytase (CEP) coating and dietary concentration. Positive and negative control diets were also 
included for treatment comparisons. Treatments were arranged in a $5 \times 2$ factorial with the main effects of phytase coating (Product 1- Product 5) and concentration (500 FTU/kg or 1,500 FTU $/ \mathrm{kg}$ ). Overall, 12 dietary treatments were utilized in the randomized complete block design.

The scope of this experiment was to optimize metrics associated with proprietary CEP coating techniques. Product 1, Product 2, and Product 3 consisted of carbohydrate-lipid coating variants while Product 4 consisted of an uncoated CEP product. Product 5 was a commercially available [15], coated, and granulated phytase product. All products were included to the negative control $(\mathrm{NC})$ diet formulation $(0.25 \% \mathrm{nPP})$ at varying concentrations.

All feed was manufactured at the West Virginia University pilot feed mill utilizing a 40 HP California Pellet Mill [16]. Master batches of the NC diet were split into 11 equal allotments. A single positive control (PC) master batch was prepared separately. A small portion of feed was removed from each allotment and individually placed in a Hobart mixer [17]. Phytase products were added at the expense of sand, and allowed to mix for 10 minutes. Each $\mathrm{NC}$ feed allotment was individually placed in a vertical screw mixer [18] along with the portion of feed/phytase mixture and allowed to mix for 10 minutes. Mixed feed was then conveyed to the pellet mill where diets were steam conditioned at $85^{\circ} \mathrm{C}$ for 10 seconds and extruded through a 4.7 x $38 \mathrm{~mm}$ pellet die. Hot pellet temperature (HPT) was measured by collecting extruded pellets in an insulated container and using a thermocouple thermometer [19] and an 80PK-24 temperature probe. Pellet durability was determined 24 hours post-pelleting using a New Holmen Pellet Tester [20], for all treatments, across all three growth periods. Starter and grower period diets were passed through a roller mill and provided as crumbled pellets while finisher period diets were provided as intact pellets. Feed samples for each treatment and growth period were collected for mineral analyses [21]. Mash and pelleted feed samples from each treatment in 
the finisher period were analyzed for phytase activity determination using the AOAC 2000.12 method [22-23].

A total of 2,496 Hubbard x Cobb straight-run, day old chicks were obtained from a commercial hatchery [24], weighed, and placed in one of 96 floor pens at a count of 26 broilers per pen. The 12 dietary treatments were randomly allotted to adjacent pens blocked by location within the barn located at the West Virginia University Animal Science Farm. Each dietary treatment was applied to eight replicate pens of broilers. Feed and water were provided ad libitum and local commercial temperature and lighting manipulations were utilized throughout the $38 \mathrm{~d}$ trial. Broilers were weighed as a pen at the end of the starter and grower periods. Following grower period (d22) pen weight determination, three broilers per pen were randomly selected and euthanized via cervical dislocation. Expired broiler weights were recorded prior to middle toe and tibia excision from the left leg. Middle toe excision occurred by separating the joint between the second and third tarsal bones from the distal end. The experimental unit size then decreased to 23 birds per pen, less mortality, when birds were placed on finisher diets. On d 38 broilers were separated by sex and weighed individually. From each pen, three male broilers $\pm 100 \mathrm{~g}$ of the male broiler mean weight were euthanized via cervical dislocation and the left middle toe and tibia were excised using the aforementioned methods. Toes and tibiae were dried at $105^{\circ} \mathrm{C}$ for 48 hours. Dried toes were placed in a muffle furnace at $600^{\circ} \mathrm{C}$ for 18 hours. The lipid fraction was extracted from tibiae by refluxing petroleum ether over dried tibiae in a soxhlet tube apparatus for 16 hours. Dried and fat extracted tibiae were then placed in a muffle furnace at $600^{\circ} \mathrm{C}$ for 18 hours. All animals were reared in accordance with protocols established by the West Virginia University Animal Care and Use Committee [ACUC 15-0408]. 


\section{Statistical Analysis}

Treatments were arranged in a 5 (product) x 2 (concentration) factorial. Positive and negative control diets were also included for treatment comparisons. All 12 treatments were arranged in a randomized complete block design and analyzed using the GLM procedure of SAS [25]. Blocking criterion was location within the research facility and alpha was designated as 0.05. Main effect interactions were also considered. A Fisher's LSD test was employed to further explore significant multiple comparison analyses.

\section{RESULTS AND DISCUSSIONS}

\section{Feed Manufacture}

Growth period specific diet formulations can be found in Table 1 with descriptive feed manufacturing analyses corresponding to each growth period located in Table 2. Generally, pellet durability was highest during the starter period and decreased with subsequent growth periods. Decreasing crude protein [26] and increasing metabolizable energy with soybean oil inclusions [27] have been shown to decrease pellet quality and likely contributed to the decreased pellet quality in the current study.

\section{Phytase Activity}

Phytase activity was determined for both unprocessed mash and pelleted feed (Table 3). Average post-pelleting phytase retention for diets that were formulated to contain coated CEP at $500 \mathrm{FTU} / \mathrm{kg}$ was $58 \%$ while average retention increased to $63 \%$ when diets were formulated to contain coated CEP at 1,500 FTU/kg. When considering post-pelleting activity retention for the uncoated CEP product, average retention was $48 \%$ and $37.5 \%$ when diets were formulated to 500 and 1,500 FTU/kg, respectively. The commercial phytase retention ranged from 84 to over $100 \%$, as previous product testing optimized retention. However, averaging analyzed phytase 
activity across all three growth periods and dietary treatments indicated an average difference of $494 \mathrm{FTU} / \mathrm{kg}$ between diets formulated to contain 500 and 1,500 FTU/kg inclusions of phytase (Table 3). Considering that activity determination was not replicated and was presented as descriptive data, previously reported phytase activity variations [6] may have contributed to these average retention value differences. Understanding phytase activity retention and activity determination variations is essential for product optimization. Inconsistent retention values may contribute to insufficient $\mathrm{P}$ release, which is documented in the literature [28]. Furthermore, Loop et al. reported that evaluations of phytases should include in vivo bird testing beyond in vitro activity assays to fully assess phytase efficacy [6].

\section{Overall Period (d1-38) Broiler Performance}

Main effects did not interact to affect the overall period live bird performance $(\mathrm{P}>0.05)$. Phytase product coating affected feed intake (FI) such that birds provided Product 5 numerically consumed the most feed. Birds that were provided Products 2 and 3 consumed similar amounts as those fed Product 5, whereas birds provided Products 1 and 4 consumed less feed $(\mathrm{P}<0.05)$ (Table 5). Additionally, birds that were provided phytase at 1,500 FTU/kg of the diet consumed, on average, $259 \mathrm{~g}$ per bird more than birds that were provided phytase at $500 \mathrm{FTU} / \mathrm{kg}$ of the diet $(\mathrm{P}<0.0001)$. Boney and Moritz reported no difference in FI when studying diet composition and phytase inclusions $(\mathrm{D} 1-10 \mathrm{nPP}=0.60)[1]$. Perhaps, current study non-phytate $\mathrm{P}(\mathrm{nPP})$ values utilized for the NC diet presented true P deficiencies, presenting more evident differences. Live weight gain (LWG) was affected by both main effects. Birds that were provided Product 5 demonstrated the highest LWG while birds that were provided either Product 1 or Product 4 demonstrated the least LWG $(\mathrm{P}<0.05)$. Products 2 and 3 yielded intermediate $\mathrm{LWG}(\mathrm{P}<0.05)$. Similar to FI, birds that were provided CEP at 1,500 FTU/kg improved LWG, on average, by 
$240 \mathrm{~g}$ per bird, relative to birds provided CEP at $500 \mathrm{FTU} / \mathrm{kg}$. Feed conversion ratio (FCR) was not affected by phytase product or concentration $(\mathrm{P}>0.05)$. Mortality was corrected to account for the three birds per pen that were removed on $\mathrm{d} 21$. These birds were weighed and used in subsequent mortality corrected FCR calculations. Corrected mortality results show that birds provided Product 5 had the lowest mortality percentage while birds provided Product 4 had the highest mortality percentage. All other products were intermediate $(\mathrm{P}<0.05)$. Mortality results may be explained due to Product 5 being a commercially available and previously optimized for maximal P release. Furthermore, Product 4 was an uncoated CEP, potentially hindering $\mathrm{P}$ release from the diet following steam conditioning and pelleting. Phytase concentration affected mortality percentage $(\mathrm{P}=0.0070)$ by decreasing mortality when birds were provided elevated levels of phytase (Table 5). Gehring et al. reported contradicting results where no mortality differences were apparent between varying levels of phytase supplementation to a NC diet (D1$14 \mathrm{nPP}=0.33$ ) [5]. Differences in mortality results may be explained by the differences in $\mathrm{nPP}$ values, affecting the degree of P deficiency.

Multiple comparison analysis of the 12 dietary treatments demonstrated that the positive and negative control diets differed for all measured variables. Birds that were provided phytase increased FI and LWG above the NC, regardless of product and concentration. These results indicate P deficiencies in the NC, ultimately providing an ideal model for determining phytase efficacy. It is well documented that phytase inclusion to $\mathrm{P}$ deficient diets increases growth performance metrics $[1,2,4,5,29]$. Feed intake was highest when birds were provided the PC. Birds that were provided 1,500 FTU/kg of Product 3 and Product 5 consumed similar amounts of feed as the PC birds. Feed intake was lowest when broilers were provided the NC diet. All other treatments were intermediate $(\mathrm{P}<0.05)$ (Table 5). Campasino et al. reported similar FI results 
when comparing differing concentrations of phytase ranging from 400 to $1,600 \mathrm{FTU} / \mathrm{kg}$ [4].

Live weight gain was highest when birds were provided the PC and lowest when birds were provided the NC. All other treatments were intermediate $(\mathrm{P}<0.05)$. Broilers were most feed efficient when provided the PC treatment. Birds provided either 500 or 1,500 FTU/kg of Product 5 were similarly feed efficient. Birds that were provided the NC were least feed efficient $(\mathrm{P}<0.05)$ (Table 5). Multiple comparison analyses validated an adequate phytase testing model as phytase addition resulted in significantly better performance. Furthermore, elevated inclusions of a commercially available product (Product 5) was not able to liberate $\mathrm{P}$ to a degree that resulted in similar LWG and FCR to that of the PC.

\section{Overall Period (d1-38) Bone Mineralization}

Toe ash and tibia ash data are displayed in Table 6. Toe ash has been shown to have a linear relationship with tibia ash, however subjectivity in sample collection may magnify errors [30]. Furthermore, Scholey and Burton concluded that care must be taken when collecting toe ash to ensure consistency [31]. Both measures were recorded for the current study without regard to correlation between collection methods. Product coating main effects demonstrate that birds provided Product 5 had the highest toe ash and birds consuming all other products resulted in decreased toe ash $(\mathrm{P}<0.05)$. Additionally, birds that were provided CEP at 1,500 FTU/kg increased toe ash compared to those provided CEP at $500 \mathrm{FTU} / \mathrm{kg}(\mathrm{P}=0.0068)$. These results differ from toe ash work conducted by Cabahug et al. utilizing wheat based diets and phytase inclusions differing by $400 \mathrm{FTU} / \mathrm{kg}$ per treatment [32]. Perhaps, dietary substrate and phytase inclusion interact to affect toe ash measures. Additionally, subjectivity in toe sampling may have played a role in the sensitivity of these measures. Day 38 tibia ash and mg tibia ash per bird were similar to toe ash (Table 6). Birds that were provided Product 5 increased both metrics 
while birds provided Product 1 and Product 4 decreased tibia ash percentage and mg of tibia ash. All other products were intermediate $(\mathrm{P}<0.05)$. Moreover, birds that were provided phytase at $1,500 \mathrm{FTU} / \mathrm{kg}$ increased tibia mineralization when compared to birds provided phytase at 500 FTU/kg. Malloy et al. reported increased d 42 tibia ash when broilers were provided a PC diet or a NC diet supplemented with phytase, relative to a NC diet. Interestingly, these authors reported no improvements in tibia ash measures when phytase concentrations increased (500-2,500 FTU/kg) [33]. Conversely, Malloy et al. reported d21 tibia ash improvements above the NC when phytase was included at 300 and $500 \mathrm{FTU} / \mathrm{kg}$. Additional d 21 tibia ash improvements above the NC and NC diets supplemented with 300 and $500 \mathrm{FTU} / \mathrm{kg}$ were noted when the NC diet was supplemented with phytase at 1,000 and 2,500 FTU/kg, resulting in similar tibia ash as broilers provided the PC diet [33]. Perhaps, the sensitivity of the toe ash measurement may be affected by broiler age.

Multiple comparison analysis of $\mathrm{d} 38$ bone mineralization variables show that bone mineralization followed broiler performance patterns. Birds provided the PC diet demonstrated the most bone mineralization while birds that were provided Product 5 at 1,500 FTU/kg had similar toe and tibia mineralization. Birds consuming the NC had the lowest ash. All other treatments were intermediate for bone mineralization metrics $(\mathrm{P}<0.05)$.

\section{Starter Period (d1-10) Broiler Performance}

Starter period performance results are displayed in Table 7. Similar to the overall period results, birds provided Product 2, Product 3, and Product 5 all consumed similar amounts of feed with birds provided Product 3 numerically consuming the most feed $(\mathrm{P}<0.05)$. Birds that were provided Product 4 had the lowest FI, $11 \mathrm{~g}$ per bird less than birds provided Product 3 . Feed intake tended to be higher when birds were provided phytase at 1,500 FTU/kg compared to 500 
FTU/kg $(\mathrm{P}=0.0501)$. Starter period data demonstrated $7 \mathrm{~g}$ per bird LWG increase $(\mathrm{P}=0.0003)$ and a 3.7 point FCR decrease $(\mathrm{P}=0.0148)$ when birds were provided elevated inclusions of phytase. Once again, similar to the overall period, multiple comparison analyses showed PC fed birds had increased FI and LWG while NC fed birds decreased these metrics $(\mathrm{P}<0.05)$.

\section{Grower Period (d11-21) Broiler Performance}

Grower period results are displayed in Table 7. The main effect of phytase concentration affected FI, LWG, and FCR in a similar manner as in the overall (d1-38) period, increasing FI and LWG when birds were provided phytase at 1,500 FTU/kg relative to birds that were provided phytase at $500 \mathrm{FTU} / \mathrm{kg}(\mathrm{P}<0.0001)$, while having no effect on $\mathrm{FCR}(\mathrm{P}=0.1374)$. Multiple comparison analyses showed that birds fed the PC consumed, on average, $297 \mathrm{~g}$ per bird more than NC fed birds. Birds fed Product 5 at 1,500 FTU/kg consumed similar amounts of feed as PC fed birds and all other treatment combinations were intermediate $(\mathrm{P}<0.05)$. Bird LWG was affected similarly, increasing average gains by $244 \mathrm{~g}$ per bird when PC fed birds were compared to NC fed birds. Yet again, birds provided Product 5 at 1,500 FTU/kg had similar gains as $\mathrm{PC}$ fed birds $(\mathrm{P}<0.05)$.

\section{Bone Mineralization (d21)}

Results from d21 toe ash and tibia ash can be found in Table 6 . Unlike the overall period results, toe ash was not affected by either main effect $(\mathrm{P}>0.05)$. Standard error of the mean for each main effect was higher on $\mathrm{d} 21$ than $\mathrm{d} 38$. This increase in error likely contributed to the lack of statistical differences for $\mathrm{d} 21$ toe ash. Although an extraction protocol was followed, variations to individual extraction techniques may have contributed to increased error. This speculation is supported by Garcia and Dale who reported that the portion of bone most sensitive to mineralization differences are the proximal and distal ends, which contain growth plates [13]. 
Even minimal variations to extraction techniques could contribute to error. Tibia ash and mg tibia ash per bird were affected by both CEP product and concentration. Birds that were provided Product 5 demonstrated higher tibia ash percentage and mg tibia ash per bird $(\mathrm{P}<0.0001)$ than all other CEP products. Birds provided phytase concentrations of 1,500 FTU/kg increased d21 tibia ash and mg tibia ash per bird $(\mathrm{P}<0.0001)$ when compared to birds provided CEP at 500 FTU/kg. Tang et al reported similar d21 tibia mineralization results where phytase included at $250 \mathrm{FTU} / \mathrm{kg}$ increased tibia ash above the NC. Further increases in phytase concentration increased tibia ash percentage, which yielded similar tibia ash values as birds provided the PC [30]. Multiple comparison analysis demonstrated that PC fed birds had increased $\mathrm{d} 21$ bone mineralization relative to $\mathrm{NC}$ fed birds, with other treatment combinations being intermediate $(\mathrm{P}<0.05)$.

\section{Finisher Period (d22-38) Broiler Performance}

Finisher period broiler performance results are displayed in Table 7. Finisher period FI and LWG results were similar to the overall period results. Feed intake decreased when birds were provided either Product 1 or Product 4, relative to all other products $(\mathrm{P}<0.05)$. Live weight gain decreased when broilers were provided either Product 1 or Product 4, relative to birds fed Product 5. Birds fed Product 2 and Product 3 were intermediate $(\mathrm{P}<0.05)$. Birds that were fed diets containing phytase at 1,500 FTU/kg increased average FI by 186 g per bird and average LWG by 178 g per bird $(\mathrm{P}<0.0001)$. Feed conversion ratio was not affected by either main effect in the finisher period $(\mathrm{P}>0.05)$. Multiple comparison analyses show PC fed birds increased performance metrics when compared to NC fed birds. All other treatment combinations were intermediate $(\mathrm{P}<0.05)$. The current study demonstrates that optimizing a novel phytase product requires an adequate phytase efficacy testing model which may allow differences to become 
apparent when comparing coating techniques and concentrations on activity retention, broiler

performance, and bone mineralization.

\section{CONCLUSIONS AND APPLICATIONS}

1. Multiple comparison analyses of all 12 treatments for the starter, grower, finisher, and overall periods indicated phytase inclusion benefits, increasing all performance and mineralization metrics above those of the negative control.

2. Birds that were provided the commercially available, coated and granulated phytase product (Product 5) increased d1-38 LWG, relative to birds provided all other product coating variants. However, d1-38 FCR was similar, regardless of product coating or concentration.

3. Increased standard error of the mean likely contributed to the lack of differences for $\mathrm{d} 21$ toe ash. Considering the sensitivity to toe ash measures and the lack of standardized analysis instructions, it may be beneficial to consider tibia ash measures.

4. Optimizing proprietary coating techniques and dietary concentrations of corn-expressed phytase may allow for better activity post-pelleting and improve substrate interaction to liberate bound $\mathrm{P}$ in the diet, improving performance and bone mineralization.

\section{REFERNECES AND NOTES}

1. Boney, J.W. and J.S. Moritz. 2017. Phytase dose effects in practically formulated diets that vary in ingredient composition on feed manufacturing and broiler performance. J. Appl. Poult. Res. 26:273-285.

2. Shaw, A.L., J.B. Hess, J.P. Blake, and N.E. Ward. 2011. Assessment of experimental phytase enzyme product on live performance, bone mineralization, and phosphorus excretion in broiler chickens. J. Appl. Poult res. 20:561-566.

3. Evans, A.M., J.B. Boney, and J.S. Moritz. 2017. The effect of poultry litter biochar on pellet quality, one to $21 \mathrm{~d}$ broiler performance, digesta viscosity, bone mineralization, and apparent ileal amino acid digestibility. J. Appl. Poult res. 26:8998.

4. Campasino, a. T. York, C. Wyatt, M.R. Bedford, and W.A. Dozier, III. 2014. Effect of increasing supplemental phytase concentration in diets fed to Hubbard x Cobb 500 male broilers from 1 to 42 days of age. J. Appl. Poult. Res 23:705-714. 
5. Gehring, C.K., M.R. Bedford, and W.A. Dozier, III. 2014. Effects of step-up and step-down phytase regimens on performance and processing yields of male broilers from 1 to $35 \mathrm{~d}$ of age. J. Appl. Poult. Res. 23:252-259.

6. Loop, S.A., K.G.S. Lily, L.K. Shires, C.K. Gehring, K.R. Beaman, M.E. Persia, and J.S. Moritz. 2012. The phytase analytical activity of pelleted diets may not adequately describe efficacy in the bird. J. Appl. Poult. Res. 21:492-501.

7. dos Santos, T.T., C.L. Walk, and S. Srinongkote. 2014. Influence of phytate level on broiler performance and the efficacy of 2 microbial phytases from 0 to 21 days of age. J. Appl. Poult. Res. 23:181-187.

8. Iyer, P.V. and L. Ananthanarayan. 2008. Enzyme stability and stabilization- aqueous and non-aqueous environment. Proc. Biochem. 43:1019-1032.

9. Lumry, R. and H. Eyring. 1954. Conformation Changes of Proteins. J. Phys. Chem. 58:110-120.

10. Sulabo, R.C., C.K. Jones, M.D. Tokach, R.D. Goodband, S.S. Dritz, D.R. Campbell, B.W. Ratliff, J.M. DeRouchey, and J.L. Nelssen. 2011. Factors affecting storage stability of various commercial phytase sources. J. Anim. Sci. 89:4262-4271.

11. Lei, X.G. and J.M. Porres. 2003. Phytase enzymology, applications, and biotechnology. Biotechnol. Letters 25:1787-1794.

12. Pirgozliev, V.O., O. Oduguwa, T. Acamovic, and M.R. Bedford. 2007. Diets containing Escherichia coli- derived phytase on young chickens and turkeys: Effects on performance, metabolizable energy, endogenous secretions, and intestinal morphology. Poult. Sci. 86:705-713.

13. Garcia, A.R. and N. Dale. 2006. Foot ash as a means of quantifying bone mineralization in chicks. Poult. Sci. 15:103-109.

14. Yoshida, M., and H. Hoshii. 1983. Relationship between ash content s of the tibia bone and the toe of chicks. Jpn. Poult. Sci. 20:51-54.

15. Axtra®Phy, Danisco Animal Nutrition/DuPont, Marlborough, Wilshire, UK.

16. Master Model Pellet Mill, California Pellet Mill Company, Crawfordsville, IN.

17. Hobart Mixer Hobart paddle mixer (model 4146) Hobart Corp., Troy, OH.

18. MFP Vertical Mixer, Easy Automation Inc., Welcome, MN.

19. Fluke 51 II, Everette, WA.

20. New Holmen Portable Pellet Durability Tester, Lignotech USA, Inc., Rothschild, WI.

21. NP Analytical Laboratories, St. Louis, MO.

22. AOAC. 2000. Method 2000.12: Phytase activity in feed: Colorimetric enzymatic

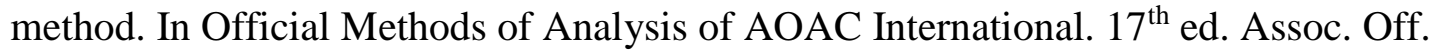
Anal. Chem., Arlington, VA. A 50-g sample was extracted with $500 \mathrm{~mL}$ of distilled water containing $0.01 \%$ Tween 20 . A $100-\mu \mathrm{L}$ extract was diluted with $300 \mathrm{~mL}$ of acetate buffer until reaching $\mathrm{pH}$ 5.5. After pre-incubation of the diluted extract at $37^{\circ} \mathrm{C}, 0.8 \mathrm{~mL}$ of sodium phytate was added, and the sample was incubated for $30 \mathrm{~min}$ at $37^{\circ} \mathrm{C}$. The reaction was stopped via addition of $0.8 \mathrm{~mL}$ of molybdate-vanadate stop reagent. A blank was included, and after its pre-incubation, the stop reagent was added before the addition of the substrate. The yellow complex was measured colorimetrically at $415 \mathrm{~nm}$. The value obtained from the blank was then subtracted 
from the sample value, and the phosphate released was quantified with a phosphate standard curve.

23. Eurofins Nutritional Analysis Center, Des Moines, IA.

24. Pilgrim's Pride Corporation, Moorefield, WV.

25. SAS Institute. 2017. The SAS System for Windows 2017. Release 9.4. SAS Inst. Inc., Cary, NC.

26. Buchanan, N.P., K.G.S. Lilly, C.K. Gehring, and J.S. Moritz. 2010. The effects of altering diet formulation and manufacturing technique on pellet quality. J. Appl. Poult. Res. 19:112-120.

27. Wamsley, K.G.S. and J.S. Moritz. 2013. Resolving poor pellet quality and maintaining amino acid digestibility in commercial turkey diet feed manufacture. J. Appl. Poult. Res. 22:439-446.

28. Bedford, M.R., C.L. Walk, and H.V. Masey O’Neill. 2016. Assessing measurements in feed enzyme research: Phytase evaluation in broilers. J. Appl. Poult Res. 25:305314.

29. Shirley, R.B. and H.M Edwards. 2003. Graded Levels of Phytase Past Industry Standards Improves Broiler Performance. Poult. Sci. 82:671-680.

30. Tang, H.O., X.H. Gao, F. Ji, S. Tong, and X.J. Li. 2012. Effects of thermostable phytase on the growth performance and bone mineralization of broilers. J. Appl. Poult. Res. 21:476-483.

31. Scholey, D.V. and E.J. Burton. 2017. The effect of bone choice on quantification of mineralization in broiler chickens up to 6 weeks of age. J. Appl. Poult. Res. 0:1-6.

32. Cabahug, S., V. Ravindran, P.H. Selle, and W.L. Bryden. 1999. Response of broiler chickens to microbial phytase supplementation as influenced by dietary phytic acid and non-phytate phosphorus contents. I. Effects on bird performance and toe ash. Br. Poult. Sci. 40:660-666.

33. Malloy, M.N., A.G. Stephens, M.E. Freeman, M.K. Jones, J.M. Faser, N.M. Dale, and A.J. Davis. 2017. Foot ash can replace tibia ash as a quantification method for bone mineralization in broilers at 21 and 42 days of age. J. Appl. Poult. Res. 26:175182.

34. Angel, R., N.M. Tamim, T.J. Applegate, A.S. Dhandu, and L.E. Ellestad. 2002. Phytic acid chemistry: Influence on phytin-phosphorous availability and phytase efficacy. J. Appl. Poult. Res. 11:471-480.

35. M. Donohue. 2013. The Challenges in Feeding Broilers in Times of High and Volatile Feed Ingredient Costs: How to Cover the Costs?. 2013 Mid-Atlantic Nutrition Conference proceedings.

36. P. B. Tillman and W.A. Dozier. 2013. Current Amino Acid Considerations for Broilers: Requirements, Ratios, Economics. www.thepoultryfederation.com 
Table 1. Diet composition of positive and negative control diets ${ }^{1}$ for starter, grower, and finisher periods

\begin{tabular}{|c|c|c|c|c|c|c|}
\hline \multirow{3}{*}{ Ingredient } & \multicolumn{2}{|c|}{ Starter (D1-10) } & \multicolumn{2}{|c|}{ Grower (D11-21) } & \multicolumn{2}{|c|}{ Finisher (D22-38) } \\
\hline & $\begin{array}{l}\text { Positive } \\
\text { Control }\end{array}$ & $\begin{array}{c}\text { Negative } \\
\text { Control }\end{array}$ & $\begin{array}{l}\text { Positive } \\
\text { Control }\end{array}$ & $\begin{array}{c}\text { Negative } \\
\text { Control }\end{array}$ & $\begin{array}{l}\text { Positive } \\
\text { Control }\end{array}$ & $\begin{array}{c}\text { Negative } \\
\text { Control }\end{array}$ \\
\hline & \multicolumn{2}{|r|}{ 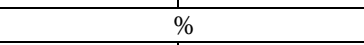 } & \multicolumn{2}{|r|}{ 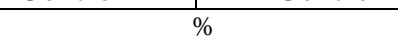 } & \multicolumn{2}{|c|}{$\%$} \\
\hline Corn & 51.68 & 52.58 & 56.05 & 56.99 & 57.92 & 58.77 \\
\hline Soybean Meal (48\%) & 34.58 & 34.50 & 30.32 & 30.20 & 28.68 & 28.58 \\
\hline Corn DDGS & 5.00 & 5.00 & 5.00 & 5.00 & 5.00 & 5.00 \\
\hline Soybean Oil & 3.74 & 3.45 & 4.13 & 3.84 & 4.56 & 4.29 \\
\hline Limestone & 1.81 & 2.22 & 1.67 & 2.07 & 1.54 & 1.91 \\
\hline DL-Methionine & 0.49 & 0.49 & 0.37 & 0.37 & 0.23 & 0.23 \\
\hline Dicalcium Phosphate & 1.45 & 0.52 & 1.30 & 0.37 & 1.13 & 0.29 \\
\hline Salt & 0.27 & 0.27 & 0.30 & 0.30 & 0.30 & 0.30 \\
\hline Vitamin/Mineral Premix $^{2}$ & 0.25 & 0.25 & 0.25 & 0.25 & 0.25 & 0.25 \\
\hline Sodium Bicarbonate & 0.10 & 0.10 & 0.10 & 0.10 & 0.10 & 0.10 \\
\hline L-Lysine $\mathrm{HCl}$ & 0.21 & 0.21 & 0.21 & 0.21 & 0.13 & 0.13 \\
\hline L-Threonine & 0.32 & 0.27 & 0.20 & 0.20 & 0.06 & 0.06 \\
\hline Sand & 0.10 & 0.10 & 0.10 & 0.10 & 0.10 & 0.10 \\
\hline \multicolumn{7}{|c|}{ Calculated Nutrients } \\
\hline $\mathrm{ME}^{3}(\mathrm{kcal} / \mathrm{kg})$ & 3,000 & 3,000 & 3,072 & 3,072 & 3,132 & 3,132 \\
\hline Crude Protein $(\%)$ & 21.99 & 22.01 & 20.00 & 20.00 & 19.00 & 19.00 \\
\hline Digestible Lysine $^{4}(\%)$ & 1.20 & 1.20 & 1.10 & 1.10 & 1.00 & 1.00 \\
\hline Digestible Methionine $^{4}(\%)$ & 0.79 & 0.79 & 0.65 & 0.65 & 0.50 & 0.50 \\
\hline Digestible Met $+\mathrm{Cys}^{4}(\%)$ & 1.08 & 1.08 & 0.92 & 0.92 & 0.77 & 0.77 \\
\hline Digestible Threonine $(\%)$ & 1.01 & 1.01 & 0.84 & 0.84 & 0.68 & 0.68 \\
\hline Digestible Tryptophan ${ }^{4}(\%)$ & 0.23 & 0.23 & 0.21 & 0.21 & 0.20 & 0.20 \\
\hline Calcium $(\%)$ & 1.01 & 1.01 & 0.92 & 0.92 & 0.84 & 0.84 \\
\hline $\mathrm{nPP}^{5}(\%)$ & 0.46 & 0.25 & 0.42 & 0.21 & 0.38 & 0.19 \\
\hline Sodium $(\%)$ & 0.17 & 0.17 & 0.18 & 0.18 & 0.18 & 0.18 \\
\hline
\end{tabular}

\footnotetext{
${ }^{1}$ Calculated inclusions of experimental CEP or commercial phytase was added to the negative control diet at the expense of sand
}

${ }^{2}$ Supplied per kilogram of diet: $0.02 \%$ manganese; $0.02 \%$ zinc; $0.01 \%$ iron; $0.0025 \%$ copper; $0.0003 \%$ iodine; $0.00003 \%$ selenium; $0.69 \mathrm{mg}$ of folic acid; $386 \mathrm{mg}$ of choline; $6.61 \mathrm{mg}$ of riboflavin; 0.03 $\mathrm{mg}$ of biotin; $1.38 \mathrm{mg}$ of vitamin B6; $27.56 \mathrm{mg}$ of niacin; $6.61 \mathrm{mg}$ of pantothenic acid; $2.20 \mathrm{mg}$ of thiamine; $0.83 \mathrm{mg}$ of menadione; $0.01 \mathrm{mg}$ of vitamin B12; $16.53 \mathrm{IU}$ of vitamin $\mathrm{E}$; 2,133 IU of vitamin D3; and 7,716 of vitamin A.

${ }^{3}$ Metabolizable Energy and Non-Phytate Phosphorus were based on Agristat values as suggested by M. Donohue. 2013 [35]. Non-phytate Phosphorus in the NC was reduced by 0.15 of the US average.

${ }^{4}$ Digestible amino acids were based on the digestible lysine values suggested by P. B. Tillman and W.A. Dozier. 2013 [36]. Digestible amino acid to digestible lysine ratios followed further recommendations of this communication.

${ }^{5} \mathrm{nPP}=$ Non-phytate phosphorus 
Table 2. Descriptive Feed Manufacturing Data for Starter, Grower, and Finisher Periods

\begin{tabular}{|c|c|c|c|c|c|c|c|c|c|c|}
\hline \multirow{2}{*}{\multicolumn{2}{|c|}{ Treatment }} & \multicolumn{9}{|c|}{ Growth Period } \\
\hline & & \multicolumn{3}{|c|}{ Starter (D1-10) } & \multicolumn{3}{|c|}{ Grower (D11-21) } & \multicolumn{3}{|c|}{ Finisher (D22-38) } \\
\hline Product & $\begin{array}{c}\text { Concentration } \\
\text { (FTU/kg) }\end{array}$ & $\begin{array}{c}\text { Motor } \\
\text { Amperage }^{1} \\
\text { (A) }\end{array}$ & $\begin{array}{c}\text { Hot Pellet } \\
\text { Temperature } \\
\left({ }^{\circ} \mathrm{C}\right)\end{array}$ & $\begin{array}{c}\text { Pellet } \\
\text { Durability }^{3} \\
(\%)\end{array}$ & $\begin{array}{c}\text { Motor } \\
\text { Amperage }^{1} \\
\text { (A) }\end{array}$ & $\begin{array}{c}\text { Hot Pellet } \\
\text { Temperature } \\
\left({ }^{\circ} \mathrm{C}\right)\end{array}$ & $\begin{array}{c}\text { Pellet } \\
\text { Durability }^{3} \\
(\%)\end{array}$ & $\begin{array}{c}\text { Motor } \\
\text { Amperage }^{1} \\
\text { (A) }\end{array}$ & $\begin{array}{c}\text { Hot Pellet } \\
\text { Temperature } \\
\left({ }^{\circ} \mathrm{C}\right)\end{array}$ & $\begin{array}{c}\text { Pellet } \\
\text { Durability }^{3} \\
(\%)\end{array}$ \\
\hline \multirow{2}{*}{1} & 500 & 17.1 & 84.8 & 68.49 & 17.8 & 85.2 & 59.89 & 17.4 & 83.7 & 37.38 \\
\hline & 1,500 & 17.4 & 84.5 & 64.89 & 17.9 & 85.6 & 67.96 & 17.4 & 84.4 & 41.03 \\
\hline \multirow{2}{*}{2} & 500 & 17.6 & 85.0 & 58.47 & 18.1 & 86.0 & 71.58 & 17.7 & 83.7 & 36.32 \\
\hline & 1,500 & 17.3 & 84.1 & 62.91 & 17.6 & 83.7 & 52.99 & 18.0 & 84.2 & 39.76 \\
\hline \multirow{2}{*}{3} & 500 & 17.2 & 83.9 & 64.43 & 18.0 & 83.4 & 50.19 & 17.8 & 83.6 & 41.49 \\
\hline & 1,500 & 17.9 & 82.7 & 68.60 & 17.8 & 85.3 & 49.50 & 17.9 & 84.2 & 48.75 \\
\hline \multirow{2}{*}{4} & 500 & 17.4 & 84.3 & 68.26 & 18.3 & 84.6 & 49.52 & 17.2 & 83.7 & 45.62 \\
\hline & 1,500 & 17.3 & 83.1 & 69.25 & 17.8 & 84.2 & 49.04 & 17.4 & 82.9 & 42.80 \\
\hline \multirow{2}{*}{5} & 500 & 17.7 & 84.4 & 69.71 & 18.1 & 85.2 & 50.20 & 17.4 & 83.8 & 42.60 \\
\hline & 1,500 & 17.7 & 83.1 & 68.68 & 18.1 & 83.7 & 47.63 & 17.5 & 83.9 & 41.80 \\
\hline \multicolumn{2}{|c|}{ Negative Control } & 17.1 & 82.2 & 63.76 & 18.2 & 85.0 & 59.74 & 17.6 & 83.3 & 44.81 \\
\hline \multicolumn{2}{|c|}{ Positive Control } & 17.6 & 83.6 & 54.50 & 18.6 & 87.2 & 75.76 & 18.0 & 84.7 & 42.13 \\
\hline
\end{tabular}

${ }^{1}$ Motor amperage was determined by recording the average of an amperage range from the digital output from a square-D meter.

${ }^{2}$ Hot Pellet Temperature was determined by collecting pellets from the stream of extruded pellets in an insulated container and obtaining a temperature reading from a thermocouple thermometer.

${ }^{3}$ Pellet durability was determined 24 hours post-pelleting using the New Holmen Portable Pellet durability Tester, Lignotech USA, INC., Rothschild, WI 
Table 3. Phytase Activity ${ }^{1}$ for Starter, Grower, and Finisher Periods

\begin{tabular}{|c|c|c|c|c|c|c|c|}
\hline \multirow{2}{*}{\multicolumn{2}{|c|}{ Treatment }} & \multicolumn{6}{|c|}{ Growth Period } \\
\hline & & \multicolumn{2}{|c|}{ Starter (D1-10) } & \multicolumn{2}{|c|}{ Grower (D11-21) } & \multicolumn{2}{|c|}{ Finisher (D22-38) } \\
\hline Product & $\begin{array}{c}\text { Concentration } \\
\text { (FTU/kg) }\end{array}$ & $\begin{array}{c}\text { Phytase Activity- } \\
\text { Mash }^{2} \\
(\mathrm{FTU} / \mathrm{kg}) \\
\end{array}$ & $\begin{array}{c}\text { Phytase Activity- } \\
\text { Pellets }^{3} \\
\text { (FTU/kg) }\end{array}$ & $\begin{array}{c}\text { Phytase Activity- } \\
\text { Mash }^{2} \\
\text { (FTU/kg) }\end{array}$ & $\begin{array}{c}\text { Phytase Activity- } \\
\text { Pellets }^{3} \\
\text { (FTU/kg) }\end{array}$ & $\begin{array}{c}\text { Phytase Activity- } \\
\text { Mash }^{2} \\
\text { (FTU/kg) }\end{array}$ & $\begin{array}{c}\text { Phytase Activity } \\
\text { Pellets }^{3} \\
\text { (FTU/kg) }\end{array}$ \\
\hline \multirow{2}{*}{1} & 500 & 380 & 250 & 370 & 200 & 579 & 245 \\
\hline & 1,500 & 1,200 & 620 & 1,100 & 500 & 1415 & 841 \\
\hline \multirow{2}{*}{2} & 500 & 580 & 300 & 380 & 290 & 386 & 285 \\
\hline & 1,500 & 1,300 & 710 & 1,300 & 960 & 1,315 & 1,152 \\
\hline \multirow{2}{*}{3} & 500 & 550 & 340 & 480 & 250 & 685 & 382 \\
\hline & 1,500 & 1,600 & 930 & 1,900 & 1,200 & 1,588 & 1,055 \\
\hline \multirow{2}{*}{4} & 500 & 380 & 100 & 400 & 140 & 347 & 304 \\
\hline & 1,500 & 790 & 300 & 880 & 310 & 1,203 & 467 \\
\hline \multirow{2}{*}{5} & 500 & 360 & 350 & 290 & 360 & 312 & 762 \\
\hline & 1,500 & 980 & 800 & 680 & 510 & 1,821 & 1,616 \\
\hline \multicolumn{2}{|c|}{ Negative Control } & $<50$ & 77 & $<50$ & $<50$ & 0 & 63 \\
\hline \multicolumn{2}{|c|}{ Positive Control } & 120 & 63 & 84 & $<50$ & 0 & 0 \\
\hline
\end{tabular}

${ }^{1}$ Phytase activity was determined at a commercial laboratory using the AOAC 2000.12 method.

${ }^{2}$ Unconditioned mash samples were collected directly from the feed screw auger immediately before entering the steam conditioning barrel.

${ }^{3}$ Pelleted feed samples were collected as pellets exited the horizontal belt cooler 
Table 4. Mineral Analysis and nPP Calculations for Starter, Grower, and Finisher Periods

\begin{tabular}{|c|c|c|c|c|c|c|c|c|c|c|c|c|c|}
\hline \multirow{2}{*}{\multicolumn{2}{|c|}{ Treatment }} & \multicolumn{12}{|c|}{ Growth Period } \\
\hline & & \multicolumn{4}{|c|}{ Starter (D1-10) } & \multicolumn{4}{|c|}{ Grower (D11-21) } & \multicolumn{4}{|c|}{$\begin{array}{l}\text { Finisher (D22-38) } \\
\end{array}$} \\
\hline Product & $\begin{array}{c}\text { Concentration } \\
\text { (FTU/kg) }\end{array}$ & $\begin{array}{c}\text { Total } \\
\text { Phosphorus } \\
(\%)\end{array}$ & $\begin{array}{c}\text { Phytic } \\
\text { Acid } \\
(\%)\end{array}$ & $\begin{array}{l}\mathrm{nPP}^{1} \\
(\%)\end{array}$ & $\begin{array}{l}\text { Calcium } \\
(\%)\end{array}$ & $\begin{array}{c}\text { Total } \\
\text { Phosphorus } \\
(\%)\end{array}$ & $\begin{array}{c}\text { Phytic } \\
\text { Acid } \\
(\%)\end{array}$ & $\begin{array}{l}\mathrm{nPP}^{1} \\
(\%)\end{array}$ & $\begin{array}{l}\text { Calcium } \\
(\%)\end{array}$ & $\begin{array}{c}\text { Total } \\
\text { Phosphorus } \\
(\%)\end{array}$ & $\begin{array}{c}\text { Phytic } \\
\text { Acid } \\
(\%)\end{array}$ & $\begin{array}{l}\mathrm{nPP}^{1} \\
(\%)\end{array}$ & $\begin{array}{l}\text { Calcium } \\
(\%)\end{array}$ \\
\hline \multirow{2}{*}{1} & 500 & 0.481 & 0.881 & 0.233 & 0.919 & 0.859 & 0.425 & 0.857 & 0.184 & 0.413 & 0.878 & 0.166 & 0.750 \\
\hline & 1,500 & 0.463 & 0.849 & 0.224 & 0.970 & 0.829 & 0.421 & 0.871 & 0.176 & 0.399 & 0.931 & 0.137 & 0.785 \\
\hline \multirow{2}{*}{2} & 500 & 0.479 & 0.858 & 0.238 & 0.949 & 0.780 & 0.419 & 0.877 & 0.172 & 0.413 & 0.910 & 0.157 & 0.761 \\
\hline & 1,500 & 0.472 & 0.914 & 0.215 & 0.791 & 0.867 & 0.430 & 0.886 & 0.181 & 0.431 & 0.942 & 0.166 & 0.760 \\
\hline \multirow{2}{*}{3} & 500 & 0.473 & 0.893 & 0.222 & 0.910 & 0.956 & 0.422 & 0.862 & 0.179 & 0.452 & 0.861 & 0.210 & 0.739 \\
\hline & 1,500 & 0.468 & 0.886 & 0.219 & 0.956 & 1.10 & 0.425 & 0.829 & 0.192 & 0.440 & 0.910 & 0.184 & 0.790 \\
\hline \multirow{2}{*}{4} & 500 & 0.466 & 0.891 & 0.215 & 0.901 & 1.06 & 0.437 & 0.840 & 0.201 & 0.432 & 0.924 & 0.172 & 0.756 \\
\hline & 1,500 & 0.480 & 0.986 & 0.202 & 0.818 & 0.906 & 0.430 & 0.939 & 0.166 & 0.421 & 0.914 & 0.164 & 0.653 \\
\hline \multirow{2}{*}{5} & 500 & 0.465 & 0.884 & 0.216 & 1.32 & 0.864 & 0.413 & 0.890 & 0.163 & 0.434 & 0.916 & 0.176 & 0.708 \\
\hline & 1,500 & 0.468 & 0.826 & 0.236 & 1.12 & 0.989 & 0.438 & 0.899 & 0.185 & 0.431 & 0.899 & 0.178 & 0.765 \\
\hline \multicolumn{2}{|c|}{ Negative Control } & 0.515 & 0.914 & 0.258 & 1.01 & 0.440 & 0.862 & 0.197 & 0.717 & 0.433 & 0.942 & 0.168 & 0.754 \\
\hline \multicolumn{2}{|c|}{ Positive Control } & 0.651 & 0.838 & 0.415 & 1.18 & 0.575 & 0.884 & 0.326 & 0.895 & 0.523 & 0.843 & 0.286 & 0.770 \\
\hline
\end{tabular}


Table 5. Effects of CEP Product and Concentration on Overall Period (d1-38) Broiler Performance

\begin{tabular}{|c|c|c|c|c|c|c|}
\hline Product & $\begin{array}{l}\text { Concentration } \\
\text { (FTU/kg) }\end{array}$ & $\begin{array}{l}\text { Avg. Body Weight } \\
(\mathrm{kg})\end{array}$ & $\begin{array}{c}\mathrm{FI}^{1} \\
(\mathrm{~kg} / \mathrm{bird})\end{array}$ & $\begin{array}{c}\mathrm{LWG}^{2} \\
\text { (kg/bird) }\end{array}$ & $\mathrm{FCR}^{3}$ & $\begin{array}{c}\text { Corrected Mortality }{ }^{4} \\
(\%)\end{array}$ \\
\hline \multirow{2}{*}{1} & 500 & $1.954^{\mathrm{e}}$ & $3.390^{\mathrm{f}}$ & $1.727^{\mathrm{f}}$ & $1.561^{\mathrm{abc}}$ & $9.616^{\text {bcd }}$ \\
\hline & 1,500 & $2.198^{\mathrm{d}}$ & $3.707^{\mathrm{cd}}$ & $1.997^{\mathrm{d}}$ & $1.519^{\mathrm{bcd}}$ & $7.693^{\text {cde }}$ \\
\hline \multirow{2}{*}{2} & 500 & $2.129^{\mathrm{d}}$ & $3.738^{\mathrm{cd}}$ & $1.865^{\mathrm{e}}$ & $1.547^{\mathrm{abcd}}$ & $12.981^{\mathrm{bc}}$ \\
\hline & 1,500 & $2.314^{\mathrm{c}}$ & $3.830^{\mathrm{bc}}$ & $2.136^{\mathrm{c}}$ & $1.519^{\mathrm{bcd}}$ & $3.847^{\mathrm{de}}$ \\
\hline \multirow{2}{*}{3} & 500 & $2.150^{\mathrm{d}}$ & $3.623^{\mathrm{de}}$ & $1.964^{\mathrm{de}}$ & $1.535^{\mathrm{abcd}}$ & $5.770^{\mathrm{de}}$ \\
\hline & 1,500 & $2.367^{\mathrm{c}}$ & $3.983^{\mathrm{ab}}$ & $2.180^{\mathrm{c}}$ & $1.526^{\mathrm{abcd}}$ & $6.731^{\mathrm{cde}}$ \\
\hline \multirow{2}{*}{4} & 500 & $1.962^{\mathrm{e}}$ & $3.487^{\mathrm{ef}}$ & $1.686^{\mathrm{f}}$ & $1.565^{\mathrm{abc}}$ & $14.904^{\mathrm{b}}$ \\
\hline & 1,500 & $2.151^{\mathrm{d}}$ & $3.733^{\mathrm{cd}}$ & $1.950^{\mathrm{de}}$ & $1.574^{\mathrm{ab}}$ & $7.212^{\mathrm{cde}}$ \\
\hline \multirow{2}{*}{5} & 500 & $2.289^{c}$ & $3.754^{\mathrm{cd}}$ & $2.113^{\mathrm{c}}$ & $1.511^{\mathrm{cde}}$ & $4.327^{\mathrm{de}}$ \\
\hline & 1,500 & $2.474^{\mathrm{b}}$ & $4.029^{\mathrm{a}}$ & $2.292^{\mathrm{b}}$ & $1.495^{\mathrm{de}}$ & $2.885^{\mathrm{e}}$ \\
\hline \multicolumn{2}{|c|}{ Negative Control } & $1.657^{\mathrm{f}}$ & $3.193^{\mathrm{g}}$ & $1.249^{\mathrm{g}}$ & $1.580^{\mathrm{a}}$ & $28.366^{\mathrm{a}}$ \\
\hline \multicolumn{2}{|c|}{ Positive Control } & $2.600^{\mathrm{a}}$ & $4.151^{\mathrm{a}}$ & $2.428^{\mathrm{a}}$ & $1.458^{\mathrm{e}}$ & $2.404^{\mathrm{e}}$ \\
\hline \multicolumn{2}{|c|}{ P-Value } & $<0.0001$ & $<0.0001$ & $<0.0001$ & 0.0033 & $<0.0001$ \\
\hline \multicolumn{2}{|c|}{ SEM $^{5}$} & 0.029 & 0.061 & 0.039 & 0.020 & 2.249 \\
\hline \multicolumn{7}{|c|}{ Product Means } \\
\hline 1 & -- & $2.076^{\mathrm{c}}$ & $3.549^{\mathrm{b}}$ & $1.862^{\mathrm{c}}$ & 1.540 & $8.654^{\mathrm{ab}}$ \\
\hline 2 & -- & $2.221^{\mathrm{b}}$ & $3.784^{\mathrm{a}}$ & $2.001^{\mathrm{b}}$ & 1.533 & $8.414^{\mathrm{ab}}$ \\
\hline 3 & -- & $2.259^{\mathrm{b}}$ & $3.803^{\mathrm{a}}$ & $2.072^{\mathrm{b}}$ & 1.530 & $6.250^{\mathrm{bc}}$ \\
\hline 4 & -- & $2.056^{\mathrm{c}}$ & $3.610^{\mathrm{b}}$ & $1.818^{\mathrm{c}}$ & 1.569 & $11.058^{\mathrm{a}}$ \\
\hline 5 & -- & $2.381^{\mathrm{a}}$ & $3.892^{\mathrm{a}}$ & $2.203^{\mathrm{a}}$ & 1.503 & $3.606^{\mathrm{c}}$ \\
\hline \multicolumn{2}{|c|}{ Product SEM $^{5}$} & 0.021 & 0.044 & 0.027 & 0.016 & 1.548 \\
\hline \multicolumn{7}{|c|}{ Concentration Means } \\
\hline-- & 500 & $2.097^{\mathrm{b}}$ & $3.598^{\mathrm{b}}$ & $1.871^{\mathrm{b}}$ & 1.544 & $9.520^{\mathrm{a}}$ \\
\hline-- & 1,500 & $2.301^{\mathrm{a}}$ & $3.857^{\mathrm{a}}$ & $2.111^{\mathrm{a}}$ & 1.527 & $5.674^{\mathrm{b}}$ \\
\hline \multicolumn{2}{|c|}{ Concentration SEM $^{5}$} & 0.0135 & 0.028 & 0.017 & 0.010 & 0.979 \\
\hline \multicolumn{7}{|c|}{ Probability } \\
\hline \multicolumn{2}{|c|}{ Product } & $<0.0001$ & $<0.0001$ & $<0.0001$ & 0.0932 & 0.0158 \\
\hline \multicolumn{2}{|c|}{ Concentration } & $<0.0001$ & $<0.0001$ & $<0.0001$ & 0.2438 & 0.0070 \\
\hline \multicolumn{2}{|c|}{ Product x Concentration } & 0.8213 & 0.2676 & 0.6988 & 0.8546 & 0.1094 \\
\hline
\end{tabular}

${ }^{1}$ D1-38 FI= D1-21 FI/bird + D22-38 FI/bird. This corrected the measurement for the removal of 3 birds per pen for toe and tibia excision on D21

${ }^{2}$ D1-38 LWG= D1-21 LWG/bird + D22-38 LWG/bird. This corrected the measurement for the removal of 3 birds per pen for toe and tibia excision on D21

${ }^{3}$ D1-38 FCR was corrected for mortality, which included the weight of the three birds per pen removed for toe and tibia analyses on D21

${ }^{4}$ Corrected Mortality $=((100-((\mathrm{D} 38$ Bird \#/D1 bird \# $\left.) * 100))-((3 / 26) * 100))\right)$. This corrected the measurement for the removal of 3 birds per pen for toe and tibia excision on D21

${ }^{5} \mathrm{SEM}=$ Pooled standard error of the mean. 
Table 6. Effect of CEP Product and Concentration on D21 and D38 Toe and Tibia Ash

\begin{tabular}{|c|c|c|c|c|c|c|c|}
\hline \multirow{2}{*}{\multicolumn{2}{|c|}{ Treatment }} & \multicolumn{3}{|c|}{ D 21} & \multicolumn{3}{|c|}{ D 38} \\
\hline & & \multirow{2}{*}{$\begin{array}{c}\text { Toe } \mathrm{Ash}^{1} \\
(\%)\end{array}$} & \multirow{2}{*}{$\begin{array}{c}\text { Tibia Ash }{ }^{2} \\
(\%)\end{array}$} & \multirow{2}{*}{$\begin{array}{c}\text { mg Tibia Ash/bird }{ }^{3} \\
\text { (mg/bird) }\end{array}$} & \multirow{2}{*}{$\begin{array}{c}\text { Toe } A_{s h}{ }^{1} \\
(\%)\end{array}$} & \multirow{2}{*}{$\begin{array}{c}\text { Tibia Ash }{ }^{2} \\
(\%)\end{array}$} & \multirow{2}{*}{$\begin{array}{c}\text { mg Tibia Ash/bird } \\
\text { (mg/bird) }\end{array}$} \\
\hline Product & Concentration (FTU/kg) & & & & & & \\
\hline \multirow{2}{*}{1} & 500 & $8.81^{\text {defg }}$ & $44.21^{\mathrm{f}}$ & $467.4^{\mathrm{f}}$ & $10.85^{\text {bcd }}$ & $42.89^{\mathrm{e}}$ & $1837.5^{\mathrm{f}}$ \\
\hline & 1,500 & $9.28^{\text {cdef }}$ & $45.86^{\mathrm{cde}}$ & $566.1^{\mathrm{cd}}$ & $10.78^{\text {bcd }}$ & $44.52^{\mathrm{cd}}$ & $2241.7^{\text {cde }}$ \\
\hline \multirow{2}{*}{2} & 500 & $8.45^{\text {fg }}$ & $44.66^{\mathrm{ef}}$ & $475.3^{\mathrm{ef}}$ & $10.43^{\mathrm{cd}}$ & $44.13^{\mathrm{cd}}$ & $2095.3^{\mathrm{e}}$ \\
\hline & 1,500 & $9.62^{\text {cde }}$ & $46.32^{\mathrm{bcd}}$ & $632.3^{\mathrm{bc}}$ & $10.84^{\text {bcd }}$ & $45.58^{\mathrm{b}}$ & $2364.9^{\text {bcd }}$ \\
\hline \multirow{2}{*}{3} & 500 & $8.87^{\text {defg }}$ & $45.16^{\text {def }}$ & $549.7^{\mathrm{d}}$ & $10.99^{\mathrm{bc}}$ & $44.378^{\mathrm{cd}}$ & $2132.4^{\mathrm{de}}$ \\
\hline & 1,500 & $9.78^{\mathrm{cd}}$ & $47.26^{\mathrm{b}}$ & $657.6^{\mathrm{b}}$ & $11.26^{\mathrm{b}}$ & $45.09^{\mathrm{bc}}$ & $2506.3^{\mathrm{b}}$ \\
\hline \multirow{2}{*}{4} & 500 & $9.94^{\mathrm{bc}}$ & $44.56^{\mathrm{f}}$ & $461.8^{f}$ & $10.21^{\mathrm{d}}$ & $42.64^{\mathrm{e}}$ & $1830.5^{\mathrm{f}}$ \\
\hline & 1,500 & $8.77^{\mathrm{efg}}$ & $44.93^{\text {ef }}$ & $543.1^{\mathrm{de}}$ & $10.96^{\mathrm{bc}}$ & $43.98^{\mathrm{d}}$ & $2051.0^{\mathrm{ef}}$ \\
\hline \multirow{2}{*}{5} & 500 & $9.47^{\mathrm{cde}}$ & $46.72^{\mathrm{bc}}$ & $634.7^{\mathrm{bc}}$ & $11.24^{\mathrm{b}}$ & $45.53^{\mathrm{b}}$ & $2443.8^{\mathrm{bc}}$ \\
\hline & 1,500 & $10.82^{\mathrm{ab}}$ & $48.92^{\mathrm{a}}$ & $803.0^{\mathrm{a}}$ & $12.26^{\mathrm{a}}$ & $46.87^{\mathrm{a}}$ & $3028.5^{\mathrm{a}}$ \\
\hline \multicolumn{2}{|c|}{ Negative Control } & $7.94^{\mathrm{g}}$ & $41.58^{\mathrm{g}}$ & $319.0^{\mathrm{g}}$ & $10.42^{\mathrm{cd}}$ & $41.65^{\mathrm{f}}$ & $1480.9^{\mathrm{g}}$ \\
\hline \multicolumn{2}{|c|}{ Positive Control } & $11.05^{\mathrm{a}}$ & $49.36^{\mathrm{a}}$ & $870.3^{\mathrm{a}}$ & $12.27^{\mathrm{a}}$ & $47.22^{\mathrm{a}}$ & $3067.1^{\mathrm{a}}$ \\
\hline \multicolumn{2}{|c|}{ P-Value } & $<0.0001$ & $<0.0001$ & $<0.0001$ & $<0.0001$ & $<0.0001$ & $<0.0001$ \\
\hline \multicolumn{2}{|c|}{ SEM $^{4}$} & 0.357 & 0.450 & 25.200 & 0.241 & 0.339 & 82.831 \\
\hline \multicolumn{8}{|c|}{ Product Means } \\
\hline 1 & -- & 9.049 & $45.039^{c}$ & $516.77^{\mathrm{cd}}$ & $10.82^{\mathrm{b}}$ & $43.70^{c}$ & $2039.5^{\mathrm{c}}$ \\
\hline 2 & -- & 9.040 & $45.493^{\mathrm{bc}}$ & $553.85^{\mathrm{bc}}$ & $10.64^{\mathrm{b}}$ & $44.86^{\mathrm{b}}$ & $2230.1^{\mathrm{b}}$ \\
\hline 3 & -- & 9.326 & $46.212^{\mathrm{b}}$ & $603.71^{\mathrm{b}}$ & $11.12^{\mathrm{b}}$ & $44.73^{\mathrm{b}}$ & $2319.3^{b}$ \\
\hline 4 & -- & 9.358 & $44.748^{\mathrm{c}}$ & $502.48^{\mathrm{d}}$ & $10.59^{\mathrm{b}}$ & $43.31^{\mathrm{c}}$ & $1940.7^{\mathrm{c}}$ \\
\hline 5 & -- & 10.150 & $47.824^{\mathrm{a}}$ & $718.90^{\mathrm{a}}$ & $11.75^{\mathrm{a}}$ & $46.20^{\mathrm{a}}$ & $2736.1^{\mathrm{a}}$ \\
\hline \multicolumn{2}{|c|}{ Product SEM $^{4}$} & 0.480 & 0.291 & 17.946 & 0.190 & 0.272 & 60.282 \\
\hline \multicolumn{8}{|c|}{ Concentration Means } \\
\hline-- & 500 & 9.112 & $45.065^{\mathrm{b}}$ & $517.83^{\mathrm{b}}$ & $10.74^{\mathrm{b}}$ & $43.91^{\mathrm{b}}$ & $2067.8^{\mathrm{b}}$ \\
\hline-- & 1,500 & 9.658 & $46.662^{\mathrm{a}}$ & $640.46^{\mathrm{a}}$ & $11.22^{\mathrm{a}}$ & $45.21^{\mathrm{a}}$ & $2438.4^{\mathrm{a}}$ \\
\hline \multicolumn{2}{|c|}{ Concentration $\mathrm{SEM}^{4}$} & 0.304 & 0.184 & 11.350 & 0.120 & 0.172 & 38.125 \\
\hline \multicolumn{8}{|c|}{ Probability } \\
\hline \multicolumn{2}{|c|}{ Product } & 0.4752 & $<0.0001$ & $<0.0001$ & 0.0002 & $<0.0001$ & $<0.0001$ \\
\hline \multicolumn{2}{|c|}{ Concentration } & 0.2083 & $<0.0001$ & $<0.0001$ & 0.0068 & $<0.0001$ & $<0.0001$ \\
\hline \multicolumn{2}{|c|}{ Product x Concentration } & 0.3555 & 0.1942 & 0.3543 & 0.2975 & 0.8021 & 0.2530 \\
\hline
\end{tabular}

${ }^{\mathrm{a}-\mathrm{g}}$ Means within the same column with no common superscript differ significantly $(\mathrm{P}<0.05)$

${ }^{1}$ Toe ash percentage was determined on dried middle toe samples from the left leg of $21 \mathrm{~d}$ or $38 \mathrm{~d}$ old broilers.

${ }^{2}$ Tibia ash percentage was determined on dry, fat-extracted tibiae excised from the left leg of $21 \mathrm{~d}$ or $38 \mathrm{~d}$ old broilers.

${ }^{3} \mathrm{mg}$ tibia ash per bird was determined by dividing the weight $(\mathrm{mg})$ of the tibia ash by the number birds utilized for tibia ash determination.

${ }^{4} \mathrm{SEM}=$ Pooled standard error of the mean 
Table 7. Effect of CEP Product and Concentration on Starter, Grower, and Finisher Period Broiler Performance

\begin{tabular}{|c|c|c|c|c|c|c|c|c|c|c|}
\hline \multirow{2}{*}{\multicolumn{2}{|c|}{ Treatment }} & \multirow{2}{*}{\multicolumn{3}{|c|}{ Starter (D1-10) }} & \multirow{2}{*}{\multicolumn{3}{|c|}{ Grower (D11-21) }} & \multirow{2}{*}{\multicolumn{3}{|c|}{ Finisher (D22-38) }} \\
\hline & & & & & & & & & & \\
\hline Product & Concentration (FTU/kg) & $\begin{array}{c}\mathrm{FI}^{1} \\
(\mathrm{~kg} / \mathrm{bird})\end{array}$ & $\begin{array}{c}\mathrm{LWG}^{2} \\
\text { (kg/bird) }\end{array}$ & $\mathrm{FCR}^{3}$ & $\begin{array}{c}\mathrm{FI}^{1} \\
(\mathrm{~kg} / \mathrm{bird})\end{array}$ & $\begin{array}{c}\mathrm{LWG}^{2} \\
\text { (kg/bird) }\end{array}$ & $\mathrm{FCR}^{3}$ & $\begin{array}{c}\mathrm{FI}^{1} \\
\text { (kg/bird) }\end{array}$ & $\begin{array}{c}\mathrm{LWG}^{2} \\
\text { (kg/bird) }\end{array}$ & $\mathrm{FCR}^{3}$ \\
\hline \multirow{2}{*}{1} & 500 & $0.188^{\mathrm{cd}}$ & $0.141^{\mathrm{fg}}$ & 1.303 & $0.739^{f}$ & $0.496^{\mathrm{d}}$ & $1.480^{\mathrm{ab}}$ & $2.461^{\mathrm{fg}}$ & $1.087^{\mathrm{fg}}$ & $2.038^{\mathrm{bc}}$ \\
\hline & 1,500 & $0.200^{\mathrm{b}}$ & $0.153^{\mathrm{bcd}}$ & 1.292 & $0.791^{\mathrm{de}}$ & $0.540^{\mathrm{c}}$ & $1.448^{\mathrm{bcd}}$ & $2.708^{\mathrm{d}}$ & $1.298^{\mathrm{cd}}$ & $1.967^{\mathrm{bcd}}$ \\
\hline \multirow{2}{*}{2} & 500 & $0.203^{\mathrm{b}}$ & $0.153^{\mathrm{bcd}}$ & 1.356 & $0.762^{\text {ef }}$ & $0.520^{\mathrm{c}}$ & $1.446^{\mathrm{bcd}}$ & $2.770^{\mathrm{cd}}$ & $1.189^{\mathrm{ef}}$ & $2.037^{\mathrm{bc}}$ \\
\hline & 1,500 & $0.200^{\mathrm{b}}$ & $0.153^{\mathrm{bc}}$ & 1.354 & $0.826^{\mathrm{cd}}$ & $0.571^{\mathrm{b}}$ & $1.443^{\mathrm{cd}}$ & $2.802^{\mathrm{bcd}}$ & $1.410^{\mathrm{b}}$ & $1.931^{\mathrm{cd}}$ \\
\hline \multirow{2}{*}{3} & 500 & $0.202^{\mathrm{b}}$ & $0.144^{\text {def }}$ & 1.311 & $0.770^{\mathrm{ef}}$ & $0.529^{c}$ & $1.454^{\mathrm{bcd}}$ & $2.650^{\mathrm{de}}$ & $1.291^{\mathrm{de}}$ & $1.968^{\mathrm{bcd}}$ \\
\hline & 1,500 & $0.207^{\mathrm{b}}$ & $0.152^{\text {bcde }}$ & 1.330 & $0.856^{\mathrm{bc}}$ & $0.594^{\mathrm{b}}$ & $1.427^{\mathrm{cd}}$ & $2.915^{\mathrm{abc}}$ & $1.430^{\mathrm{b}}$ & $1.964^{\mathrm{bcd}}$ \\
\hline \multirow{2}{*}{4} & 500 & $0.188^{\mathrm{cd}}$ & $0.143^{\text {ef }}$ & 1.326 & $0.740^{\mathrm{f}}$ & $0.491^{\mathrm{d}}$ & $1.485^{\mathrm{ab}}$ & $2.552^{\mathrm{ef}}$ & $1.047^{\mathrm{g}}$ & $2.062^{\mathrm{b}}$ \\
\hline & 1,500 & $0.198^{\mathrm{bc}}$ & $0.149^{\text {cdef }}$ & 1.352 & $0.788^{\mathrm{de}}$ & $0.532^{\mathrm{c}}$ & $1.472^{\mathrm{abc}}$ & $2.743^{\mathrm{d}}$ & $1.265^{\mathrm{de}}$ & $2.040^{\mathrm{bc}}$ \\
\hline \multirow{2}{*}{5} & 500 & $0.196^{\mathrm{bc}}$ & $0.146^{\text {cdef }}$ & 1.334 & $0.814^{\mathrm{cd}}$ & $0.570^{\mathrm{b}}$ & $1.427^{\mathrm{cd}}$ & $2.740^{\mathrm{d}}$ & $1.395^{\mathrm{bc}}$ & $1.921^{\mathrm{d}}$ \\
\hline & 1,500 & $0.199^{\mathrm{bc}}$ & $0.159^{\mathrm{b}}$ & 1.304 & $0.898^{\mathrm{ab}}$ & $0.635^{\mathrm{a}}$ & $1.414^{\mathrm{d}}$ & $2.932^{\mathrm{ab}}$ & $1.497^{\mathrm{ab}}$ & $1.927^{\mathrm{cd}}$ \\
\hline \multicolumn{2}{|c|}{ Negative Control } & $0.182^{\mathrm{d}}$ & $0.132^{\mathrm{g}}$ & 1.314 & $0.632^{\mathrm{g}}$ & $0.409^{\mathrm{e}}$ & $1.519^{\mathrm{a}}$ & $2.372^{\mathrm{g}}$ & $0.702^{\mathrm{h}}$ & $2.185^{\mathrm{a}}$ \\
\hline \multicolumn{2}{|c|}{ Positive Control } & $0.227^{\mathrm{a}}$ & $0.172^{\mathrm{a}}$ & 1.328 & $0.929^{\mathrm{a}}$ & $0.653^{\mathrm{a}}$ & $1.416^{\mathrm{d}}$ & $2.987^{\mathrm{a}}$ & $1.597^{\mathrm{a}}$ & $1.856^{\mathrm{d}}$ \\
\hline \multicolumn{2}{|c|}{ P-Value } & $<0.0001$ & $<0.0001$ & 0.7209 & $<0.0001$ & $<0.0001$ & 0.0023 & $<0.0001$ & $<0.0001$ & $<0.0001$ \\
\hline \multicolumn{2}{|r|}{ SEM $^{4}$} & 0.004 & 0.003 & 0.025 & 0.015 & 0.008 & 0.018 & 0.055 & 0.037 & 0.040 \\
\hline \multicolumn{11}{|c|}{ Product Means } \\
\hline 1 & -- & $0.194^{\mathrm{bc}}$ & 0.147 & $1.317^{\mathrm{b}}$ & $0.765^{\mathrm{c}}$ & $0.518^{\mathrm{c}}$ & $1.464^{\mathrm{ab}}$ & $2.585^{\mathrm{b}}$ & $1.193^{\mathrm{c}}$ & 2.003 \\
\hline 2 & -- & $0.202^{\mathrm{ab}}$ & 0.153 & $1.315^{\mathrm{b}}$ & $0.794^{\mathrm{bc}}$ & $0.546^{\mathrm{b}}$ & $1.445^{\mathrm{abc}}$ & $2.786^{\mathrm{a}}$ & $1.300^{\mathrm{b}}$ & 1.984 \\
\hline 3 & -- & $0.204^{\mathrm{a}}$ & 0.148 & $1.371^{\mathrm{a}}$ & $0.813^{\mathrm{b}}$ & $0.561^{\mathrm{b}}$ & $1.440^{\mathrm{bc}}$ & $2.782^{\mathrm{a}}$ & $1.360^{\mathrm{b}}$ & 1.966 \\
\hline 4 & -- & $0.193^{\mathrm{c}}$ & 0.146 & $1.318^{\mathrm{b}}$ & $0.764^{\mathrm{c}}$ & $0.511^{\mathrm{c}}$ & $1.479^{\mathrm{a}}$ & $2.648^{\mathrm{b}}$ & $1.156^{\mathrm{c}}$ & 2.051 \\
\hline 5 & -- & $0.198^{\mathrm{abc}}$ & 0.152 & $1.295^{\mathrm{b}}$ & $0.856^{\mathrm{a}}$ & $0.603^{\mathrm{a}}$ & $1.420^{\mathrm{c}}$ & $2.836^{\mathrm{a}}$ & $1.446^{\mathrm{a}}$ & 1.924 \\
\hline \multicolumn{2}{|c|}{${\text { Product } \text { SEM }^{4}}^{\prime}$} & 0.002 & 0.002 & 0.016 & 0.011 & 0.006 & 0.013 & 0.024 & 0.025 & 0.031 \\
\hline \multicolumn{11}{|c|}{ Concentration Means } \\
\hline-- & $500 \mathrm{FTU} / \mathrm{kg}$ & 0.196 & $0.145^{\mathrm{b}}$ & $1.342^{\mathrm{a}}$ & $0.765^{\mathrm{b}}$ & $0.521^{\mathrm{b}}$ & 1.458 & $2.634^{\mathrm{b}}$ & $1.202^{\mathrm{b}}$ & 2.005 \\
\hline-- & $1,500 \mathrm{FTU} / \mathrm{kg}$ & 0.201 & $0.153^{\mathrm{a}}$ & $1.305^{\mathrm{b}}$ & $0.832^{\mathrm{a}}$ & $0.574^{\mathrm{a}}$ & 1.441 & $2.820^{\mathrm{a}}$ & $1.380^{\mathrm{a}}$ & 1.966 \\
\hline \multicolumn{2}{|c|}{ Concentration SEM ${ }^{4}$} & 0.001 & 0.001 & 0.010 & 0.007 & 0.003 & 0.008 & 0.024 & 0.016 & 0.020 \\
\hline \multicolumn{11}{|c|}{ Probability } \\
\hline & Product & 0.0396 & 0.1313 & $\mathbf{0 . 0 2 2 7}$ & $<0.0001$ & $<0.0001$ & 0.0284 & $<0.0001$ & $<0.0001$ & 0.0849 \\
\hline \multicolumn{2}{|c|}{ Concentration } & 0.0501 & 0.0003 & 0.0148 & $<0.0001$ & $<0.0001$ & 0.1374 & $<0.0001$ & $<0.0001$ & 0.1722 \\
\hline $\operatorname{Prc}$ & $\mathrm{t} \times$ Concentration & 0.3470 & 0.2890 & 0.2406 & 0.6478 & 0.4795 & 0.9404 & 0.2313 & 0.3567 & 0.7020 \\
\hline
\end{tabular}

${ }^{\mathrm{a}-\mathrm{e}}$ Means within the same column with no common superscript differ significantly $(\mathrm{P}<0.05)$

${ }^{1} \mathrm{FI}=$ Feed intake per bird

${ }^{2} \mathrm{LWG}=$ Live weight gain per bird

${ }^{3} \mathrm{FCR}=$ Mortality corrected feed conversion ratio

${ }^{4} \mathrm{SEM}=$ Pooled standard error of the mean 
EDUCATION

DOCTOR OF PHILOSOPHY CANDIDATE

Nutrition and Food Science

West Virginia University
YEARS ATTENDED (EX:2015- 2017)

Degree Completion Date: October 30, 2017

Morgantown, West Virginia

Dissertation: Evaluating Steam Conditioning Manipulations and Grain Expressed Enzymes Effects on Feed Manufacturing Metrics, Feed Hygiene, Broiler Performance, and Bone Mineralization

MASTER OF SCIENCE

Animal and Food Science

YEARS ATTENDED (EX: 2013-2014)

West Virginia University Morgantown, West Virginia

Thesis: Evaluating the Inclusion of Phytase Super-dose in Various Broiler Diet Formulations and Novel Pellet Binders

BACHELOR OF SCIENCE

Animal and Nutritional Science

West Virginia University

YEARS ATTENDED (EX 2009-2013) Morgantown, West Virginia

\section{EDUCATION AWARDS/HONORS}

\section{Awards and Honors}

- WVU Davis College of Agriculture, Natural Resources, and Design Graduate Enrichment Fund Awards Committee:

$>$ Farm Credit Agriculture Graduate Student Fund- Winner

- Davis Student Research and Creative Scholarship Competition- Runner-Up

- Poultry Science Association Student Paper Competition- Certificate of Excellence

- Mid- Atlantic Nutrition Conference Student Poster Competition- Winner
2017

2016

2015

2015 
- WVU Mentorship Program with mentorship from Mr. Joel Newman

$>$ President of the American Feed Industry Association (AFIA)

October 2014-present

- American FFA Degree Recipient

- Caldwell High School (OH) FFA Chapter Annual Awards Banquet

$>$ Keynote Speaker 2013

- National Society of Collegiate Scholars member 2011

- Davis College of Agriculture, Natural Resources, and Design Dean's List

> Fall 2009, Spring 2010, Spring 2013, and Fall 2013

- Davis College of Agriculture, Natural Resources, and Design President's List

$>$ Spring 2014

- Caldwell (OH) High School Graduate

2009

- National Honors Society Member, Caldwell High School Chapter

2008-2009

\section{Scholarships/Grants Received}

- Louretta and Earle Elmore Scholarship

2012-2013

- PELL Grant

2009-2013

- Academic Competitiveness Grant

2009-2011

- Scholarship Office Award

2009-2010

\section{Publications}

\section{Peer-Reviewed Manuscripts}

J.W. Boney and J.S. Moritz. 2017. Phytase dose effects in practically formulated diets that vary in ingredient composition on feed manufacture and broiler performance. Journal of Applied Poultry Research 26:273-285.

J.W. Boney and J.S. Moritz. 2017. The Effects of Spirulina Algae Inclusion and Conditioning Temperature on Feed Manufacture, Pellet Quality, and True Amino Acid Digestibility. Animal Feed Science and Technology 224:20-29.

A.M. Evans, J.W. Boney, and J.S. Moritz. 2016. The effect of poultry litter biochar on pellet quality, 1-21d broiler performance, digesta viscosity, bone mineralization, and apparent ileal amino acid digestibility. Journal of Applied Poultry Research 26:89-98.

T.R. Rigby, B.G. Glover, K.L. Foltz, J.W. Boney, and J.S. Moritz. 2017. Effects of modifying diet and feed manufacture concern areas that are notorious for decreasing pellet quality. Journal of Applied Poultry Research. (In Review). 
A.N. Bergeron, J.W. Boney, and J.S. Moritz. 2017. The effects of diet formulation and thermal processes associated with pelleting on d1-18 broiler performance and digestible amino acid concentration. Journal of Applied Poultry Research (In Review).

\section{Peer-Reviewed Abstracts}

J.W. Boney, A.N. Bergeron, and J.S. Moritz. 2017. The effects of varying long-term steam conditioning temperature and antimicrobial inclusion on the mitigation of Enterococcus faecium 8459, a non-pathogenic surrogate of Salmonella. Poult. Sci. Vol. 96 (E-suppl. 1): 60.

A.N. Bergeron, J.W. Boney, and J.S. Moritz. 2017. The effects of diet formulation and degree of processing on $18 \mathrm{~d}$ performance and amino acid digestibility. Poult Sci. Vol. 96 (E-suppl. 1): 8.

A.N. Bergeron, J.W. Boney, B.G. Glover, and J. S. Moritz. 2017. Diet formulation and feed processing effects on 18-d broiler performance. Poult. Sci. Vol. 96 (E-suppl. 1): M85.

B.G. Glover, J.M. Hadfield, J.W. Boney, A.N. Bergeron, and J.S. Moritz. 2017. Effects of environment, feed form, and caloric density on energy partitioned to performance and immune response. Poult. Sci. Vol. 96 (E-suppl. 1): M86.

V.B. Homan, J.W. Boney*, and J.S. Moritz. 2017. The effect of diets varying in commercial phytase product subjected to increasing steam conditioning temperature on broiler performance and tibia mineralization. Poult. Sci. Vol. 96 (E-suppl. 1): M87. * Presenting author

J.W. Boney and J.S. Moritz. 2016. The effects of varying short-term steam conditioning temperatures on the mitigation of Enterococcus faecium 8459, a nonpathogenic surrogate of Salmonella. Poult Sci. Vol. 95 (E-suppl. 1): 58.

J.W. Boney and J.S. Moritz. 2015. The effects of Spirulina algae inclusion and conditioning temperature on feed manufacture and pellet quality. Poult. Sci. Vol. 94 (E-suppl. 1): 96.

A.M. Evans, J.W. Boney*, and J.S. Moritz. 2015. The effect of poultry litter biochar on pellet quality, 1-21d broiler performance, digesta viscosity, bone mineralization, and apparent ileal amino acid digestibility. Poult. Sci. Vol. 94 (E-suppl. 1): 156. * Presenting author

R.B. Sellers ${ }^{1}$, J.W. Boney ${ }^{2}$, C. McDaniels ${ }^{1}$, J.S. Moritz ${ }^{2}$, and K.G.S. Wamsely ${ }^{1}$. 2015. Liquid application method (LAM), feed form (FF), and feed pen location effects on D28-56 Ross x Ross 708 male broiler performance and processing characteristics. Poult. Sci. Vol. 94 (E-suppl. 1): 80.

J.W. Boney and J.S. Moritz. 2014. HiPhos dose effects in practically formulated diets that vary in ingredient composition on formulation cost and broiler performance. Poult. Sci. Vol. 93. (Esuppl. 1): 26.

J.W. Boney, A.E. Lamp, and J.S. Moritz. 2013. The effects of wheat supplementation to corn and soybean meal based diets on manufacture of pellets and subsequent turkey performance. Poult. Sci. Vol. 92 (E-suppl. 1): 43. 
R.B. Sellers ${ }^{1}$, J.W. Boney ${ }^{2}$, C.McDaniels ${ }^{1}$, J.S. Moritz ${ }^{2}$, and K.G.S. Wamsley ${ }^{1}$. 2013. Feed form and liquid application method effects on feed augering segregation. Poult. Sci. Vol. 92 (E-suppl. 1): 67.

\section{Manuscripts in Preparation}

J.W. Boney, J.L. Weidhaas, J. Jaczynski, and J.S. Moritz. 2017. Steam Conditioning Manipulations and Antimicrobial Inclusion on Feed Manufacturing and Salmonella Surrogate Mitigation. J. Appl. Poult. Res. (In Preparation).

J.W. Boney, B.G. Glover, A.N. Bergeron, H.L. Baldwin, J.N. Broomhead, and J.S. Moritz. 2017. Corn-Expressed Phytase Product and Concentration Effects on D1-38 Broiler Performance, Toe Ash, and Tibia Ash. J. Appl. Poult. Res. (In Preparation).

J.W. Boney, B.G. Glover, J.N. Broomhead, and J.S. Moritz. 2017. The Effects of CornExpressed Phytase Varying in Particle Size, Concentration, and Coating on D1-38 Broiler Performance and Tibia Ash Analysis. J. Appl. Poult. Res. (In Preparation).

\section{RESEARCH EXPERIENCE}

\section{National Meeting Paper Presentations}

- 2017 Poultry Science Association (Orlando, FL)

$>$ "The effects of long-term steam conditioning temperature variations and antimicrobial inclusion on the mitigation of a Salmonella surrogate"

- 2017 International Poultry Scientific Forum (IPSF- Atlanta, GA)

$>$ "The effect of diets varying in commercial phytase product subjected to increasing steam conditioning temperature on broiler performance and tibia mineralization"

- 2016 Poultry Science Association (New Orleans, LA)

$>$ "The effects of varying short-term steam conditioning temperature on the mitigation of Enterococcus faecium 8459, a nonpathogenic surrogate of Salmonella"

- 2015 Poultry Science Association (Louisville, KY)

$>$ "The effects of Spirulina algae inclusion and conditioning temperature on feed manufacture and pellet quality"

- 2015 Poultry Science Association (Louisville, KY)

$>$ "The effect of poultry litter biochar on pellet quality, 1-21d broiler performance, digesta viscosity, bone mineralization, and apparent ileal amino acid digestibility"

- 2014 Poultry Science Association (Corpus Christi, TX) 
"HiPhos dose effects in practically formulated diets that vary in ingredient composition on formulation cost and broiler performance"

- 2013 Poultry Science Association (San Diego, CA) (Undergraduate Student)

$>$ "The effects of wheat supplementation to corn and soybean meal based diets on manufacture of pellets and subsequent turkey performance"

\section{Regional Meeting Poster Presentations}

- 2015 Mid-Atlantic Nutrition Conference

$>$ "The effects of Spirulina algae inclusion and conditioning temperature on feed manufacture and pellet quality"

\section{Graduate Research Assistantship}

- WVU Pilot Feed Mill Manager

May 2012- present

$>$ Duties

- Knowledge of FSMA policies and updates

- FDA compliance

- Research feed manufacture operations

- General feed mill maintenance

- Monthly feed manufacture reports

- Ingredient sourcing

- Ingredient shipping/delivery

- Complete feed coordination and transport

- Feed mill demonstrations, tours, and teaching

- Facility use scheduling

\section{Graduate Teaching Assistant}

- ANNU 362- Advanced Applied Non-ruminant Nutrition

$>$ Roles included assisting students in a laboratory as they explored proximate analysis testing on a non-traditional feed ingredient. Proximate analysis values were utilized in a feed formulation program where students learned the essentials of diet formulation. Formulations were used at the feed mill and manufactured feed was provided to broiler chicks from D7-21, during which time students tested a nutritional principle.

- ANPR 338- Poultry Judging

$>$ Roles included instructing classes and selecting top individuals to compete in the national competition. The position also included in taking the top individuals to Baton rouge, LA for the national poultry judging competition, setting up the competition and grading participants score cards. 
- ANPR 369- Poultry Production Laboratory

$>$ Roles included assisting students as they gained knowledge of poultry operations and organize a class field trip to Pilgrim's Pride, Inc. where students could obtain first-hand knowledge of the operations of a vertically integrated operation.

- Guest Lectures/Laboratory Instruction

$>$ AGBI 513- Nutritional Biochemistry Laboratory

$>$ AGBI 498- Honors Agricultural Biochemistry

$>$ ANNU 362- Advanced Applied Non-ruminant Nutrition

$>$ ANPR 367- Poultry Production

\section{Graduate Research}

- Led a contract study with Agrivida to determine performance and mineralization effects of coating variations of corn-expressed phytase

- Led an in-house experiment to determine the effects of long-term steam conditioning on Salmonella mitigation

- Led an in-house experiment to determine the effects of short-term steam conditioning on Salmonella mitigation

- Led a contract study with Agrivida to determine optimal corn-expressed phytase particle size, concentration, and coating measured through 38 day broiler performance and tibia ash

- Led a contract study with Agrivida to determine the thermal stability of experimental glucanase enzyme products

- Led a contract study with Huvepharma to determine efficacy of experimental xylanase products on 21 day broiler performance and digesta viscosity

- Caitec Inc. viscosity of various feedstuffs

- Attended Biomass Utilization for Green Materials and Energy Conference

- Led an in-house pelleting trail utilizing Spirulina algae to determine its effects on feed manufacturing parameters, pellet quality, and true amino acid digestibility 
- Led a contract study with DSM Nutritional Products, Inc. utilizing a phytase enzyme product that was included in varying inclusions in diets that varied in ingredient composition

- Led an in-house experiment examining pellet quality and nutrient densities of pellets and fines of broiler and turkey feed samples collected throughout the United States

- Led an in-house experiment to determine the effects of feeder space access and broiler density on broiler performance

- Led a contract study with POET Nutrition analyzing amino acid digestibility of various feedstuffs utilizing a cecectomized rooster model

- Assisted graduate and undergraduate students with research experiments 2011-present
$>$ Ingredient sourcing
$>$ Ingredient shipping/delivery
$>$ Feed manufacturing
$>$ Complete feed transport
$>$ Project execution

\section{National and Regional Scientific Meeting Attendance}

- Arkansas Nutrition Conference

$$
>\text { 2017- Rogers, AK }
$$

- Mid-Atlantic Nutrition Conference

$$
\text { 2015- Timonium, MD }
$$

- Poultry Science Association Annual Meeting

$$
\begin{array}{ll}
> & \text { 2017- Orlando, FL } \\
> & 2016-\text { New Orleans, LA } \\
> & 2015 \text { - Louisville, KY } \\
> & \text { 2014- Corpus Christi, TX } \\
> & \text { 2013- San Diego, CA } \\
> & \text { 2012- Athens, GA }
\end{array}
$$

- International Poultry Scientific Forum- Atlanta, GA
$>2017$
$>2014$
$>2012$
> 2010 


\section{State Extension Activities}

- West Virginia Poultry Association Donor Letter 2017

- Ag Safety Days- Preston County (WV) 2017

- Monongalia County (WV) 4-H members took part in poultry feeding, rearing, health, and $\begin{array}{ll}\text { processing demonstrations } & 2017\end{array}$

- Ag Field Days- Gilmer County (WV) 2016

- Governor's Choice Demonstrations 2015

$>$ Feed mill demonstration and avian dissection workshop for selected $8^{\text {th }}$ grade students from West Virginia

- Davis College of Agriculture, Natural Resources and Design Alumni Donor Letter

- Pendleton County Poultry Judging Team Training

$>$ Students were to represent West Virginia at the national 4-H poultry judging competition

- Urban Agriculture Conference

- Assisted with a traveling poultry processing demonstration in various locations throughout the state of West Virginia

2013-2015

- WVU Animal Science Farm tours

- Mason-Dixon Elementary School- Career Day participant

2014

- Hands-on Ag Day

2012, 2014- 2015

- Ag in the Classroom

2012

- Poultry Festival (Moorefield, WV)

2012-2017

- Family Farm Day poultry display

2011-2014

- State and County Fair Poultry Displays

2011-2016

\section{- WV State Fair \\ ○ Monongalia County Fair}

- Berkeley County (WV) Youth Fair- Poultry Exhibit Judge

- Monongalia County (WV) Fair- Poultry Exhibit Judge

2013-2014

- West Virginia State FFA Poultry CDE Competition

- A-STEM of Mind Cooking with Math Camp

- Organic Field Days- WVU Certified Organic Farm

2012-2015

- Davis College Welcome Back BBQ

2011-2017

\section{EXPERIENCE}


WVU Poultry Judging Team Member

- Louisiana State University (2013)

- $12^{\text {th }}$ individual overall

- University of Arkansas (2012)

- $19^{\text {th }}$ individual overall

Federal Work Study

2011-2012

- Introduction into feed manufacture, poultry rearing, and applied poultry nutrition research at West Virginia University

Aviagen Turkey, Inc. Summer Internship Program

- Overview of commercial turkey breeding operations

- 8 week program 